\begin{abstract}
UNIVERSIDADE DE SÃO PAULO
FACULDADE DE CIÊNCIAS FARMACÊUTICAS

Programa de Pós-Graduação Tecnologia Bioquímico-Farmacêutica Área de Tecnologia de Fermentações

Produção de bacteriocina por Bifidobacterium lactis a partir de soro de leite
\end{abstract}

Eduardo Marcos Balciunas

Dissertação para obtenção do grau de

MESTRE

Orientador:

Prof. Dr. Ricardo Pinheiro de Souza Oliveira

São Paulo

2013 



\section{UNIVERSIDADE DE SÃO PAULO \\ FACULDADE DE CIÊNCIAS FARMACÊUTICAS}

Programa de Pós-Graduação Tecnologia Bioquímico-Farmacêutica Área de Tecnologia de Fermentações

\section{Produção de bacteriocina por Bifidobacterium lactis a partir de soro de leite}

Versão corrigida da Dissertação conforme Resolução CoPGr 5890.

O original encontra-se disponível no Serviço de Pós-Graduação da FCF/USP.

Eduardo Marcos Balciunas

Dissertação para obtenção do grau de MESTRE

Orientador:

Prof. Dr. Ricardo Pinheiro de Souza

Oliveira 
Ficha Catalográfica

Elaborada pela Divisão de Biblioteca e

Documentação do Conjunto das Químicas da USP.

\begin{tabular}{|c|c|}
\hline B174p & $\begin{array}{l}\text { Balciunas, Eduardo Marcos } \\
\text { Produção de bacteriocina por Bifidobacterium lactis a partir } \\
\text { de soro de leite / Eduardo Marcos Balciunas. -- São Paulo, } \\
2013 . \\
\quad 100 \mathrm{p}\end{array}$ \\
\hline & $\begin{array}{l}\text { Dissertação (mestrado) - Faculdade de Ciências Farmacêticas } \\
\text { da Universidade de São Paulo. Departamento de Tecnologia } \\
\text { Bioquímico-Farmacêutica. } \\
\text { Orientador: Oliveira, Ricardo Pinheiro de Souza }\end{array}$ \\
\hline & $\begin{array}{l}\text { 1. Fermentação: Tecnologia de alimentos 2. Microbiologia } \\
\text { de alimentos I. T. II. Oliveira, Ricardo Pinheiro de Souza, } \\
\text { orientador. }\end{array}$ \\
\hline & 664.02 \\
\hline
\end{tabular}


Eduardo Marcos Balciunas

\title{
Produção de bacteriocina por Bifidobacterium lactis a partir de soro de leite
}

\author{
Comissão Julgadora da \\ Dissertação para obtenção do grau de Mestre \\ Prof. Dr. Ricardo Pinheiro de Souza Oliveira \\ Orientador/Presidente
}

Michele Vitolo

$1^{\circ}$. examinador

Attilio Converti

$2^{\circ}$. examinador

São Paulo, 13 de Stembro de 2013 



\section{DEDICATÓRIA}

Aos meus pais, que me trouxeram para este mundo esempre apoiaram meus sonhos, não importandoo rumo que estes me levassem. 


\section{AGRADECIMENTOS}

Ao Prof. Dr. Ricardo Pinheiro de Souza Oliveira, que, nos anos de convivência, muito me ensinou, contribuindo para meu crescimento científico e intelectual, e se tornou um grande amigo. Assim como Jesus fez da água, o vinho, ele me fez de um graduado, um mestre.

À FAPESP (Fundação de Amparo à Pesquisa do Estado de São Paulo) pelo suporte, apoio e financiamento do projeto.

Ao Prof. Dr. Adalberto Pessoa Junior, pela atenção, pelos conselhos e pelo apoio durante o processo de ingresso e orientação.

À USP, pela oportunidade de realização do curso de mestrado.

À Fundação de Amparo à Pesquisa do Estado de São Paulo, pela concessão da bolsa de mestrado e pelo apoio financeiro para a realização desta pesquisa.

Ao meus parceiros de mestrado, Fábio e Sabrina, por tornarem meus dias no laboratório mais divertidos e pelas horas de brain storm. 
"The end will crush the light and sends a message, it won't please the naked eye, without an end there is no light to foretell, to blind you, the law of the claw reigns on and after still." (Philip Hansen Anselmo) 


\section{Balciunas, E. M. Produção de bacteriocina por Bifidobacterium lactis a partir de soro de leite. Dissertação (Mestrado) - Faculdade de Ciências Farmacêuticas, Universidade de São Paulo, São Paulo, 2013.}

\section{RESUMO}

Objetivou-se a produção de bacteriocina de Bifidobacterium animalis subsp. lactis, comparando-se os meios de cultivo sintéticos BSM (Bifidus Selective Medium) e MRS (Man Rogosa and Sharpe) com o meio de cultivo natural (soro de leite). Inicialmente, foram determinadas curvas de crescimento e de pós-acidificação, consumo de glicose, lactose e produção de bacteriocina de B.lactis através de processos fermentativos utilizando os meios de cultivo BSM, MRS e soro de leite $(\mathrm{SL})$. Os microrganismos indicadores utilizados no teste de sensibilidade à bacteriocina produzida por B. lactis foram Lactobacillus sakei, Escherichia coli e Listeria monocytogenes. Considerando a cepa $B$. lactis uma espécie de bactéria aerotolerante, foi realizado, em meio de cultura BSM, estudo prévio avaliando o seu crescimento, com a variação da agitação (25, 50 e 100 rpm) e com tempo de cultivo de $30 \mathrm{~h}$, a $37^{\circ} \mathrm{C}$ de temperatura. Os melhores resultados de crescimento celular $(9,4$ $\log U \mathrm{UFC} / \mathrm{mL}$ ) foram obtidos na agitação de $50 \mathrm{rpm}$. Determinada a melhor condição de agitação $(50 \mathrm{rpm})$ e temperatura $\left(37^{\circ} \mathrm{C}\right)$, foi realizado, em soro de leite, estudo de crescimento, acidificação e consumo de lactose, variando a concentração de sólidos totais dissolvidos $(5,10,15,20$ e $25 \%$ p/v), para se estabelecer a concentração de soro de leite ideal para os estudos de suplementação. A maior quantidade de biomassa produzida, aliada à menor pós-acidificação, foi encontrada em soro de leite a $10 \%(\mathrm{p} / \mathrm{v})$ de sólidos totais, no qual o microrganismo apresentou, ao final do cultivo (30 horas), contagem de 9,13 log UFC/mL e valor de $\mathrm{pH} 4,29$, respectivamente. Também se verificou a influência dos meios de cultivo no crescimento e na produção de bacteriocina de $B$. lactis em agitador rotativo (shaker), que consistiu na análise comparativa do efeito da suplementação de $1 \%$ dos seguintes ingredientes: extrato de levedura (EL), inulina (I), L-cisteína (CI) e Tween $80\left(\mathrm{~T}_{80}\right)$. As melhores condições de cultivo encontradas para a maior produção de biomassa e bacteriocina foram obtidas no soro de leite, à concentração de $10 \%(\mathrm{p} / \mathrm{v})$ suplementado com $1 \%$ de extrato de levedura $(9,9 \log$ UFC/mL e $200 \mathrm{UA} / \mathrm{mL})$. Na etapa final do trabalho, estas condições foram testadas em fermentador de bancada, 
quando foi observado que o crescimento de Bifidobacterium lactis foi $10 \%$ maior em relação ao agitador rotativo. Quanto à atividade da bacteriocina produzida em fermentador de bancada, não houve diferença em relação ao agitador rotativo (200 $\mathrm{UA} / \mathrm{mL}$ ). Esta diferença no crescimento pode ser devido as melhores condições de anaerobiose oferecidas em fermentador de bancada, no qual houve a injeção de nitrogênio no meio de cultivo, sendo que, no agitador rotativo, a condição de anaerobiose foi gerada por um agente externo ao meio (uso de jarras de anaerobiose). Através do presente trabalho, pode-se concluir que a produção de bacteriocina por $B$. lactis é viável e apresenta resultados promissores quando utilizada a combinação soro de leite adicionado de extrato de levedura, o qual apresentou atividade antimicrobiana contra a cepa Listeria monocytogenes. A otimização do processo em fermentador de bancada demonstrou-se interessante quanto à produção de bacteriocina em nível industrial.

Palavras-chave: Bifidobacterium lactis, soro de leite, bacteriocina, anaerobiose, suplementação. 


\section{Balciunas, E. M. Production of bacteriocin by Bifidobacterium lactis from whey. Thesis (Master) - Faculty of Pharmaceutical Sciences, University of São Paulo, São Paulo, 2013.}

\section{ABSTRACT}

The objective was the production of bacteriocins by Bifidobacterium animalis subsp. lactis, comparing the synthetic culture medium BSM (Bifidus Selective Medium) and MRS (Man Rogosa and Sharpe) with the natural culture medium (whey). Initially, growth and post-acidification curves were determined, consumption of glucose, lactose and $B$. lactis bacteriocin production by fermentation processes using culture media BSM, MRS and milk whey (SL).The indicator organisms used in the test sensitivity to bacteriocin produced by $B$. lactis were Lactobacillus sakei, Escherichia coli and Listeria monocytogenes. Given the strain B. lactis one aerotolerant species of bacteria, it was conducted in culture medium BSM, a preliminary study assessing the growth, by varying the agitation $(25,50$, and $100 \mathrm{rpm})$ with cultivation time of $30 \mathrm{~h}$ at $37^{\circ} \mathrm{C}$ temperature. The best results of cell growth $(9.4 \log \mathrm{CFU} / \mathrm{mL}$ ) were obtained at $50 \mathrm{rpm}$ agitation. After the best condition of agitation (50 rpm) and temperature $\left(37^{\circ} \mathrm{C}\right)$ determination, it was performed on whey, a study of growth, acidification and consumption of lactose, varying the concentration of total dissolved solids $(5,10,15,20$ and $25 \% \mathrm{w} / \mathrm{v})$, to settle the best concentration of whey for studies of supplementation. The highest amount of biomass produced, combined with the lowest post acidification was found in whey at $10 \%(\mathrm{w} / \mathrm{v})$ of total solids, wherein the microorganism presented at the end of culture (30 hours) a counting of $9.13 \log \mathrm{CFU} / \mathrm{mL}$ and $\mathrm{pH} 4.29$, respectively. It was also verified the influence from the culture media on $B$. lactis growth and production of bacteriocin on a rotary shaker (shaker), which was the comparative analysis from the effect of supplementation by $1 \%$ of the following ingredients: yeast extract (EL), inulin (I), L-cysteine (IC) and Tween $80\left(T_{80}\right)$. The best growing conditions found for higher biomass and bacteriocin production were obtained from the whey concentration of $10 \%(\mathrm{w} / \mathrm{v})$ supplemented with $1 \%$ yeast extract (9.9 log CFU/ml to $200 \mathrm{AU} / \mathrm{mL}$ ). In the final stage of the work, these conditions were tested in bench fermentor, where it was observed that the growth of Bifidobacterium lactis was $10 \%$ higher than in the rotary shaker. Regarding the activity of bacteriocin produced in fermenter bench, there was 
no difference in the rotary shaker (200 AU / mL). This difference in growth may be due to the better anaerobic conditions offered in bench fermentor, which was the injection of nitrogen into the medium, and in a rotary shaker, the anaerobic condition was generated by an external agent to the medium (use of anaerobic jars). Through this study, it can be concluded that bacteriocin production by $B$. lactis is achievable and shows promising results when used the combination whey added yeast extract, which showed antimicrobial activity against the strain Listeria monocytogenes. The optimization process bench fermentor has been shown interesting as bacteriocin production at industrial level.

Keywords: Bifidobacterium lactis, whey, bacteriocin, anaerobic, supplementation. 


\section{LISTA DE ILUSTRAÇÕES}

PÁG.

Curva de crescimento de Bifidobacterium lactis utilizando Figura 1 meio de cultivo BSM suplementado com extrato de levedura (EL), L-cisteína (Cl), Tween 80 ( $\left.\mathrm{T}_{80}\right)$ e inulina (I).

Curva de $\mathrm{pH}$ de Bifidobacterium lactis utilizando caldo BSM Figura 2 suplementado com extrato de levedura (EL), L-cisteína $(\mathrm{Cl})$, 19 Tween $80\left(T_{80}\right)$ e inulina (I).

Curva de crescimento de Bifidobacterium lactis utilizando Figura 3 caldo MRS suplementado com extrato de levedura (EL), L23 cisteína $(\mathrm{Cl})$, Tween $80\left(\mathrm{~T}_{80}\right)$ e inulina $(\mathrm{I})$.

Curva de $\mathrm{pH}$ de Bifidobacterium lactis utilizando caldo MRS Figura 4 suplementado com extrato de levedura (EL), L-cisteína (Cl), 23 Tween $80\left(T_{80}\right)$ e inulina (I).

Figura 5

Curva de crescimento de Bifidobacterium lactis nas variações de concentração de soro de leite a 5, 10, 15, 20 e $25 \%$ p/v.

Figura 6

Curva de $\mathrm{pH}$ de Bifidobacterium lactis nas variações de concentração de soro de leite a 5, 10, 15, 20 e 25 \% p/v.

Curva de crescimento de Bifidobacterium lactis utilizando Figura 7 soro de leite suplementado com extrato de levedura (EL), Lcisteína $(\mathrm{Cl})$, Tween $80\left(\mathrm{~T}_{80}\right)$ e inulina (I). 
Curva de $\mathrm{pH}$ de Bifidobacterium lactis utilizando soro de leite Figura 8 suplementado com extrato de levedura (EL), L-cisteína (Cl), 30 Tween $80\left(T_{80}\right)$ e inulina (I).

Curva de crescimento das cepas Bifidobacterium lactis e Figura 9 Bifidobacterium animalis utilizando soro de leite 32 suplementado com $1 \%$ de levedura.

Curva de $\mathrm{pH}$ das cepas Bifidobacterium lactis e Figura 10 Bifidobacterium animalis utilizando soro de leite 33 suplementado com $1 \%$ de levedura.

Curva de crescimento de Bifidobacterium lactis em Figura 11 fermentador de bancada e em shaker utilizando soro de leite 35 suplementado com $1 \%$ de extrato de levedura.

Curva de $\mathrm{pH}$ de Bifidobacterium lactis em fermentador de Figura 12 bancada e em shaker utilizando soro de leite suplementado 35 com $1 \%$ de extrato de levedura.

Atividade antimicrobiana da bacteriocina produzida por Figura 13 Bifidobacterium lactis utilizando os meios de cultivo: BSM, MRS e soro de leite e cultivo em fermentador de bancada utilizando o soro de leite em presença de inulina (I), Lcisteína $(\mathrm{Cl})$, Tween $80\left(\mathrm{~T}_{80}\right)$ e extrato de levedura (EL). 


\section{LISTA DE TABELAS}

PÁG.

Tabela 1 Concentração celular de Bifidobacterium lactis após 30 horas de cultivo a diferentes agitações (shaker) utilizando meio BSM.

Concentração de glicose $(g / L)$ em meio de cultivo BSM

Tabela 2 suplementado com extrato de levedura (EL), Tween 80 ( $\left.T_{80}\right)$, L20 cisteína (CI) e inulina (I) após 27 horas de cultivo (início da fase estacionária).

Concentração de glicose ( $\mathrm{g} / \mathrm{L})$ caldo MRS suplementado com

Tabela 3 extrato de levedura (EL), Tween $80\left(\mathrm{~T}_{80}\right)$, L-cisteína $(\mathrm{Cl})$ e inulina (I) após 27 horas de cultivo (início da fase estacionária).

Determinação da concentração de lactose no tempo inicial $\left(T_{0}\right)$

Tabela 4 e no tempo final de cultivo $\left(\mathbf{T}_{\mathbf{3 0}}\right)$ de Bifidobacterium lactis utilizando soro de leite em diferentes concentrações.

Concentração de lactose e ácido lático ( $\mathrm{g} / \mathrm{L})$ em caldo soro de

Tabela 5 leite (SL) suplementado com extrato de levedura (EL), Tween 80 ( $\left.\mathrm{T}_{80}\right)$, L-cisteína $(\mathrm{Cl})$ e inulina $(\mathrm{I})$ após 27 horas de cultivo (início da fase estacionária).

Velocidades específicas de crescimento de Bifidobacterium lactis utilizando os meios de cultivo MRS, BSM e soro de leite Tabela 6 (SL) em presença de inulina (I), L-cisteína $(\mathrm{Cl})$, Tween $80\left(\mathrm{~T}_{80}\right)$, BA (cultivo de B. animalis ATCC 25527 em shaker utilizando soro de leite suplementado com extrato de levedura) e F (cultivo de $B$. lactis em fermentador de bancada utilizando soro de leite suplementado com extrato de levedura). 


\section{LISTA DE ABREVIATURAS E SIGLAS}

\begin{tabular}{|c|c|}
\hline $\mathrm{AU}$ & Unidades arbitrárias de atividade da bacteriocina $\left(\mathrm{mg} \mathrm{mL}^{-1}\right)$ \\
\hline BSM & Bifidus Selective Medium \\
\hline MRS & Man Rogosa Sharpe \\
\hline $\mathrm{BHI}$ & Brain Heart Infusion \\
\hline SL & Soro de Leite \\
\hline LAB & Bactérias ácido-láticas \\
\hline rpm & Rotações por minuto \\
\hline$S_{i}$ e $S_{f}$ & Concentrações inicial e final de substrato $\left(\mathrm{g} \mathrm{L}^{-1}\right)$ \\
\hline GRAS & $\begin{array}{l}\text { Geralmente Reconhecidas como Seguras (Generally } \\
\text { Recognized As Safe) }\end{array}$ \\
\hline $\mathrm{t}$ & Tempo de cultivo \\
\hline$t_{g}$ & Tempo de geração $(\mathrm{h})$ \\
\hline UFC & Unidade formadora de colônia $(\mathrm{mL})$ \\
\hline$x$ & Concentração celular $\left(\mathrm{mg} \cdot \mathrm{L}^{1}\right)$ \\
\hline$\mu_{\max }$ & Velocidade específica de crescimento $\left(\mathrm{h}^{-}\right)$ \\
\hline$T_{80}$ & Tween 80 \\
\hline I & Inulina \\
\hline $\mathrm{Cl}$ & L-Cisteína \\
\hline EL & Extrato de Levedura \\
\hline $\mathrm{h}$ & Hora \\
\hline DBO & Demanda Biológica de Oxigênio \\
\hline & Partes por milhão \\
\hline
\end{tabular}




\section{SUMÁRIO}

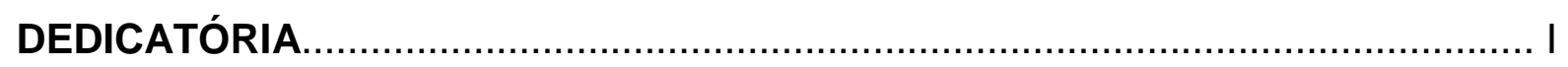

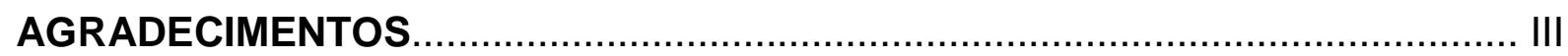

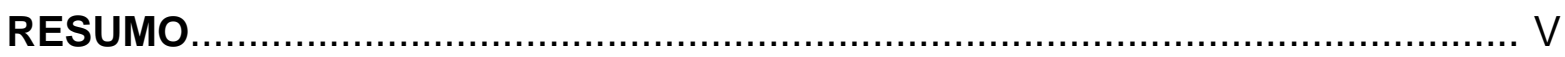

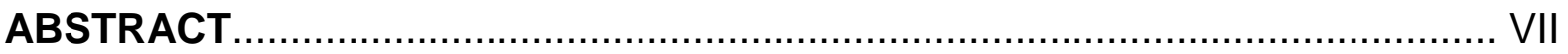

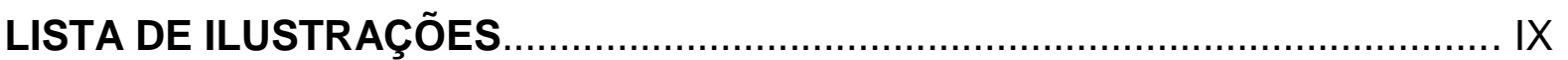

LISTA DE TABELAS

LISTA DE ABREVIATURAS E SIGLAS ......................................................... XII

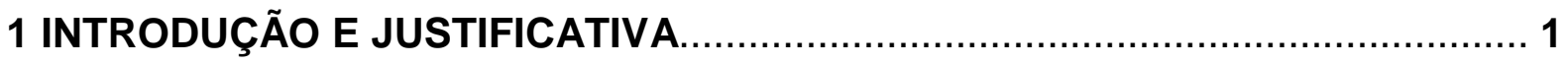

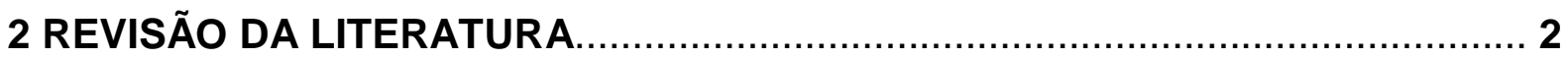

З OBJETIVOS

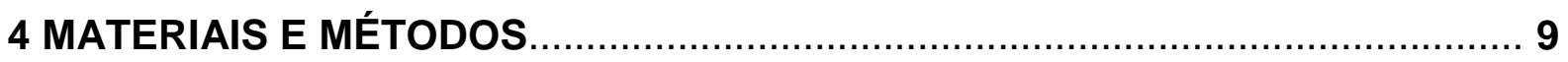

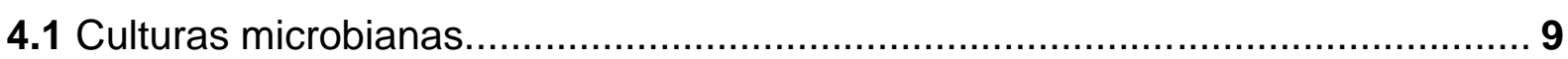

4.2 Preparação dos meios de cultura............................................................ 10

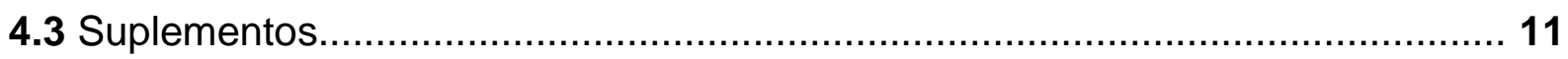

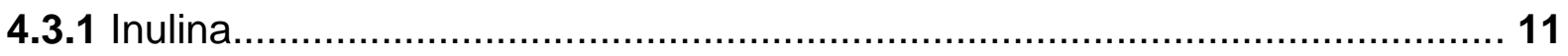

4.3.2 Tween 80

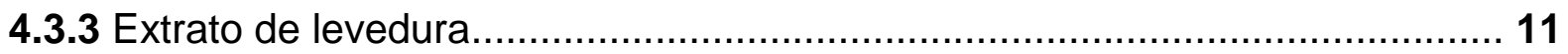

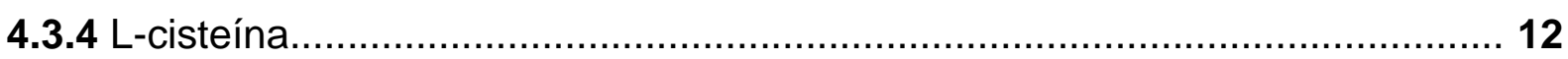

4.4 Preparação do inóculo em agitador rotativo.................................................... 12

4.5 Preparação do inóculo para fermentador de bancada....................................... 13

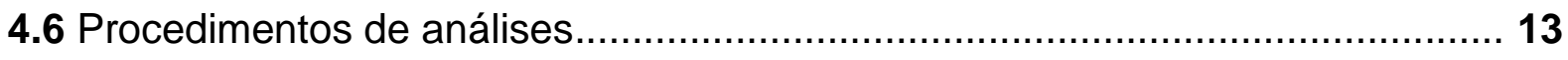

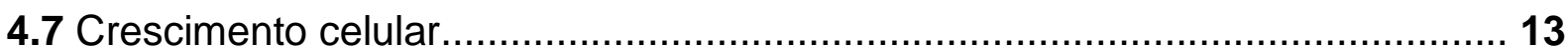

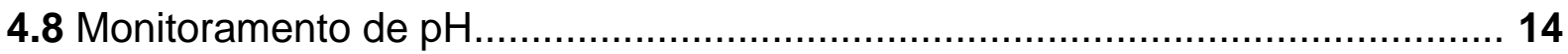


4.9 Determinação de glicose, lactose e ácido lático

4.10 Determinação da atividade da bacteriocina....................................... 15

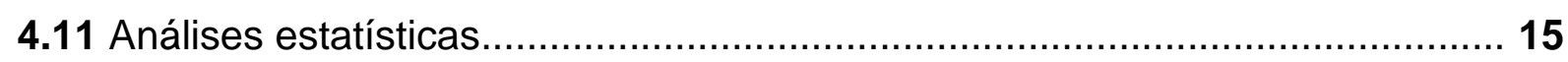

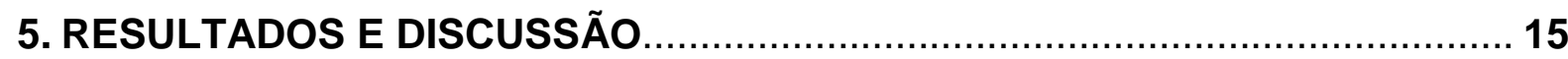

5.1 Influência da velocidade de agitação dos meios de cultivo 16

5.2 Meio de cultivo BSM suplementado com L-cisteína, extrato de levedura, inulina e Tween 80 . 17

5.3 Caldo MRS suplementado com L-cisteína, extrato de levedura, inulina ou Tween 80 . 20

5.4 Soro de leite suplementado com L-cisteína, extrato de levedura, inulina ou Tween 80 .

5.4.1 Determinação do teor de sólidos totais em soro de leite controle e crescimento celular.

5.4.2 Soro de leite a $10 \%$ de sólidos totais suplementado com L-cisteína, extrato de levedura, inulina ou Tween 80 .

5.5 Estudo comparativo entre Bifidobacterium animalis e Bifidobacterium lactis...... 31

5.6 Fermentador de bancada. 33

5.7 Velocidade específica de crescimento ( $\mu$ max) e tempo de geração $(\mathrm{tg})$. 36

5.8 Atividade da bacteriocina. 39

6 CONCLUSÃO

7 SUGESTÕES PARA TRABALHOS.

8 ATIVIDADES ACADÊMICAS.

9 REFERÊNCIAS. 



\section{INTRODUÇÃO E JUSTIFICATIVA}

O soro de leite é considerado um subproduto de elevado valor nutricional, sendo constituído por aproximadamente $6,5 \%$ de sólidos totais; dentre os quais: $4,6 \%$ de lactose, $0,8 \%$ de proteína, $0,5 \%$ de ácidos graxos, de $0,5 \%$ a $0,8 \%$ de matéria mineral e de $0,2 \%$ de $0,8 \%$ de ácido lático (ANTUNES, 2003). Ressalta-se que as proteínas e os ácidos graxos, presentes no soro de leite, são as fontes de peptídeos bioativos e de ácido linoleico conjugado (CLA), respectivamente, as quais promovem efeitos benéficos à saúde do consumidor. Aproximadamente $85 \%$ a $95 \%$ do volume de leite manufaturado é descartado como soro, representando, desta forma, uma notável fonte de poluição, causada por sua alta demanda biológica e bioquímica de oxigênio e matéria orgânica (LIU et al., 2006, YOSHIDA; ANTUNES, 2009). Portanto, torna-se interessante o uso deste subproduto como substrato em fermentação na produção de biomoléculas com alto valor agregado, como compostos antimicrobianos produzidos por bactérias láticas.

As bactérias ácido-láticas são microrganismos que requerem meios sintéticos complexos, como caldos MRS ${ }^{\circledR}$ e $\mathrm{M} 7^{\circledR}$, para o crescimento microbiano. Apesar de comercialmente disponíveis, estes meios possuem elevado custo, o qual encarece e inviabiliza a produção em larga escala. Por isto, torna-se atrativa a pesquisa por novas formulações para a produção de novas bacteriocinas e até mesmo a utilização de diferentes compostos antimicrobianos, principalmente de classes diferentes, com o objetivo de aumentar a eficiência destes compostos na bioconservação de alimentos.

Ressalta-se a inovação científica e tecnológica do presente trabalho no que tange à utilização do soro de leite como meio de cultivo, valorizando o conceito da produção de uma biomolécula de alto valor agregado, pois o soro de leite é um subproduto gerado pelas indústrias de laticínios. Portanto, utilizando-se o soro de leite em pó como meio de cultura, inicia-se uma pesquisa direcionada a questões ambientais. Aponta-se que, no Brasil, $50 \%$ do soro de leite é descartado, sem tratamento, em rios, necessitando de cautela nesse descarte (BRIÃO, 2000). Considerando a produção de queijos, são $9 \mathrm{~kg}$ de soro de leite para $1 \mathrm{~kg}$ de massa de queijo produzido (ROOBBINS et al., 1996). O descarte incorreto do soro, em 
cursos de água, pode causar sérios danos, devido à alta taxa de DBO (Demanda Biológica de Oxigênio) (PARKIN; MARSHALL, 1976). Neste caso, a produção de um antimicrobiano poderia ser associada com a reciclagem ou a reutilização de material de descarte industrial.

\section{REVISÃO DA LITERATURA}

O soro de leite é uma porção aquosa que se separa do coágulo durante a fabricação convencional do queijo e consiste em cerca de 85 a $90 \%$ do volume de leite utilizado para a transformação em queijo e contém $55 \%$ dos nutrientes contidos no leite (KOSIKOWSKI, 1979). As proteínas do soro estão em torno de $20 \%$ do total de proteínas contidas no leite, sendo $50 \%$ de $\beta$-lactoglobulina e $25 \%$ de $\alpha$ lactoalbumina, podendo variar de acordo com a produção de soro e o tipo de queijo (CHEEKE; STANGEL, 1973). Principalmente na América do Norte e na Europa, grandes quantidades de soro de leite estão disponíveis, em 2008, os valores resultantes estimados relatados são de $4.10^{7}$ toneladas para os EUA, e $5.10^{7}$ toneladas para a Europa (GHALY; EL-TAWEEL, 1997). Soro mostra uma carência bioquímica de oxigénio (DBO, 40.000 - 60.000 ppm) e a demanda química de oxigénio (DQO, 50,000 - 80,000 ppm) elevadas, fazendo com que o escoamento do soro excedente seja bastante caro, ressaltando que a lactose, o composto predominanto no soro de leite, é o principal componente responsável por estes altos valores de BOD e COD (KIM et al., 1995, VIÑAS et al., 1994).

As propriedades antimicrobianas de bactérias ácido-láticas (LAB) permitiram o aumento da vidadeprateleira de muitos alimentos, através de processos de fermentação. A inibição de microrganismos deteriorantes dos alimentos pode ser atribuída à produção de compostos antimicrobianos, incluindo ácidos orgânicos, peróxido de hidrogênio, antibióticos e bacteriocinas (SARIKA; LIPTON; AISHWARYA, 2010). As bactérias ácido-láticas são um grupo diversificado e extremamente útil de microrganismos que, apesar de não pertencerem a um grupo taxonômico estrito, estão associados, já que possuem propriedades comuns (PFEILER; KLAENHAMMER, 2007). A característica comum é a produção de ácido láctico como produto principal ou único de uma fermentação. Devido a produção de 
ácido láctico, as bactérias ácido-láticas têm sido historicamente associadas à fermentação de alimentos; como resultado, muitas delas, como Lactococcus, Oenococcus, Lactobacillus, Leuconostoc e Pedicoccus sp., são geralmente reconhecidas como seguras (GRAS) (MAYO et al., 2010), embora outras espécies, principalmente pertencentes aos gêneros Enterococcus e Streptococcus, são consideradas como patogênicas oportunistas na natureza (MADIGAN; MARTINKO; PARKER, 2003).

Algumas espécies de Lactobacillus e Bifidobacterium, utilizadas na fabricação de produtos lácteos fermentados, inibem o crescimento de outros microrganismos, incluindo os patogênicos intestinais e os deteriorantes, através da produção de compostos antibacterianos ou bacteriocinas (AHMAD et al., 2010). Além disso, essas espécies citadas, podem ser consideradas probióticas. Para isso, tem sido sugerido que uma das desejáveis propriedades das cepas probióticas seja a habilidade de produzir substâncias, como bacteriocinas, asquais oferecem o potencial de fornecer vantagem na colonização e na competição do trato gastrointestinal (TAMIME, 2005).

As bacteriocinas são geralmente definidas como peptídeos produzidos por bactérias que apresentam espectro de ação contra uma variedade de microrganismos, incluindo bactérias Gram-positivas e Gram-negativas, protozoários, fungos e vírus (REDDY; YEDERY; GUPTA, 2009). Bacteriocinas produzidas por bactérias Gram-positivas, particularmente bactérias ácido-láticas, apresentam amplo espectro como bioconservantes de alimentos e como agente terapêutico (GALVEZ et al., 2008; JACK; TAGG; RAY, 1995). O mais conhecido exemplo é a nisina, a qual éproduzida por muitas cepas de Lactoccuslactis subsp. lactis, sendo considerada o protótipo de bacteriocina de bactérias ácido-láticas (TAMIME, 2005, JOZALA et al., 2007). Novas bacteriocinas são identificadas por triagem de isolados bacterianos com atividade antimicrobiana, seguida de purificação e identificação de seus determinantes genéticos. Tais estratégias de triagem são fundamentais para a detecção e a identificação de bacteriocinas potentes de várias subclasses. Exemplos recentes incluem: uma bacteriocina de classe Ila, chamada avicina $A$, que foi identificada a partir de Enterococcus avium, estirpes isoladas de amostras de fezes de bebês humanos amamentados e saudáveis da Etiópia e da Noruega (BIRRI el al., 2010); uma bacteriocina de estrutura cíclica chamada garvicina ML, produzida por uma cepa de Lactococcus garvieae, isolado do pato-real (BORRERO et al., 2011); 
uma bacteriocina de classe Ilb, a enterocina X, de Enterococcus faecalis, isolada a partir de maçãs (HU et al., 2010), e uma bacteriocina glicolisada (glicocina $F$ ) de $L b$. plantarum, isolada de milho fermentado (KELLY; ASMUNDSON; HUANG, 1996; STEPPER et al., 2011).

A nisina foi descoberta em 1928, quando Rogers e Whittier observaram metabólitos inibitórios de LAB (Rogers e Whittier, 1928). A nisina tem sido extensivamente estudada e, em 1988, foi aprovada pela Food and Drug Administration (FDA), recebendo a denominação de Generally Recognized as Safe (GRAS) para ser usada como um conservante em muitos alimentos processados. Como resultado disso, pesquisas nesse campo começaram a crescer rapidamente, o que levou à descoberta de grande número de bacteriocinas produzidas por bactérias láticas (GALVEZ et al., 2008; REDDY; YEDERY; GUPTA, 2009).

Bacteriocinas são normalmente sintetizadas como pré-peptídios inativos que possuem uma sequência terminal $\mathrm{N}$ guia (XIE; VAN DER DONK, 2004). Este precursor é transportado para a superfície da célula durante a fase de crescimento exponencial e enzimaticamente convertido na sua forma ativa. $O$ transportador contém uma porção terminal $\mathrm{N}$ peptídica responsável pela clivagem do peptídeo guia, bem como uma porção terminal $C$ responsável pela hidrólise de ATP e fornecimento de energia (AUCHER et al., 2005). Para a classe II, proteínas acessórias são usadas para facilitar a translocação da membrana e/ou para clivar o peptídeo guia. O sistema responsável pela regulação da produção de bacteriocina é composto por três componentes: um peptídeo indutor (ou fator de ativação por realimentação), a histidina quinase transmembrana (receptor de realimentação) e um regulador de resposta (NES; EIJSINK, 1999). O peptídeo indutor é sintetizado no ribossomo em níveis baixos como um pré-peptídeo, que é clivado e segregado para o meio extracelular pelo sistema de transporte. Quando este composto atinge uma determinada concentração, ele ativa a histidina quinase transmembranar, o que leva à autofosforilação do resíduo de histidina, assim transferindo o fosfato a uma proteína reguladora de resposta. O regulador fosforilado ativa a transcrição da bacteriocina, além dos elementos que compõem o sistema de regulação, iniciando uma reação positiva (NES, EIJSINK, 1999). A regulação da produção de lantibióticos, tais como a nisina e a subtilina, é feita pela própria bacteriocina, que atua como um sistema de realimentação para estimular a sua produção em níveis elevados (KLEEREBEZEM; QUADRI, 2001). O mecanismo de imunidade de 
bactérias produtoras de bacteriocinas é capaz de distinguir entre a bacteriocina produzida pela própria bactéria e a produzida por outras. A sua proteção pode ser promovida por uma classe específica de proteínas e/ou pelo sistema de transporte. O mecanismo pelo qual estes funcionam é semelhante, sequestrando a proteína estrutural ou competindo pelo receptor antagonista da bacteriocina (HOFFMANN et al., 2004).

Segundo Twomey et al. (2002), as bacteriocinas estão distribuídas em 3 classes. Em geral, a Classe I, ou Lantibióticos, representada pela nisina, é constituída por peptídeos termoestáveis de baixa massa molar $(<10 \mathrm{kDa})$, diferenciados dos demais pela presença de lantionina e derivados. A Classe II é composta por pequenos peptídeos (<10 kDa) termoestáveis, divididos em três subclasses: Ila (pediocina e enterocina), Ilb (lactocina G) e Ilc (lactocina B). A Classe III é representada por peptídeos termolábeis de alta massa molar (>30 kDa), como helveticina J. É importante salientar que na Classe II encontra-se a bacteriocina produzida por Bifidobacterium bifidum (YILDIRIM; JOHNSON, 1998).

A atividade de bacteriocinas produzidas por bactérias ácido-láticas diferentes não é uniforme ou constante e depende da composição química e das condições físicas do alimento em que estão presentes. A atividade depende principalmente do $\mathrm{pH}$ e é reduzida pela afinidade dos compostos presentes no alimento, pela absorção celular, atividade de proteases e outras enzimas (SCHILLINGER; GEISEN; HOLZAPFEL, 1996). Uma correlação entre a degradação da nisina e extensão da proteólise em creme pasteurizado foi encontrada por Phillips, Griffths e Muir (1983). Buyong, Kok e Luchansky (1998) descreveram a redução da atividade da pediocina, de 64.000 para $2.000 \mathrm{UA} / \mathrm{g}$, após seis meses de maturação do queijo tipo cheddar devido à ação de proteases e peptidases. $\mathrm{O} \mathrm{NaCl}$, a certas concentrações, pode reduzir o crescimento de culturas láticas e,consequentemente, a produção de bacteriocinas, além de proteger a bactéria alvo, como a L. monocytogenes, da ação das bacteriocinas (HUGAS et al., 2002). Sarantinopoulos et al. (2002) observaram a redução na atividade de bacteriocinas e o aumento na taxa de crescimento de Enterococcus faecium FAIR-E 198 após a adição de $2 \%$ de $\mathrm{NaCl}$ em meio MRS. Nilsen, Nes e Holo (1998) descreveram que a redução na produção de bacteriocina na presença do sal se deve à interferência do $\mathrm{NaCl}$ na produção do fator de ligação do receptor de indução. 
A eficiência inibitória das bacteriocinas também está associada ao nível de contaminação do microrganismo alvo. Se a contaminação inicial é muito elevada, a atividade da bacteriocina será baixa e não será capaz de prevenir o desenvolvimento e a contaminação pelo microrganismo. Rilla, Martinez e Rodriguez (2004) investigaram a ação de Lc. lactis subsp. lactis IPLA 729 contra S. aureus em dois níveis diferentes de concentração, especificamente $1,8 \cdot 10^{4}$ e $7.2 \cdot 10^{6}$ UFC $\mathrm{mL}^{-1}$, após $24 \mathrm{~h}$ de incubação. Em particular, estes pesquisadores não detectaram $S$. aureus em várias amostras diluídas, enquanto que em algumas amostras mais concentradas foram encontradas altas concentrações desse microrganismo patogênico $\left(5.0 \cdot 10^{4} \mathrm{UFC} \mathrm{mL}^{-1}\right)$.

As bifidobactérias foram primeiramente isoladas e descritas em 1899-1900 por Tissier. Bifidobacterium spp. são microrganismos Gram-positivos, anaeróbicos, sendo algumas espécies aerotolerantes, como no caso de Bifidobacterium animalis subsp. lactis (LI et al., 2010), esporulantes e não possuem motilidade. Além disso, esses microrganismos são catalase negativos (BIAVATI; MATTARELLI, 2005).

Até recentemente, mais de 34 espécies foram atribuídas ao gênero Bifidobacterium (VENTURA et al., 2007). As bifidobactérias têm sido isoladas de várias fontes, entre as quais a microbiota intestinal de seres humanos. São também consideradas como um dos gêneros predominantes do trato gastrointestinal (FALK et al., 1998). Essa predominância no trato gastrointestinal torna interessante o uso das bifidobactérias como probióticos, considerando que muitos efeitos positivos à saúde têm sido atribuídos a esses microrganismos (UELIVON, 2006). Um dos efeitos positivos das bifidobactérias no trato gastrointestinal de humanos poderia ser a produção de compostos antimicrobianos como, por exemplo, ácidos orgânicos, ácidos graxos (CLA - ácido linoleico conjugado) e bacteriocinas. Metabolicamente, as bifidobactérias produzem ácidos lático e acético sem produzir $\mathrm{CO}_{2}$, exceto durante a degradação do gluconato. Bifidobacterium spp. de origem humana fermenta glicose, galactose, lactose e frutose como fontes de carbono (GOMES; MALCATA, 1999), utilizando uma via metabólica muito diferente da tradicional, que deveria ser levada em conta em qualquer estudo metabólico.

Diferentemente da situação dos Lactobacillus, somente número limitado de estudos tem sido realizado no que diz respeito à produção de compostos antimicrobianos ou bacteriocinas por cepas de bifidobactérias. Espécies de Bifidobacterium são geralmente inibidores de ampla gama de microrganismos, 
devido à sua produção intensa de ácido lático e ácido acético como produtos do próprio metabolismo (EKLUND 1983). Gibson e Wang (1994) demonstraram que oito espécies de bifidobactérias apresentaram atividades antagônicas em relação aos patógenos Gram-positivos e Gram-negativos, não apenas devido à presença de ácidos, mas também devido às substâncias bactericidas ou bacteriostáticas excretadas por estas cepas de Bifidobacterium.

Yildirim e Johnson (1998) isolaram a primeira bacteriocina de Bifidobacterium, conhecida como Bifidocina B. Esta bacteriocina demonstrou-se muito eficaz contra microrganismos patogênicos de origem alimentar (YILDIRIM; WINTERS; JOHNSON, 1999). Estudos in vitro mostraram que bifidobactérias inibiram a ação da Escherichiacoli 0157:H7 entero-hemorrágica (GAGNON et al., 2004) e L. monocytogenes, devido à produção de compostos inibidores (TOURE et al., 2003).

Recentemente, Ahmad et al. (2010) descobriram uma nova bacteriocina produzida por Bifidobacterium infantis em meio sintético MRS (Man Rogosa and Sharpe) suplementado com L-cisteína. Essa nova bacteriocina, denominada Bifidina I, mostrou amplo espectro de ação, incluindo bactérias Gram-negativas e Grampositivas, além de ter demonstrado clara inibição com relação à $L$. monocytogenes.

Produtos alimentares podem ser suplementados com bacteriocinas produzidas ex situ, obtidas de cultura da estirpe produtora em fermentador industrial, seguido pela recuperação adequada. Estas bacteriocinas podem ser adicionadas tanto parcialmente purificadas quanto purificadas em concentrados, o que exige a aprovação específica como conservantes, do ponto de vista legal. Até agora, a nisina e a pediocina PA-1 são as únicas bacteriocinas licenciadas como conservantes de alimentos (SIMHA et al., 2012). Muitos estudos preliminares sobre a atividade de bacteriocinas in vitro ou em sistemas alimentares estão sendo realizados com preparações parcialmente purificadas, obtidas a partir de caldos de fermentações de culturas, mas, na maioria dos casos, uma baixa concentração de bacteriocinas é recuperada (SCHILLINGER; GEISEN; HOLZAPFEL, 1996; STILES, 1996), o que demonstra a importância de se abordar esforços nas técnicas de purificação.

Os alimentos podem também ser suplementados com bacteriocinas produzidas ex situ, que podem ser adicionados sob a forma de concentrados brutos obtidos por cultura da estirpe produtora, quando produzidas em um substrato de grau alimentar (tais como o leite ou soro de leite). As preparações resultantes podem ser 
consideradas como aditivos alimentares ou ingredientes, do ponto de vista legal, uma vez que alguns dos seus componentes podem desempenhar uma função reconhecida no alimento (tais como aumento do teor de proteínas ou espessantes). Eles também contêm metabólitos derivados de células antimicrobianas (tais como ácido láctico) e bacteriocinas, proporcionando a função bactericida adicional. Outras preparações lácteas têm sido descritas, além das já comercializadas, tais como os concentrados ALTA ${ }^{\mathrm{TM}} 2341$ ou Microgard ${ }^{\mathrm{TM}}$, como lacticina 3147 (GUINANE et al., 2005 ) e variacina (O'MAHONY et al., 2001).

Bacteriocinas produzidas ex situ podem também ser aplicadas sob a forma de preparações imobilizadas, nas quais a bacteriocina parcialmente purificada é ligada a um transportador. $\mathrm{O}$ transportador atua como um reservatório e um difusor, das moléculas de bacteriocina concentrada, para a comida, assegurando o fornecimento de um gradiente contínuo de bacteriocina. O transportador também pode proteger a bacteriocina de inativação por interação com componentes alimentares e inativação enzimática. Além disso, a aplicação localizada precisa, de moléculas de bacteriocina sobre a superfície de alimentos, requer quantidades muito mais baixas de bacteriocina (em comparação com o volume de aplicação em alimentos integrais), diminuindo os custos de processamento. $\mathrm{Na}$ maioria dos casos, as preparações imobilizadas de bacteriocina são aplicadas sobre a superfície do alimento processado, evitando a contaminação pós-processo de proliferação de bactérias não desejadas na superfície do alimento. Um avanço recente nesta área é o uso de bacteriocinas imobilizadas no desenvolvimento de embalagens antimicrobianas (MAURIELLO et al., 2004, ERCOLINI et al., 2006).

A produção in situ de bacteriocinas oferece várias vantagens em relação à produção ex situ, sobre os aspectos legais e de custos. A redução dos custos dos processos de bioproteção pode ser altamente atraente, especialmente para pequenas indústrias e países em desenvolvimento, onde a segurança alimentar pode ser seriamente comprometida (HOLZAPFEL, 2002). Muitos estudos também têm focado na seleção e no desenvolvimento de culturas de proteção bacteriocinogênicas para aplicações alimentares (ROSS; MORGAN; HILL, 2002, PELÁEZ; REQUENA, 2005, MORENO et al., 2006, LEROY; VERLUYTEN; DE VUYST, 2006), tais como a inibição de bactérias deteriorantes e patogênicas durante o período de vida de prateleira de alimentos não-fermentados. Uma cultura de proteção pode crescer e produzir bacteriocina durante o armazenamento refrigerado 
do alimento, o que deve ter impacto neutro sobre suas propriedades físico-químicas e organolépticas e/ou durante condições de abuso de temperatura, em que pode até mesmo agir como o microrganismo predominante, garantindo que bactérias patogênicas não proliferem e que alimentos deteriorados não sejam consumidos (HOLZAPFEL; GEISEN; SCHILLINGER, 1995).

Atualmente, a maioria das bactérias probióticas é utilizada na formulação de bioprodutos, como, por exemplo, iogurtes, leites fermentados, sorvetes e produtos farmacêuticos, visando promover efeitos positivos à saúde e prevenção de doenças (MATTILA-SANDHOLM et al., 2002). Por outro lado, é muito importante investigar e obter possíveis biomoléculas que sejam produzidas por estes microrganismos. Portanto, torna-se necessário produzir novos tipos de bacteriocinas, as quais têm sido muito usadas, como no caso da nisina, em produtos de interesse alimentar e farmacêutico.

\section{OBJETIVOS}

O objetivo deste trabalho foi produzir bacteriocina a partir de células de Bifidobacterium animalis subsp. lactis (B. lactis) por processo fermentativo, utilizando soro de leite como meio de cultivo natural suplementado ou não com inulina, Tween 80, L-cisteína e extrato de levedura nas concentrações de $1 \%(\mathrm{p} / \mathrm{v})$, comparando-o com os meios sintéticos MRS Difco ${ }^{\mathrm{TM}}$ (Man Rogosa and Sharpe) e BSM Sigma ${ }^{\mathrm{TM}}$ (Bifidus Selective Medium).

\section{MATERIAIS E MÉTODOS}

\subsection{Culturas microbianas}

Neste trabalho, foram utilizados os seguintes microrganismos: Bifidobacterium animalis subsp. lactis HN019 (B. lactis), cultura comercial liofilizada (Danisco, 
Sassenage, França), usada como produtora de bacteriocina, e Bifidobacterium animalis subsp. animalis ATCC 25527 (B. animalis), para fins comparativos; Lactobacillus sakei ATCC 15521, Escherichia coli ATCC 25922 e Listeria monocytogenes ATCC 13932, utilizados como biossensor da produção do peptídeo antimicrobiano.

\subsection{Preparação dos meios de cultura}

O soro de leite em pó (Cargill Agrícola S.A., Campinas, SP, Brasil) foi preparado utilizando diferentes concentrações de sólidos totais, sendo elas 5, 10, 15,20 e $25 \%$ (p/v). Baseado nos resultados de crescimento celular e acidificação do meio, a melhor concentração de sólidos totais foi 10\% (p/v) (ver Figuras 5 e 6 e seção 6.4.1). A seguir, as bases de soro de leite foram suplementadas ou não com inulina, Tween 80, L-cisteína e extrato de levedura nas concentrações de 1\% (p/v) para estudos comparativos com os meios de cultivo sintéticos.

Como meios de cultivo sintético, foram preparados o caldo MRS (Man Rogosa and Sharpe Difco ${ }^{\mathrm{TM}}$, Sparks, MD, USA) e o caldo BSM (Bifidus Selective Medium, Sigma $^{\mathrm{TM}}$, St. Louis, MO, USA), suplementado ou não com $1 \%(\mathrm{p} / \mathrm{v})$ de extrato de levedura (Difco ${ }^{\mathrm{TM}}$, Sparks, MD, USA), 1\% $(\mathrm{p} / \mathrm{v})$ de Tween 80 (Alamar TecnoCientifica Ltda, Diadema, SP, Brasil), $1 \%(\mathrm{p} / \mathrm{v})$ de inulina (Beneo-Orafti Corp.,Malvern, PA, USA) e 1\% (p/v) de L-cisteína (Sigma Chemical Co., St. Louis, MO, USA), autoclavados em frascos SCHOTT ${ }^{\circledR}$ de $250 \mathrm{ml}$.

Todos os meios foram diluídos em água destilada estéril. As bases de soro de leite foram homogeneizadas com auxílio de agitador magnético, por 15 minutos, e tratadas termicamente a $90^{\circ} \mathrm{C}$, durante 5 minutos (OLIVEIRA et al., 2011), em equipamento de banho termorregulável (Fisatom, Modelo 550 A). Posteriormente, as bases foram imediatamente resfriadas em banho de gelo e distribuídas em frascos $\mathrm{SCHOTT}^{\circledR}$ estéreis em câmara de fluxo laminar. 


\subsection{Suplementos}

\subsubsection{Inulina}

A inulina foi escolhida como um dos ingredientes testados a adicionados aos meios de cultivo, pois em trabalhos recentes, a inulina foi usada como importante indutora de crescimento para bifidobactérias (OLIVEIRA et al., 2009a, 2009b, 2009c).

\subsubsection{Tween 80}

O Tween 80 ou polisorbato 80 é um tensioativo não ionico e agente emulsionante derivado do sorbitano polietoxilado e ácido oleico e é muitas vezes utilizado em alimentos. Ele é uma solução viscosa, liquida, amarela e solúvel em água. $\mathrm{Na}$ nomenclatura dos polissorbatos, a designação numérica polissorbato seguinte refere-se ao grupo lipofílico, neste caso, o ácido oleico. O Tween 80 é frequentemente usado em alimentos e outros produtos, como emulsionante (BUDAVAVI et al., 1996). O uso do Tween 80 como aditivo em meios de cultura se mostrou promissor em outros trabalhos de produção de bacteriocina encontrados na literatura (COLLADO; HERNÁNDEZ; SANZ, 2005), já que é um agente tensoativo, podendo aumentar na concentração de bacteriocinas, por facilitar a excreção desse peptídeo antimicrobiano.

\subsubsection{Extrato de levedura}

O extrato de levedura foi escolhido como um dos ingredientes a serem estudados na suplementação dos meios, pois em diversos estudos com o gênero Bifidobacterium e ouros gêneros de bactérias em diferentes meios de cultivo este ingrediente se mostrou promissor na influencia do crescimento. Loquasto et al. 
(2011) comprovaram que o extrato de levedura adicionado ao soro de leite $B$. lactis aumenta o crescimento em relação ao meio não suplementado.

\subsubsection{L-cisteína}

A cisteína é um a-aminoácido com a fórmula química $\mathrm{HO}_{2} \mathrm{CCH}\left(\mathrm{NH}_{2}\right) \mathrm{CH}_{2} \mathrm{SH}$. Mättö et al. (2006) estudaram o efeito da adição de L-cisteína no meio MRS no crescimento de Bifidobacterium animalis subsp. lactis E2010. Kiviharju, Leisola e Eerikäinen (2005) realizou um estudo de crescimento de Bifidobacterium longum ATCC 15707, adicionando L-cisteína ao meio. Nestes estudos, foi comprovado o efeito benéfico ao crescimento microbiano com a adição de L-cisteína ao meio de cultivo.

\subsection{Preparação do inóculo em agitador rotativo}

A pré-cultura foi preparada adicionando-se $45 \mathrm{mg}$ da cultura estoque liofilizada de B. lactis em $50 \mathrm{~mL}$ de caldo BSM (Sigma) em frascos $\mathrm{SCHOTT}^{\circledR}$ de $250 \mathrm{~mL}$, nas seguintes condições de processo: agitação $(50 \mathrm{rpm})$, temperatura $\left(37^{\circ} \mathrm{C}\right)$ e tempo (24h) em anaerobiose.

A pré-cultura de B. animalis foi preparada adicionando-se $100 \mu \mathrm{L}$ da cultura estoque criopreservada em $50 \mathrm{~mL}$ de caldo BSM (Sigma) em frascos $\mathrm{SCHOTT}^{\circledR}$ de $250 \mathrm{~mL}$ nas seguintes condições de processo: agitação $(50 \mathrm{rpm})$, temperatura $\left(37^{\circ} \mathrm{C}\right)$ e tempo $(24 \mathrm{~h})$ em anaerobiose.

A partir deste cultivo, uma alíquota contendo aproximadamente $10^{8} \mathrm{UFC} / \mathrm{mL}$ foi transferida para frascos $\mathrm{SCHOTT}^{\oplus}$ de $250 \mathrm{~mL}$ contendo $100 \mathrm{~mL}$ de caldo MRS, caldo BSM ou soro de leite que, em seguida, foram incubados em agitador rotacional 
(shaker) nas seguintes condições de processo: agitação (50 rpm), temperatura $\left(37^{\circ} \mathrm{C}\right)$ e tempo de cultivo (30h).

\subsection{Preparação do inóculo para fermentador de bancada}

A pré-cultura de $B$. lactis foi preparada adicionando-se $145 \mathrm{mg}$ da cultura estoque liofilizada em $150 \mathrm{~mL}$ de caldo soro de leite em frascos $\mathrm{SCHOTT}^{\circledR}$ de $250 \mathrm{~mL}$, nas seguintes condições de processo: agitação $(50 \mathrm{rpm})$, temperatura $\left(37^{\circ} \mathrm{C}\right)$ e tempo (24h) em jarras de anaerobiose. Após atingir a concentração de aproximadamente $10^{8} \mathrm{UFC} / \mathrm{mL}$ (24h), o pré-inóculo foi transferido para o fermentador de bancada contendo $1.350 \mathrm{~mL}$ de caldo soro de leite suplementado com $1 \%$ de extrato de levedura.

\subsection{Procedimentos de análises}

Nos estudos realizados em agitador rotacional (shaker) e em fermentador de bancada, as análises foram realizadas a cada 3 horas, durante 30 horas de fermentação, sendo que as alíquotas foram coletadas assepticamente dos cultivos para análises de $\mathrm{pH}$, consumo de glicose (para os meios sintéticos) e lactose (para o soro de leite), crescimento celular e determinação da atividade da bacteriocina. Cada análise foi realizada em triplicata.

\subsection{Crescimento celular}

O crescimento celular foi determinado através da diluição em série, ou seja, $0,1 \mathrm{ml}$ de amostra em tubos contendo $0,9 \mathrm{ml}$ de água peptonada esterilizada até atingir grau de diluição entre $10^{6}$ e $10^{9}$. A contagem foi realizada em placas de Petri 
contendo meio de cultura BSM e ágar, expressa na forma de log UFC/mL, através do método de pour plate. As placas foram armazenadas em jarras de anaerobiose (BBL, GasPak ${ }^{\circledR}$ SystemBecton Dickinson Microbiological System, Cockeysville, Maryland, USA) e incubadas por 48 horas a $37^{\circ} \mathrm{C}$.

\subsection{Monitoramento de $\mathrm{pH}$}

A determinação do $\mathrm{pH}$ foi realizada através do uso de um pHmetro modelo Q400M1 (Quimis, São Paulo, Brasil).

\subsection{Determinação de glicose, lactose e ácido lático}

A determinação das concentrações de lactose, glicose e de ácido lático foi realizada mediante cromatografia líquida de alta eficiência (CLAE), de acordo com o método descrito por Donkor et al. (2007). Previamente, cada amostra foi centrifugada a $15.000 \times \mathrm{g}$ por 20 minutos, utilizando uma microcentrífuga U-32R (Boeckel, Hamburg, Germany) para remoção de microrganismos e separação do sobrenadante. Posteriormente, a amostra foi diluída para a concentração entre 0,5 e $2 \mathrm{~g} / \mathrm{L}$, filtrada, através de membrana de poro 0,45 $\mu \mathrm{m}$ (Millipore), e injetada em cromatógrafo líquido Ultimate 3000 (Dionex, Sunnyvale, CA, Estados Unidos) com detector por Índice de Refração (Shodex, Kawasaki, Kanagawa, Japan), a $35{ }^{\circ} \mathrm{C}$, coluna HPX-87H (Bio-Rad, Hercules, CA, Estados Unidos), a $45^{\circ} \mathrm{C}$, fase móvel de $\mathrm{H} 2 \mathrm{SO} 4$ (5 mM) com fluxo de 0,6 mL/min. Soluções de glicose, galactose, lactose e ácidos orgânicos (10 g/l cada) foram preparadas nas concentrações de 0,$1 ; 0,2 ; 0,4$; 0,8; 1,0 e 2,0 g/l e utilizadas como padrão para elaboração da curva de calibração. A quantificação dos açúcares foi executada através de curvas-padrão previamente obtidas com soluções-padrão de glicose e lactose (Sigma ${ }^{\text {TM }}$, St. Louis, MO, USA) de alta pureza para uso em CLAE. Todas estas análises foram realizadas em triplicata. 
4.10 Determinação da atividade da bacteriocina

Para a extração da bacteriocina, a amostra retirada do meio de cultivo foi centrifugada a $13.201 \mathrm{~g}$, a $10^{\circ} \mathrm{C}$, por 10 minutos, para se retirar a biomassa. $\mathrm{O}$ sobrenadante foi retirado, para as análises de atividade da bacteriocina, e o pH foi corrigido para 6,0, para que não houvesse interferência nos testes de atividade. A amostra foi então aquecida a $90^{\circ} \mathrm{C}$, por 10 minutos, para eliminação da influência de peróxidos produzidos pela $B$. lactis (ODAMAKI et al., 2011) e para eliminação de possíveis microrganismos contaminantes. Após homogeneização em vórtice, $40 \mu \mathrm{l}$ foram aplicados em poços no ágar de cultura BHI (DIFCO ${ }^{\mathrm{TM}}$, Sparks, MD, USA), que, por sua vez, estava pré-inoculado com o microrganismo indicador (Lactobacillus sakei ATCC 15521, Escherichia coli ATCC 25922 ou Listeria monocytogenes ATCC 13932).

\subsection{Análises estatísticas}

As análises estatísticas foram realizadas utilizando o teste de Tukey HSD. Para os resultados de determinação de velocidade de agitação do meio de cultivo, concentração de glicose, lactose e ácido lático, foi utilizada a One-way ANOVA. Para os resultados de estudo de atividade de bacteriocina, velocidade específica de crescimento e crescimento celular, foi utilizada a análise de variância fatorial (Factorial ANOVA).

\section{RESULTADOS E DISCUSSÃO}




\subsection{Influência da velocidade de agitação dos meios de cultivo na contagem microbiana}

O gênero Bifidobacterium é desprovido de catalase, uma enzima essencial para degradar $\mathrm{H}_{2} \mathrm{O}_{2} \mathrm{e}$, portanto, para tal, deve contar com enzimas como a NADH oxidase e a NADH peroxidase, para eliminar o oxigênio do meio de cultivo (ODAMAKI et al., 2011). Considerando a B. lactis uma espécie de bactéria aerotolerante (LI et al., 2010), foi realizado, em meio de cultura BSM, um estudo prévio de crescimento de $B$. lactis variando a agitação (25, 50 e 100 rpm) do caldo durante o processo fermentativo a $37^{\circ} \mathrm{C}$, por 30 horas. Como demonstrado na Tabela 1, a $B$. lactis apresentou melhor crescimento $\left(13.10^{8}\right.$, ou seja, 9,13 log UFC/mL) a $50 \mathrm{rpm}$, ao final de 30 horas do cultivo fermentativo. $O$ valor das contagens foi, em média, $108 \%$ superior ao alcançado a $25 \mathrm{rpm}\left(6,5.10^{8}\right.$ ou $8,81 \mathrm{log}$ UFC $\mathrm{mL}$ ) e $182 \%$ superior em relação a $100 \mathrm{rpm}\left(4,8.10^{8}\right.$ ou $\left.8,68 \log \mathrm{UFC} / \mathrm{mL}\right)$. Estes dados reforçam os estudos sobre a sensibilidade da $B$. lactisà presença de oxigênio, quando o estudo ocorre na agitação de 100 rpm. Porém, o crescimento também é defasado a baixas rotações (25 rpm), já que esta condição possivelmente dificulta a dispersão de nutrientes no meio de cultivo (ROSS; FIEGEL, 2012).

Tabela 1. Concentração celular de Bifidobacterium lactis após 30 horas de cultivo a diferentes agitações (shaker) utilizando meio BSM. Legenda: diferentes letras na mesma coluna significam que há diferença estatística entre os valores $(P<0,05)$.

\begin{tabular}{cc}
\hline $\begin{array}{c}\text { Agitação } \\
\text { (rpm) }\end{array}$ & $\begin{array}{c}\text { Contagem (log } \\
\text { UFC/mL) }\end{array}$ \\
\hline 25 & $8,81 \pm 0,04^{\mathrm{A}}$ \\
50 & $9,13 \pm 0,03^{\mathrm{B}}$ \\
100 & $8,68 \pm 0,06^{\mathrm{C}}$ \\
\hline
\end{tabular}




\subsection{Meio de cultivo BSM suplementado com L-cisteína, extrato de levedura, inulina e Tween 80}

O meio BSM foi escolhido como meio de cultivo controle, pois é um meio sintético específico para o crescimento de bactérias do gênero Bifidobacterium, e sua suplementação foi feita para fins comparativos com os testes realizados tanto em soro de leite como em meio de cultura MRS. O meio de cultivo BSM geralmente é formulado a partir do MRS; porém, com a suplementação de antibióticos, como a "mupirocina" e a "nistatina" (SIMPSON et al., 2004, ASHRAF; SHAH, 2011). No entanto, o meio de cultivo utilizado no presente trabalho foi o BSM patenteado pela Sigma ${ }^{\mathrm{TM}}$, cuja formulação não é descrita.

Como pode ser observado na Figura 1, a $B$. lactis apresentou crescimento exponencial contínuo entre 6 e 24 horas de fermentação. A maior curva de crescimento foi observada no caldo BSM suplementado com extrato de levedura, apresentando contagem de 9,9 log UFC/mL. Este crescimento foi $108 \%$ maior em relação ao caldo BSM suplementado por cisteína, inulina ou Tween 80 , após 27 horas de cultivo, no qual a contagem de $B$. lactis foi, em média, 9,5 log UFC/mL. Em caldo BSM sem adição de suplementos (controle), a contagem, após 27 horas de cultivo, foi de 9,4 Log UFC/mL. O meio de cultivo BSM suplementado com extrato de levedura apresentou crescimento $315 \%$ maior em relação ao meio BSM não suplementado. Uma hipótese para explicar esse comportamento seria que a concentração de proteínas presentes no caldo BSM foi o principal fator limitante, em relação aos outros nutrientes presentes, para o crescimento de Bifidobacterium animalis subsp. lactis HN019. Por outro lado, na Figura 2, pode-se observar que não houve variação expressiva do $\mathrm{pH}$ entre as diferentes suplementações em caldo BSM. Isso se deve,hipoteticamente, à presença de substâncias tamponantes na formulação do caldo BSM.

A concentração de glicose foi determinada no final da fase exponencial de crescimento, ou seja, após 24 horas do cultivo fermentativo. O meio BSM suplementado com extrato de levedura apresentou a menor concentração de glicose $(0,027 \mathrm{~g} / \mathrm{L})$ em relação à concentração apresentada em presença de outros ingredientes estudados no caldo BSM, conforme apresentado na Tabela 2. A baixa concentração de glicose ao final do cultivo no meio BSM suplementado com extrato 
de levedura pode estar relacionada à curva de crescimento apresentada na Figura 1, na qual este caldo apresentou a maior concentração celular no final da fase exponencial $(9,8 \log \mathrm{UFC} / \mathrm{mL})$. O teor inicial de glicose no meio de cultura BSM foi de 4,2 $\mathrm{g} / \mathrm{L}$ (resultados não apresentados).

Comparando-se o crescimento da cepa de $B$. lactis estudada no presente trabalho com outras espécies do gênero Bifidobacterium em meio de cultivo BSM, a B. lactis apresentou crescimento maior $(9,8 \log \mathrm{UFC} / \mathrm{mL})$ em relação à Bifidobacterium bifidum NCIMB 700795 (8,86 log UFC/mL) e à Bifidobacterium bifidum NCIMB 702203 (7,36 Log UFC/mL) (SIMPSON et al., 2004). Já no caso de espécies, como Bifidobacterium longum NCIMB702259T (9,30 log UFC/mL) e Bifidobacterium thermophilum NCIMB 702254T (9,62 log UFC/mL) (SIMPSON et al., 2004), a $B$. lactis apresentou crescimento semelhante, porém ainda superior.

Quando o meio de cultivo BSM é utilizado para o crescimento de outros gêneros de bactérias, como Bacillus, Lactobacillus e Streptococcus, estes apresentam crescimento quase nulo, como pôde ser observado comBacillus cereus ATCC 9139, Lactobacillus bulgaricus ATCC 11842T e Streptococcus cremoris ATCC 19257T, as quais apresentaram crescimento menor do que 2,0 log UFC/mL (SIMPSON et al., 2004). Esse baixo crescimento de outros gêneros pode ser explicado pela presença de antibióticos no meio de cultivo (SIMPSON et al., 2004). 


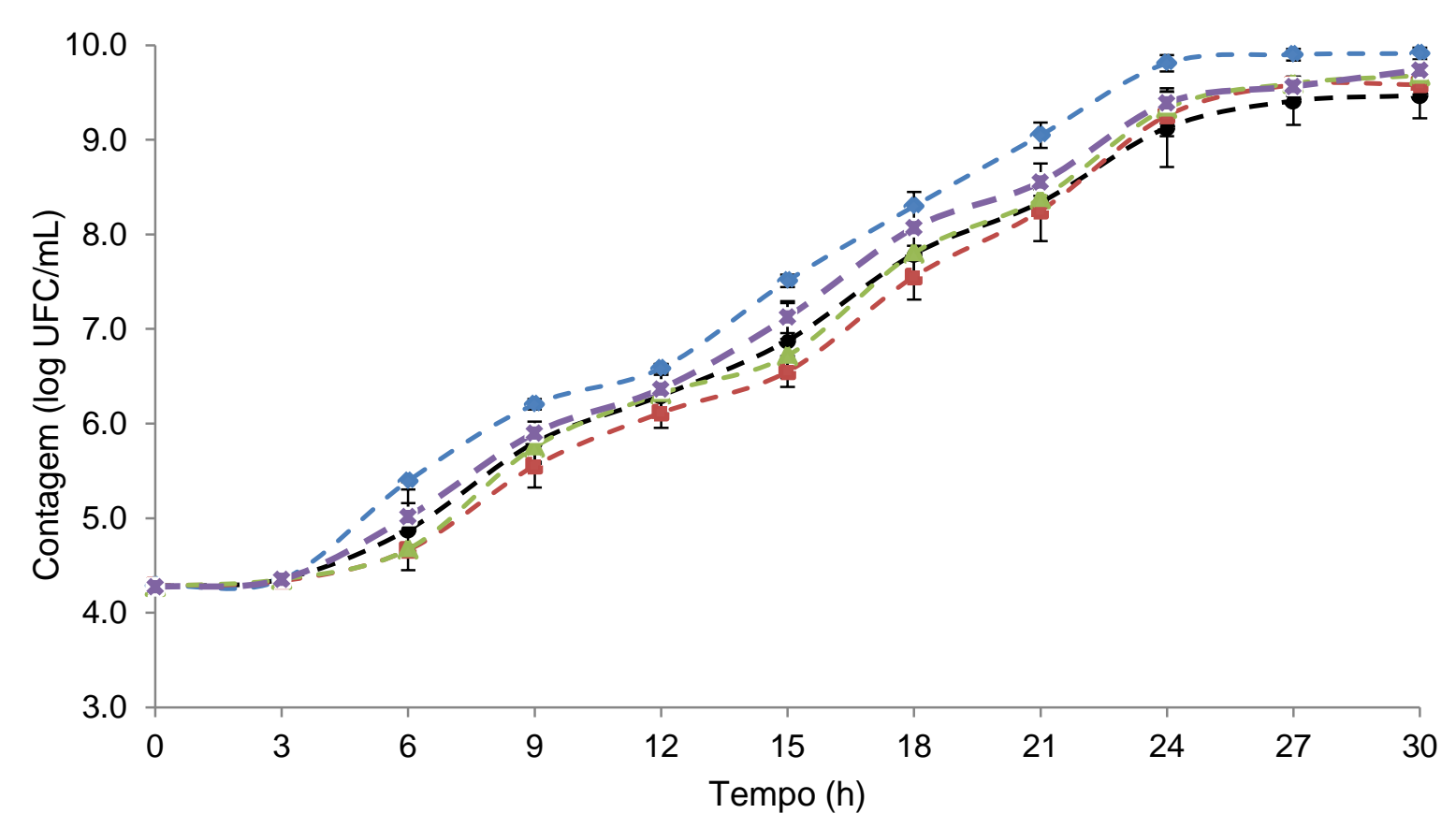

Figura 1. Curva de crescimento de Bifidobacterium lactis utilizando meio de cultivo BSM suplementado com extrato de levedura (EL), L-cisteína (Cl), Tween $80\left(\mathrm{~T}_{80}\right)$ e

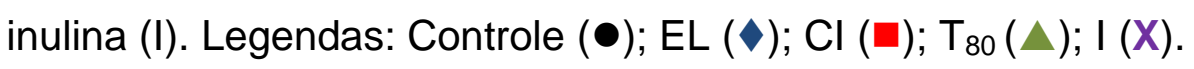

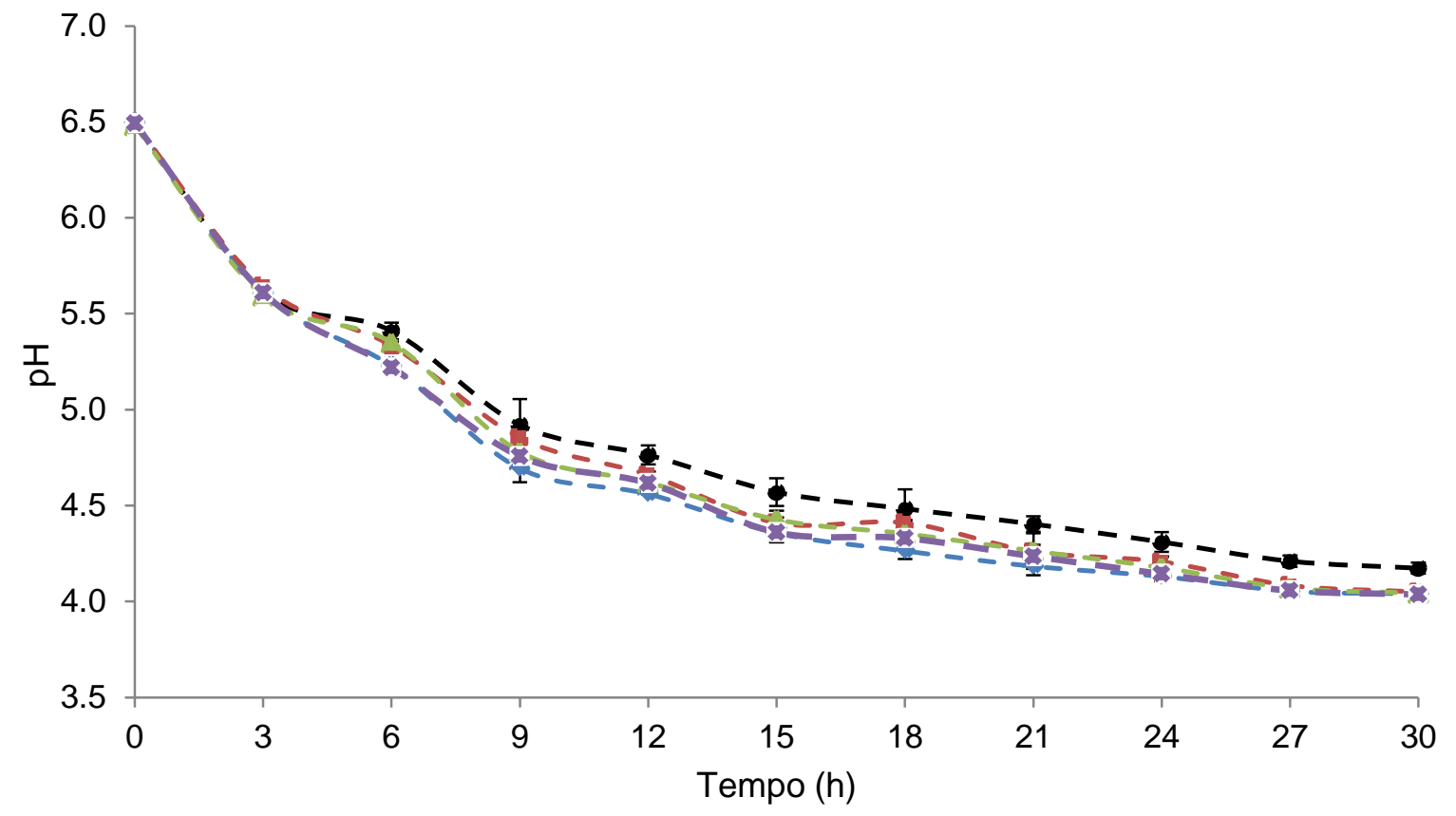

Figura 2. Curva de $\mathrm{pH}$ de Bifidobacterium lactis utilizando caldo BSM suplementado com extrato de levedura (EL), L-cisteína $(\mathrm{Cl})$, Tween $80\left(\mathrm{~T}_{80}\right)$ e inulina $(\mathrm{I})$. Legendas:

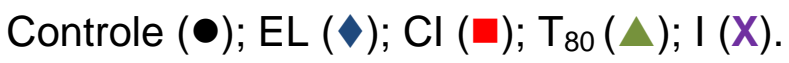


Tabela 2. Concentração de glicose ( $\mathrm{g} / \mathrm{L}$ ) em meio de cultivo BSM suplementado com extrato de levedura (EL), Tween $80\left(T_{80}\right)$, L-cisteína ( $\mathrm{Cl}$ ) e inulina (I) após 27 horas de cultivo (início da fase estacionária).

\begin{tabular}{lc}
\hline Meio de cultura & Concentração de Glicose (g/L) \\
\hline $\mathrm{BSM}$ & $0,745 \pm 0,031$ \\
$\mathrm{BSM}+\mathrm{T}_{80}$ & $0,428 \pm 0,032$ \\
$\mathrm{BSM}+\mathrm{I}$ & $0,649 \pm 0,015$ \\
$\mathrm{BSM}+\mathrm{Cl}$ & $0,514 \pm 0,021$ \\
$\mathrm{BSM}+\mathrm{EL}$ & $0,027 \pm 0,029$ \\
\hline
\end{tabular}

\subsection{Caldo MRS suplementado com L-cisteína, extrato de levedura, inulina ou Tween 80}

O meio de cultura MRS é geralmente o mais utilizado para o crescimento do gênero Bifidobacterium em laboratórios de análise de controle de qualidade industrial, já que fornece condições ideais para o crescimento não seletivo de bifidobactérias (ROY, 2001). Logo, assim como o meio BSM, o meio MRS foi escolhido para os estudos de produção de biomassa, determinação de $\mathrm{pH}$, consumo de glicose e produção de bacteriocina em relação ao soro de leite.

A determinação da curva de crescimento de Bifidobacterium lactis em caldo MRS, suplementado com L-cisteína, extrato de levedura, inulina, Tween 80 ou sem suplementação (controle), foi obtida nas condições de temperatura a $37^{\circ} \mathrm{C}$, agitação de $50 \mathrm{rpm}$ e tempo de cultivo de 30 horas. Na Figura 4, observa-se que houve crescimento celular durante todo o processo fermentativo, no qual a fase Log se encontra entre 6 e 27 horas de fermentação. A fase Log, quando utilizado o caldo MRS, foi 3 horas maior em relação ao meio de cultivo BSM; ou seja, o crescimento da $B$. lactis foi mais rápido em caldo BSM do que em MRS. 
No tempo de 27 horas de cultivo, o valor de contagem das células de $B$. lactis foi 9,43 $\log$ UFC/mL em caldo suplementado com $1 \%$ de extrato de levedura, apresentando o melhor resultado, juntamente com o caldo suplementado por Lcisteína (9,32 log UFC/mL), comparado com inulina (8,8 log UFC/mL) e Tween 80 (8,6 log UFC/mL) (Figura 4). Assim como foi observado no caldo BSM (seção 6.2), o caldo MRS apresentou crescimento celular maior quando foi suplementado com extrato de levedura. Este resultado já era esperado, pois ambos os meios de cultivo possuem formulações semelhantes.

A Figura 4 representa a curva de $\mathrm{pH}$ durante o processo fermentativo, quando adicionados os ingredientes estudados ao caldo MRS. $\mathrm{O}$ valor de $\mathrm{pH}$ do meio suplementado com Tween 80 foi o mais elevado durante a maior parte do processo fermentativo. No final do processo fermentativo (após 30 horas de fermentação), o valor de $\mathrm{pH}$ no caldo MRS suplementado com inulina, L-cisteína e extrato de levedura foi de, em média, 4,2, sendo que, no caldo MRS suplementado com Tween 80 , foi de 4,7 .

$\mathrm{Na}$ Tabela 3, pode-se observar que o caldo MRS suplementado com extrato de levedura $(0,425 \mathrm{~g} / \mathrm{L})$ apresentou menor concentração de glicose, juntamente com o caldo MRS suplementado com L-cisteína $(0,430 \mathrm{~g} / \mathrm{L})$, em relação ao caldo MRS suplementado com Tween 80 (0,473 $\mathrm{g} / \mathrm{L})$ e ao caldo MRS suplementado com inulina $(0,441 \mathrm{~g} / \mathrm{L})$. O teor de glicose, ao final da fase $\log$, apresenta diferença concomitantemente menor em proporcionalidade em relação aos resultados observados nas curvas de crescimento celular (Figura 3), com diferença deaproximadamente $10 \%$ entre a maior e a menor concentração de glicose. $O$ caldo MRS suplementado com Tween 80 apresentou diferença estatística em relação à adição de L-cisteína e extrato de levedura; porém, não apresentou diferença significativa quando suplementado com inulina. Por outro lado, os meios de cultivo MRS, suplementados com inulina, L-cisteína e extrato de levedura, não apresentaram diferença significativa entre si. O teor inicial de glicose do meio MRS suplementado foi de $1,50 \mathrm{~g} / \mathrm{L}$ (resultado não apresentado).

O crescimento da Bifidobacterium animalis subsp. lactis HN019 em meio de cultura MRS suplementado com L-cisteína se mostrou muito semelhante ao da cepa Bifidobacterium animalis subsp. lactis E2010 estudada por Mättö et al. (2006), no qual os autores utilizaram a mesma composição de meio de cultivo. Na B. lactis 
E2010 estudada por Mättö et al. (2006), a concentração de biomassa encontrada foi de aproximadamente 8,8 log UFC/mL, após 24 horas de fermentação, enquanto que na $B$. lactis $\mathrm{HN} 019$, estudada no presente trabalho, o crescimento foi de $8,9 \mathrm{log}$ $\mathrm{UFC} / \mathrm{mL}$.

O crescimento da cepa $B$. lactis em meio MRS suplementado com extrato de levedura $(9,4 \log \mathrm{UFC} / \mathrm{mL})$ foi superior quando comparado com outras espécies do mesmo gênero cultivadas em meio BSM, como as cepas Bifidobacterium bifidum NCIMB 700795 (8,9 log UFC/mL) e Bifidobacterium bifidum NCIMB 702203 (7,34 log $\mathrm{UFC} / \mathrm{mL}$ ) (SIMPSON et al., 2004). Em relação às cepas Bifidobacterium longum NCIMB 702259T (9,30 log UFC/mL) e Bifidobacterium thermophilum NCIMB 702254T (9,62 log UFC/mL), o crescimento da cepa $B$. lactis foi semelhante (SIMPSON et al., 2004).

Quando o meio de cultivo MRS suplementado com L-cisteína foi utilizado para o crescimento de outros gêneros de bactérias, que não o Bifidobacterium, estas apresentam crescimento inferior ao da B. lactis $(9,3 \log \mathrm{UFC} / \mathrm{mL})$, como pode ser observado em Bacillus cereus ATCC 9139 (7,19 log UFC/mL), Lactobacillus bulgaricus ATCC $11842 \mathrm{~T}$ (8,30 log UFC/mL) e Streptococcus cremoris ATCC $19257 \mathrm{~T}$ (7,09 log UFC/mL) (SIMPSON et al., 2004). 


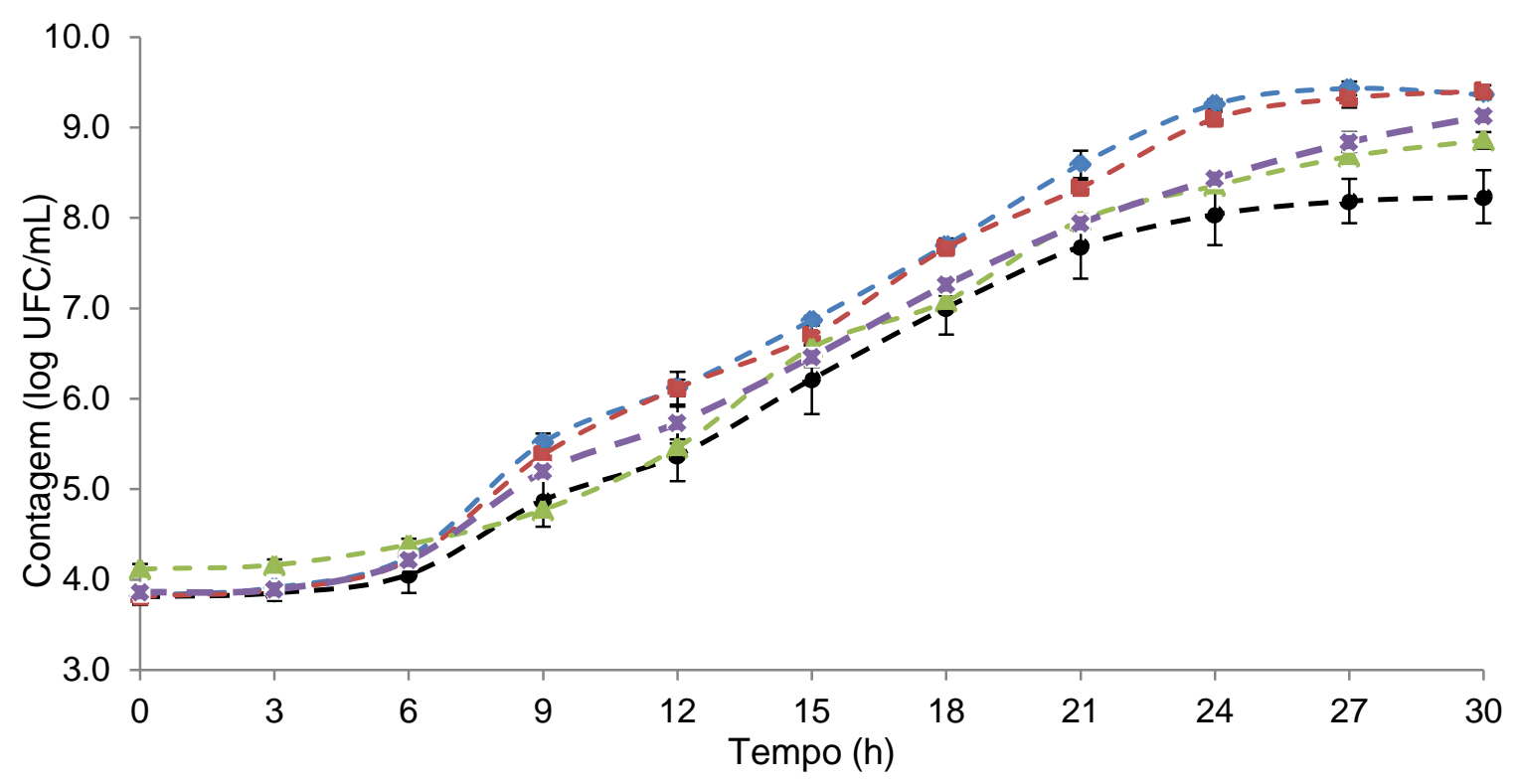

Figura 3. Curva de crescimento de Bifidobacterium lactis utilizando caldo MRS suplementado com extrato de levedura (EL), L-cisteína (Cl), Tween $80\left(T_{80}\right)$ e inulina

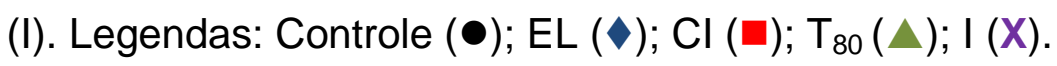

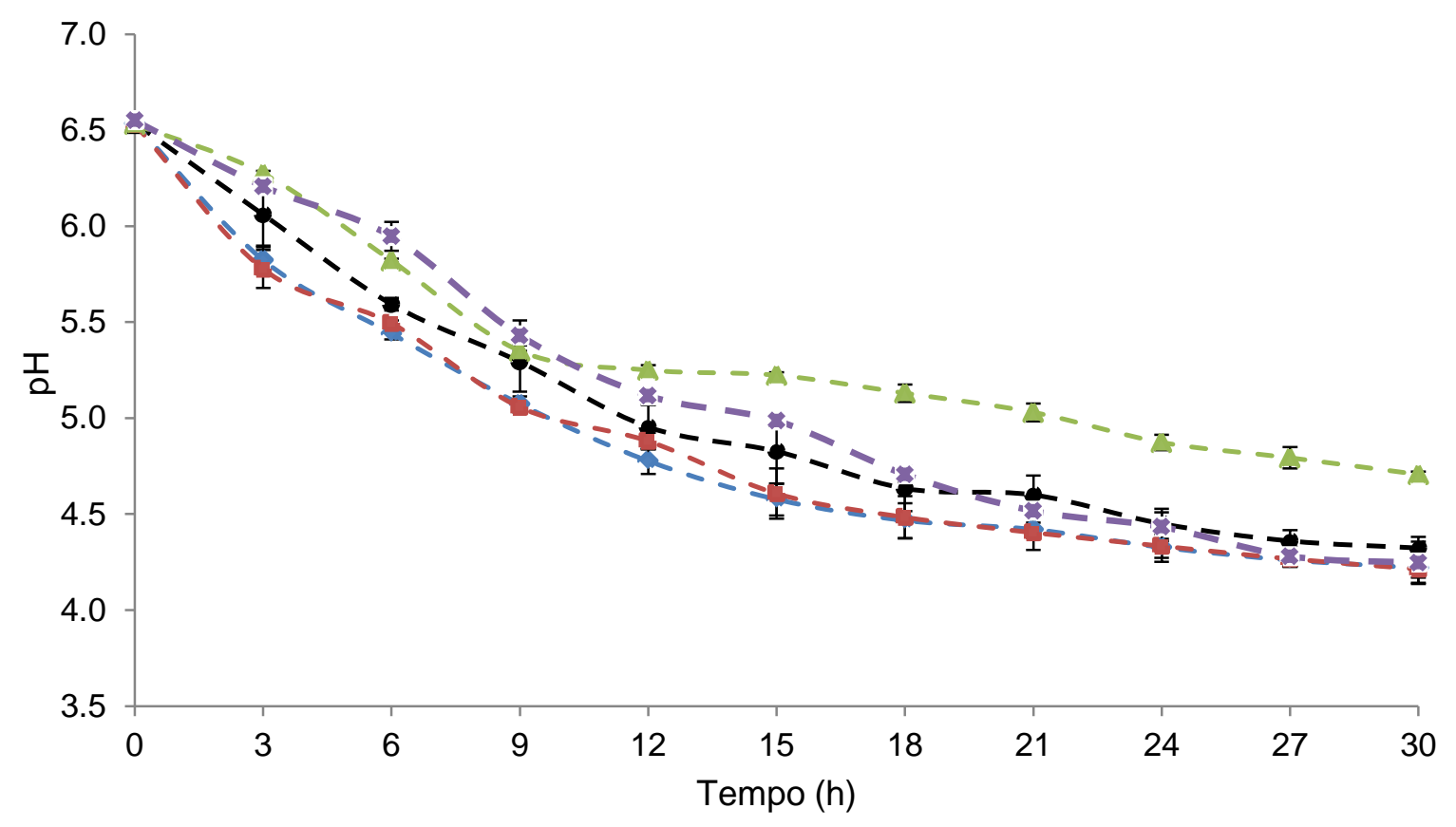

Figura 4. Curva de $\mathrm{pH}$ de Bifidobacterium lactis utilizando caldo MRS suplementado com extrato de levedura (EL), L-cisteína $(\mathrm{Cl})$, Tween $80\left(\mathrm{~T}_{80}\right)$ e inulina $(\mathrm{I})$. Legendas: Controle (•); EL (४); $\mathrm{Cl}(\square)$; $\mathrm{T}_{80}(\boldsymbol{\Delta})$; I (X). 
Tabela 3. Concentração de glicose $(\mathrm{g} / \mathrm{L})$ caldo MRS suplementado com extrato de levedura (EL), Tween $80\left(\mathrm{~T}_{80}\right)$, L-cisteína $(\mathrm{Cl})$ e inulina (I) após 27 horas de cultivo (início da fase estacionária).

\begin{tabular}{lc}
\hline Meio de cultura & Concentração de Glicose (g/L) \\
\hline MRS & $0,478 \pm 0,012$ \\
$M R S+T_{80}$ & $0,473 \pm 0,014$ \\
$M R S+I$ & $0,441 \pm 0,011$ \\
$M R S+C l$ & $0,430 \pm 0,009$ \\
$M R S+E L$. & $0,425 \pm 0,017$ \\
\hline
\end{tabular}

5.4 Soro de leite suplementado com L-cisteína, extrato de levedura, inulina ou Tween 80

Os resultados obtidos dos estudos da determinação do teor de sólidos totais que proporcionou o melhor crescimento celular de $B$. lactis estão expostos na seção 5.4.1.

\subsubsection{Determinação do teor de sólidos totais em soro de leite controle e crescimento celular}

O soro de leite utilizado no presente trabalho foi constituído de aproximadamente $60 \%$ de lactose, $15 \%$ de proteína e $1 \%$ gordura, além de cálcio, sódio e ferro (ANTUNES, 2003). Portanto, visando a maior produção de biomassa de B. lactis e considerando o soro de leite um meio complexo, houve a necessidade de se 
elaborar um estudo prévio, variando a sua concentração (5, 10, 15, 20 e 25 \% p/v), para que, a seguir, fosse realizado estudo de suplementação com os ingredientes estudados no presente trabalho.

$\mathrm{Na}$ figura 5 , no tempo de 27 horas de cultivo, o valor de contagem das células foi $8,87 \log$ UFC/mL em soro de leite com concentração de $10 \% \mathrm{p} / \mathrm{v}$, apresentando o melhor resultado, comparado a $5 \%$ (8,71 log UFC/mL), 15\% (8,26 log UFC/mL), $20 \%$ (7,44 log UFC/mL) e 25\% p/v (7,28 log UFC/mL).

Apesar de o soro de leite com concentração de 5\% apresentar uma curva de crescimento muito próxima à curva do soro com concentração de 10\% (Figura 5), o valor de $\mathrm{pH}$ do soro de leite a $5 \%$ de sólidos totais diminuiu e se estabilizou ao nível de acidez mais baixo ( $\mathrm{pH} \mathrm{4,19)} \mathrm{(Figura} \mathrm{6),} \mathrm{dentre} \mathrm{as} \mathrm{medições} \mathrm{na} \mathrm{amostra} \mathrm{após} 21$ horas de cultivo, enquanto que o soro de leite com concentração $10 \%$ só atingiu este nível após 30 horas de cultivo. Deve ser lembrado que a acidificação do meio prejudica o crescimento celular da B. lactis (JALILI; RAZAVI; SAFARI, 2010).

Como pode ser observado na Tabela 4 , houve maior consumo de lactose pela $B$. lactis no meio de cultura natural, composto por soro de leite, na concentração de 5 e $10 \%$, no qual o consumo desse dissacarídeo, do início ao final da fermentação, foi de 49 e $37 \%$, respectivamente, do total de lactose inicial. No soro de leite, em concentrações de 15, 20 e 25\%, houve o consumo de apenas 19, 17 e 15\%, respectivamente, do total de lactose inicial. Todos os resultados observados na Tabela 4 apresentam diferença estatística significativa entre si.

Através dos resultados discutidos acima, pode-se observar que o soro de leite, nas concentrações 15, 20 e $25 \%(p / v)$, apresenta teor de sólidos totais muito elevado para o crescimento adequado da $B$. lactis. Apesar de o soro de leite com concentração $5 \%$ apresentar bom consumo de lactose, as curvas de crescimento e $\mathrm{pH}$ observadas nas figuras 5 e 6 apresentam resultados inferiores, quando comparados aos apresentados nas curvas desse meio de cultivo natural na concentração de $10 \%$, sendo, portanto, o meio de cultivo escolhido para os estudos nos quais foram adicionados os ingredientes em questão. 


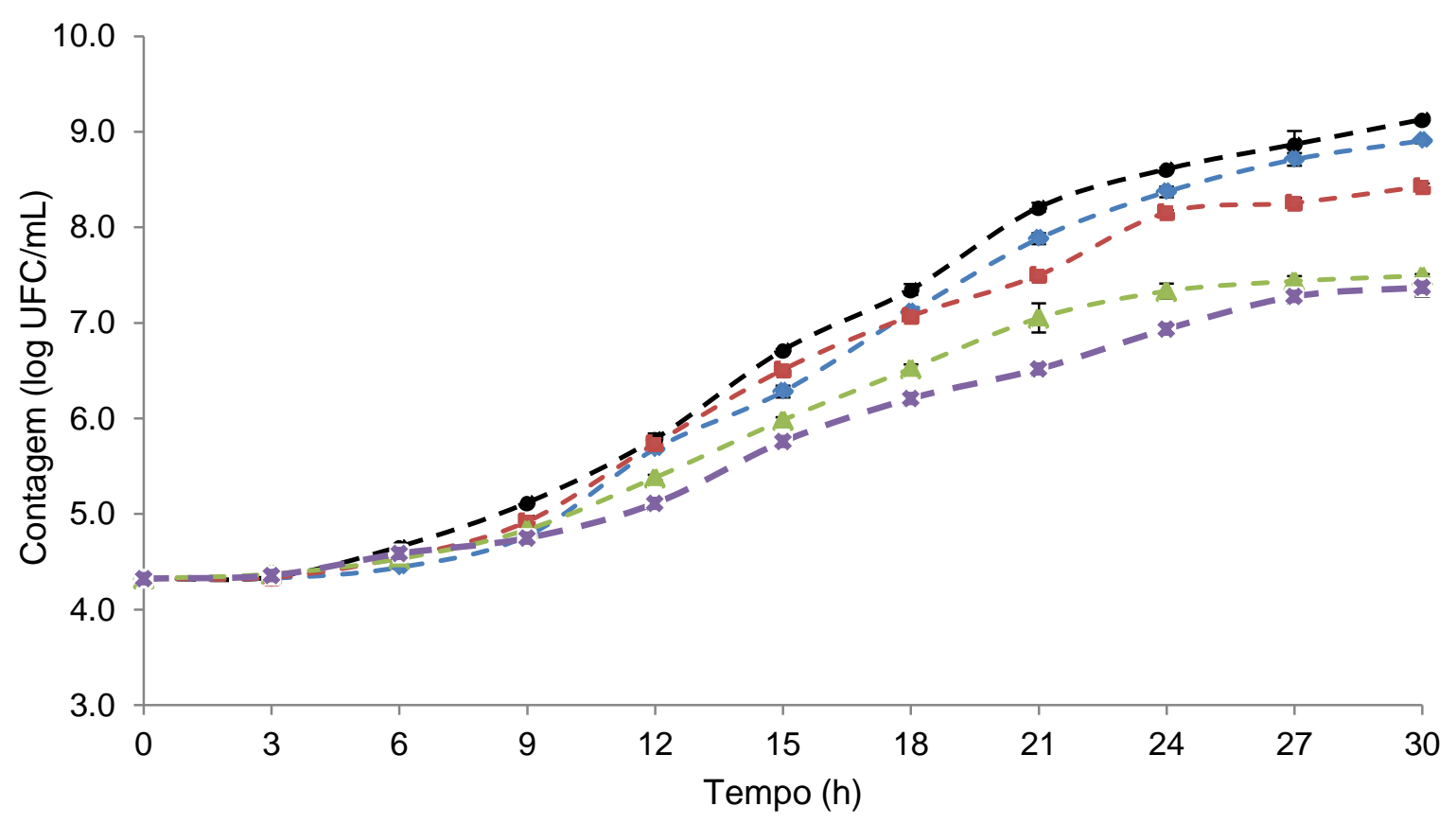

Figura 5. Curva de crescimento de Bifidobacterium lactis nas variações de concentração de soro de leite a 5, 10, 15, 20 e $25 \%$ p/v. Legendas: $5 \%$ ( $) ; 10 \%$ $(\bullet) ; 15 \%(\square) ; 20 \%(\Delta) ; 25 \%(X)$.

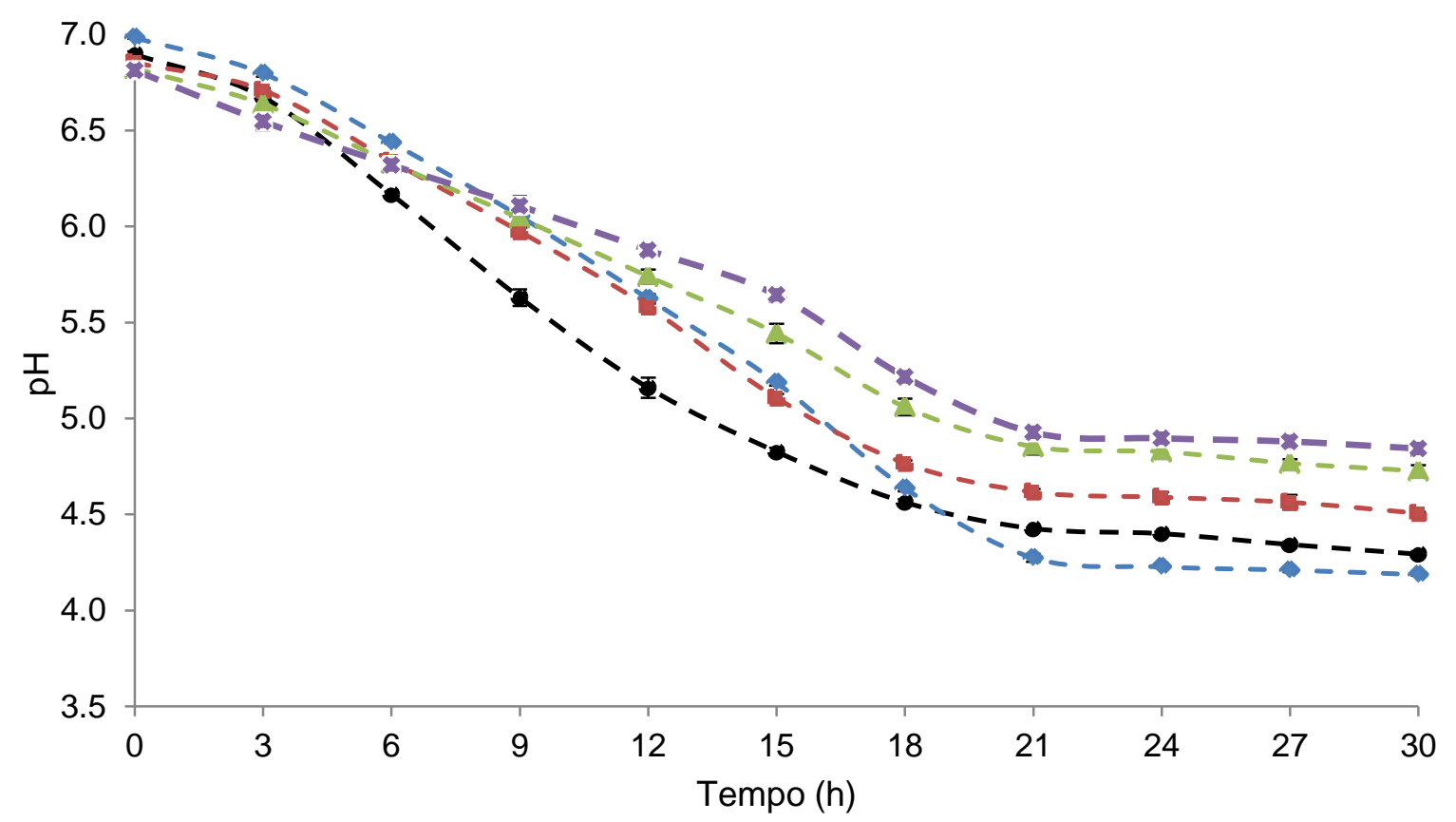

Figura 6. Curva de pH de Bifidobacterium lactis nas variações de concentração de soro de leite a 5, 10, 15, 20 e $25 \%$ p/v. Legendas: 5\% (४); 10\% (•); 15\% (ロ); $20 \%$ (A); 25\% (X). 
Tabela 4. Determinação da concentração de lactose no tempo inicial $\left(T_{0}\right)$ e no tempo final de cultivo $\left(\mathbf{T}_{30}\right)$ de Bifidobacterium lactis utilizando soro de leite em diferentes concentrações.

\begin{tabular}{cccc}
\hline $\begin{array}{c}\text { Concentração do } \\
\text { soro de leite no meio }\end{array}$ & $\begin{array}{c}\text { Concentração de } \\
\text { lactose (g/L) em } \mathbf{~ T}_{\mathbf{0}}{ }^{*}\end{array}$ & $\begin{array}{c}\text { Concentração de } \\
\text { lactose (g/L) em } \mathbf{~ T}_{\mathbf{3 0}}{ }^{* *}\end{array}$ & $\begin{array}{c}\text { \% de lactose } \\
\text { consumida }\end{array}$ \\
\hline $5 \%$ & $24,9 \pm 0,5$ & $12,7 \pm 0,3$ & $49 \%$ \\
$10 \%$ & $54,3 \pm 0,8$ & $34,4 \pm 0,3$ & $37 \%$ \\
$15 \%$ & $76,1 \pm 0,4$ & $62,4 \pm 0,7$ & $18 \%$ \\
$20 \%$ & $109,1 \pm 0,8$ & $91,3 \pm 1,2$ & $17 \%$ \\
$25 \%$ & $129,7 \pm 1,1$ & $117,8 \pm 0,9$ & $9 \%$ \\
\hline
\end{tabular}

${ }^{*} \mathrm{~T}_{0}$ : tempo inicial da fermentação $(0 \mathrm{~h})$

${ }^{* *} T_{30}$ : Tempo final da fermentação $(30 \mathrm{~h})$

\subsubsection{Soro de leite a $10 \%$ de sólidos totais suplementado com L-cisteína, extrato de levedura, inulina ou Tween 80}

Nesta etapa, foram realizados ensaios utilizando o soro de leite como meio de cultivo natural suplementado com extrato de levedura, L-cisteína, inulina ou Tween 80. As figuras 7 e 8 se referem ao crescimento celular e ao $\mathrm{pH}$, respectivamente, durante o processo fermentativo (30 horas). Com relação ao crescimento celular (Figura 7), nota-se que, após 27 horas, as contagens de B. lactis foram maiores (9,8 $\log \mathrm{UFC} / \mathrm{mL}$ ) no processo que forom adicionados inulina ou extrato de levedura, quando comparados com os valores obtidos nas amostras de soro de leite suplementado com L-cisteína (8,8 log UFC/mL) e com Tween 80 (9,2 log UFC/mL). Em trabalhos recentes, a inulina foi usada como importante indutora de crescimento para bifidobactérias (OLIVEIRA et al., 2009a, 2009b, 2009c).

A fase estacionária se iniciou após 24 horas de fermentação quando o soro de leite foi suplementado com extrato de levedura e inulina, enquanto que no soro de leite suplementado com L-cisteína, a fase estacionária se iniciou após 27 horas de 
fermentação. Quando o soro de leite foi suplementado com Tween 80, a fase estacionária se iniciou após 30 horas de fermentação. Esta diferença de tempo que o microrganismo chega à fase estacionária se deve às diferentes velocidades de crescimento durante a fase exponencial; ou seja, quando o microrganismo apresenta velocidade de crescimento elevada, o mesmo atinge o limite de crescimento para as condições presentes no meio de cultivo, entrando, assim, em fase estacionária.

As curvas correspondentes aos valores de $\mathrm{pH}$ (Figura 8) referem-se aos resultados de crescimento da $B$. lactis, que são observados nas curvas de crescimento celular (Figura 7), ou seja, o soro de leite suplementado com inulina ou com extrato de levedura apresenta, respectivamente, pós-acidificação mais acentuada em relação aos meios de cultivo naturais suplementados com Tween 80 ou com L-cisteína.

O crescimento acentuado observado no meio soro de leite suplementado com extrato de levedura pode ser explicado devido à baixa concentração de peptídeos e aminoácidos presentes no meio, os quais são necessários para o crescimento celular (ANTUNES, 2003). A Tabela 5 mostra que houve pouca diferença na concentração de lactose no final da fase exponencial de crescimento celular (27 horas). A concentração inicial de lactose é de 53,0 $\mathrm{g} / \mathrm{L}$, para todas as suplementações estudadas no soro de leite (resultado não apresentado na Tabela 5). Através da análise estatística, pode-se observar que só houve diferença significativa no consumo de lactose através da suplementação do soro de leite com extrato de levedura a $1 \% \mathrm{v} / \mathrm{v}$, já que esta suplementação apresentou o maior valor de concentração celular durante as 30 horas de cultivo e, portanto, o maior consumo de nutrientes.

$\mathrm{Na}$ Tabela 5, na qual é apresentada a concentração de ácido lático, pode-se observar que, no soro de leite suplementado com inulina $(4,55 \mathrm{~g} / \mathrm{L})$, houve concentração desse ácido orgânico maior do que em relação ao soro de leite suplementado com extrato de levedura $(3,23 \mathrm{~g} / \mathrm{L})$, havendo diferença estatística entre os valores. A produção de ácido lático durante ocultivo em soro de leite é observada em diversos gêneros de bactérias (TANG; YANG; OKOS, 1988).

$O$ extrato de levedura se mostrou um excelente suplemento para o crescimento de $B$. lactis em soro de leite, pois este meio de cultivo natural é carente de peptídeos pequenos e aminoácidos livres (GOMES et al., 1998). Como já foi observado por Gomes et al. (1998), a B. lactis apresenta crescimento superior em soro de leite 
hidrolisado suplementado com aminoácidos em relação ao soro de leite não suplementado. Em outros estudos, Loquasto et al. (2011) comprovaram que o soro de leite a $10 \% \mathrm{v} / \mathrm{v}$ suplementado com $1 \%$ de extrato de levedura é um bom meio de cultivo para $B$. lactis.

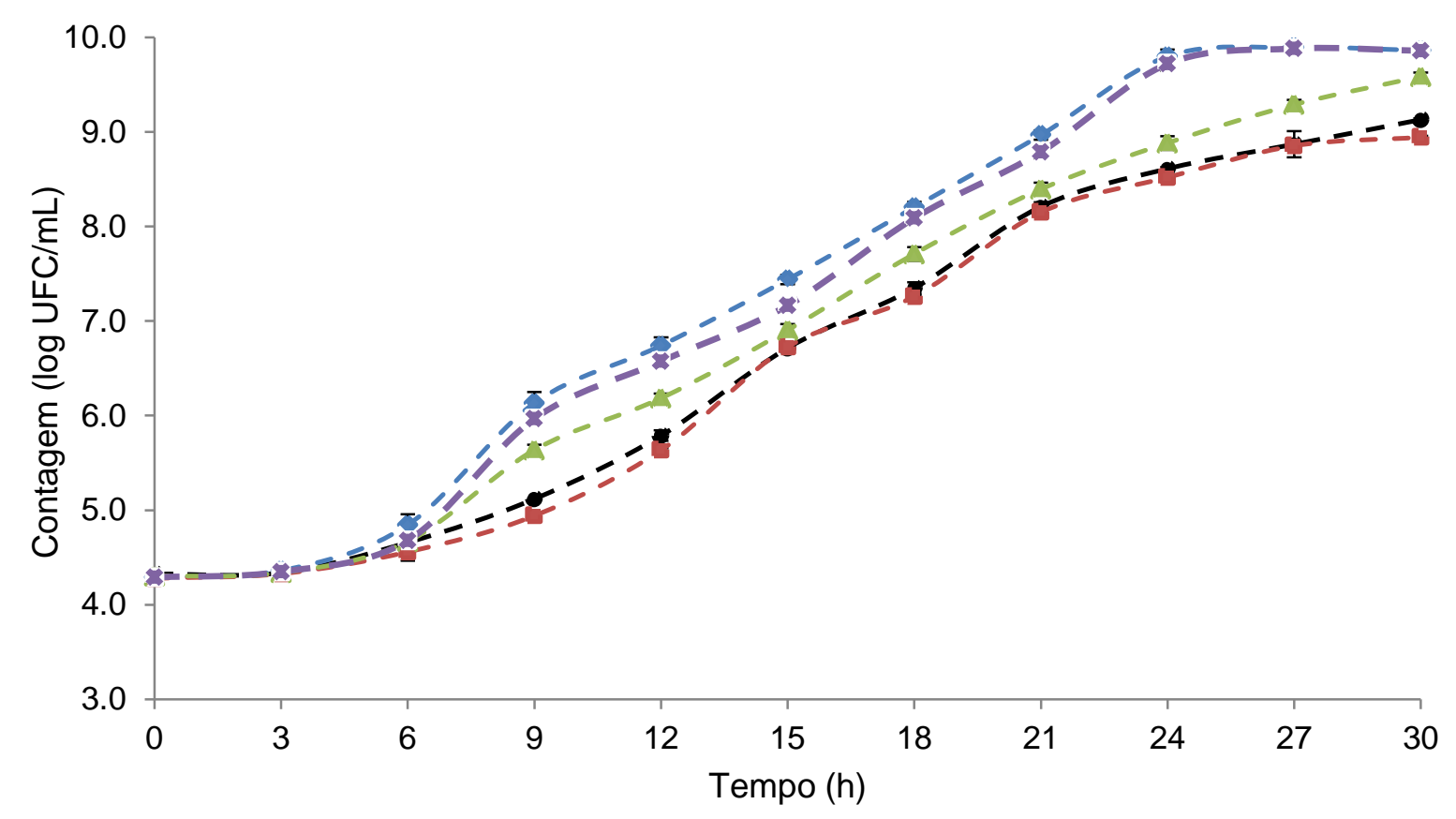

Figura 7. Curva de crescimento de Bifidobacterium lactis utilizando soro de leite suplementado com extrato de levedura (EL), L-cisteína $(\mathrm{Cl})$, Tween $80\left(\mathrm{~T}_{80}\right)$ e inulina

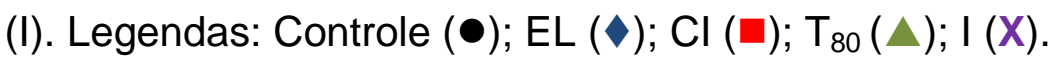




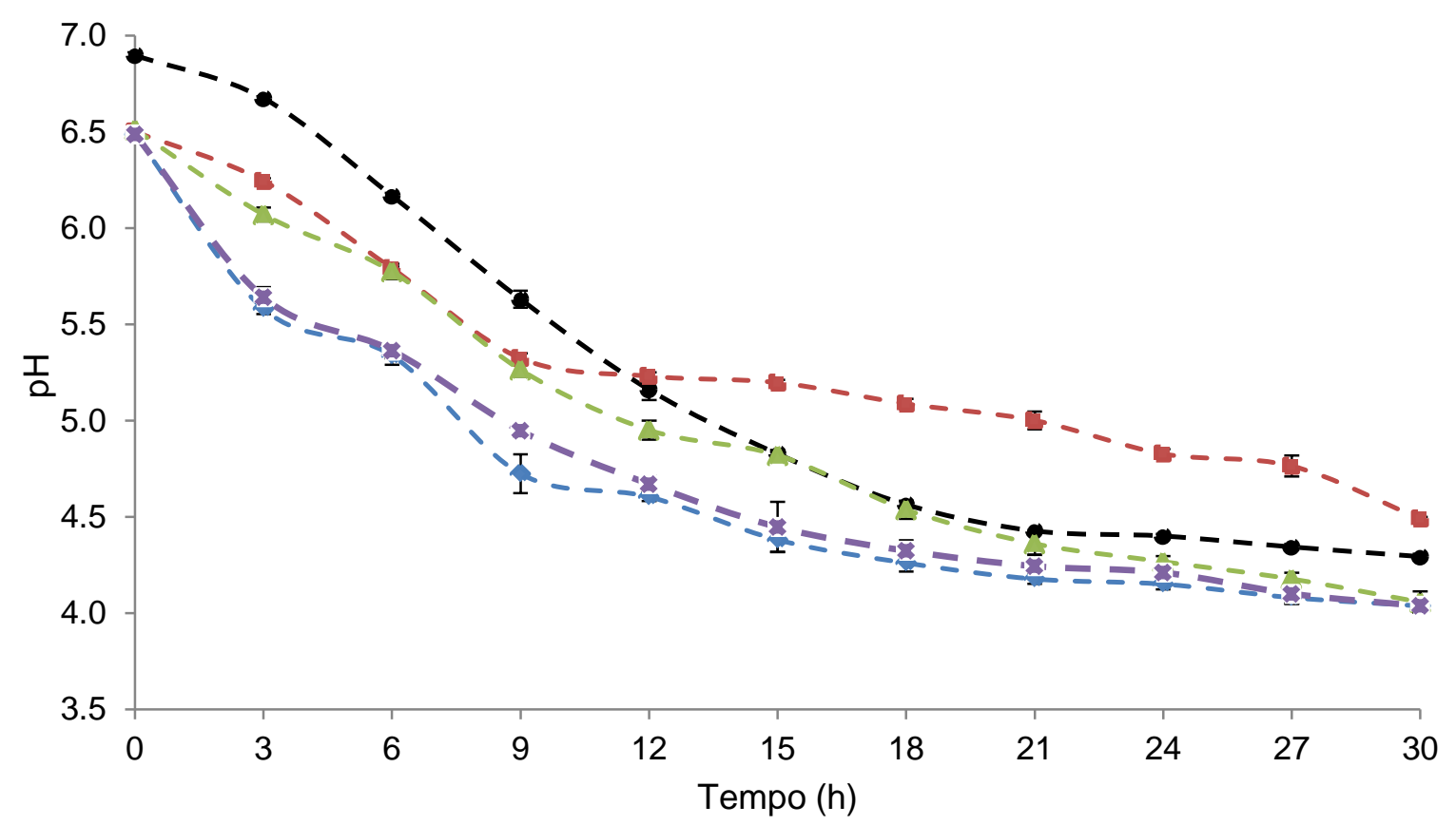

Figura 8. Curva de $\mathrm{pH}$ de Bifidobacterium lactis utilizando soro de leite suplementado com extrato de levedura (EL), L-cisteína $(\mathrm{Cl})$, Tween $80\left(\mathrm{~T}_{80}\right)$ e inulina

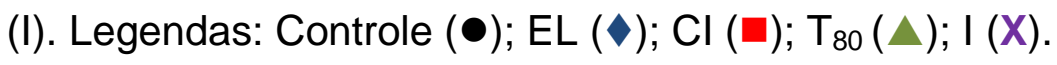

Tabela 5. Concentração de lactose e ácido lático ( $g / L)$ em caldo soro de leite (SL) suplementado com extrato de levedura (EL), Tween 80 ( $\left.\mathrm{T}_{80}\right)$, L-cisteína $(\mathrm{Cl})$ e inulina (I) após 27 horas de cultivo (início da fase estacionária). Legenda:diferentes letras na mesma coluna significam que há diferença estatística entre os valores $(P<0,05)$.

\begin{tabular}{lcc}
\hline Meio de cultura & Lactose (g/L) & Ácido Lático $(\mathbf{g} / \mathbf{L})$ \\
\hline $\mathrm{SL}+\mathrm{T}_{80}$ & $34,6 \pm 0,3^{\mathrm{B}}$ & $4,63 \pm 0,21^{\mathrm{C}}$ \\
$\mathrm{SL}+\mathrm{I}$ & $33,9 \pm 0,4^{\mathrm{B}}$ & $4,55 \pm 0,14^{\mathrm{C}}$ \\
$\mathrm{SL}+\mathrm{Cl}$ & $34,2 \pm 0,3^{\mathrm{B}}$ & $4,37 \pm 0,18^{\mathrm{C}}$ \\
$\mathrm{SL}+\mathrm{EL}$ & $32,5 \pm 0,6^{\mathrm{A}}$ & $3,23 \pm 0,12^{\mathrm{D}}$ \\
\hline
\end{tabular}




\subsection{Estudo comparativo entre Bifidobacterium animalis e Bifidobacterium lactis}

O estudo comparativo da Bifidobacterium animalis subsp. lactis HN019 com outra cepa de mesmo gênero foi necessário devido a atividade insatisfatória da bacteriocina produzida por esta cepa. A cepa Bifidobacterium animalis subsp. animalis ATCC 25527 foi escolhida, pois pertence à mesma espécie que $B$. lactis e apresenta bons resultados de atividade, como observado por Martinez et al. (2013).

Tanto a $B$. lactis como a $B$. animalis apresentaram crescimento maior, quando cultivadas em meio soro de leite suplementado com extrato de levedura em relação ao meio não suplementado, em estudos realizados por Loquasto et al. (2011). Porém, no presente estudo, o crescimento e a atividade da bacteriocina produzida por $B$. animalisforam inferiores aos de $B$. lactis, quando esta foi cultivadaneste meio. Na Figura 8, é apresentada a curva de crescimento celular de B. lactis e $B$. animalis. Em particular, no final da fase exponencial de $B$. lactis (24 horas de cultivo), a contagem foi de 9,79 log UFC/mL, sendo que, quando utilizado o $B$. animalis, o valor da contagem foi de $8,89 \log \mathrm{UFC} / \mathrm{mL}$, ou seja, uma concentração celular 8 vezes maior de $B$. lactis em relação à $B$. animalis.

Quando a curva de pós-acidificação de $B$. lactis é comparada com a curva obtida por $B$. animalis, pode-se observar que o valor de $\mathrm{pH}$ encontrado foi, em média, de 0,5 a $1 \mathrm{pH}$ menor durante as 30 horas do processo fermentativo (Figura 9). Isso se deve à diferença no crescimento entre estas duas cepas, sendo que B. lactis apresenta crescimento e consequente acidificação do meio, através da produção e da excreção de ácido lático, maiores em relação à $B$. animalis. $O \mathrm{pH}$ encontrado por Loquasto et al. (2011), ao final de 24 horas de fermentação em meio soro de leite suplementado em ambos microrganismos, foi de 4,3, semelhante ao encontrado em B. lactis $(\mathrm{pH} 4,2)$ no presente estudo.

Loquasto et al. (2011) observaram que o crescimento da $B$. animalis e da $B$. lactis não foi diferente entre si em meio soro de leite, porém seu estudo foi realizado em anaerobiose completa e não em microaerofilia. Quando a $B$. animalis é cultivada em aerobiose, não há crescimento celular (LOQUASTO et al., 2011), porém, em meio MRS em anaerobiose, a concentração celular encontrada por Lima et al. (2009) foi 
de 10,13 log UFC, evidenciando a sensibilidade do microrganismo à presença de oxigênio.

Em relação à atividade antimicrobiana frente à $L$. monocytogenes ATCC 13932, não houve diferença significativa entre as cepas $B$. animalis $(190 \mathrm{AU} / \mathrm{mL})$ e $B$. lactis (200 AU/mL). Estes resultados não justificariam o estudo da cepa $B$. animalis ATCC 25527 (como cepa comparada à $B$. lactis) em fermentador de bancada. $O$ baixo desempenho da cepa $B$. animalis nas condições ótimas encontradas para $B$. lactis pode ser explicado devido a primeira ser um microrganismo anaeróbio estrito (LOQUASTO et al., 2011), diferentemente da B. lactis, que é um microrganismo anaeróbio aerotolerante (LI et al., 2010).

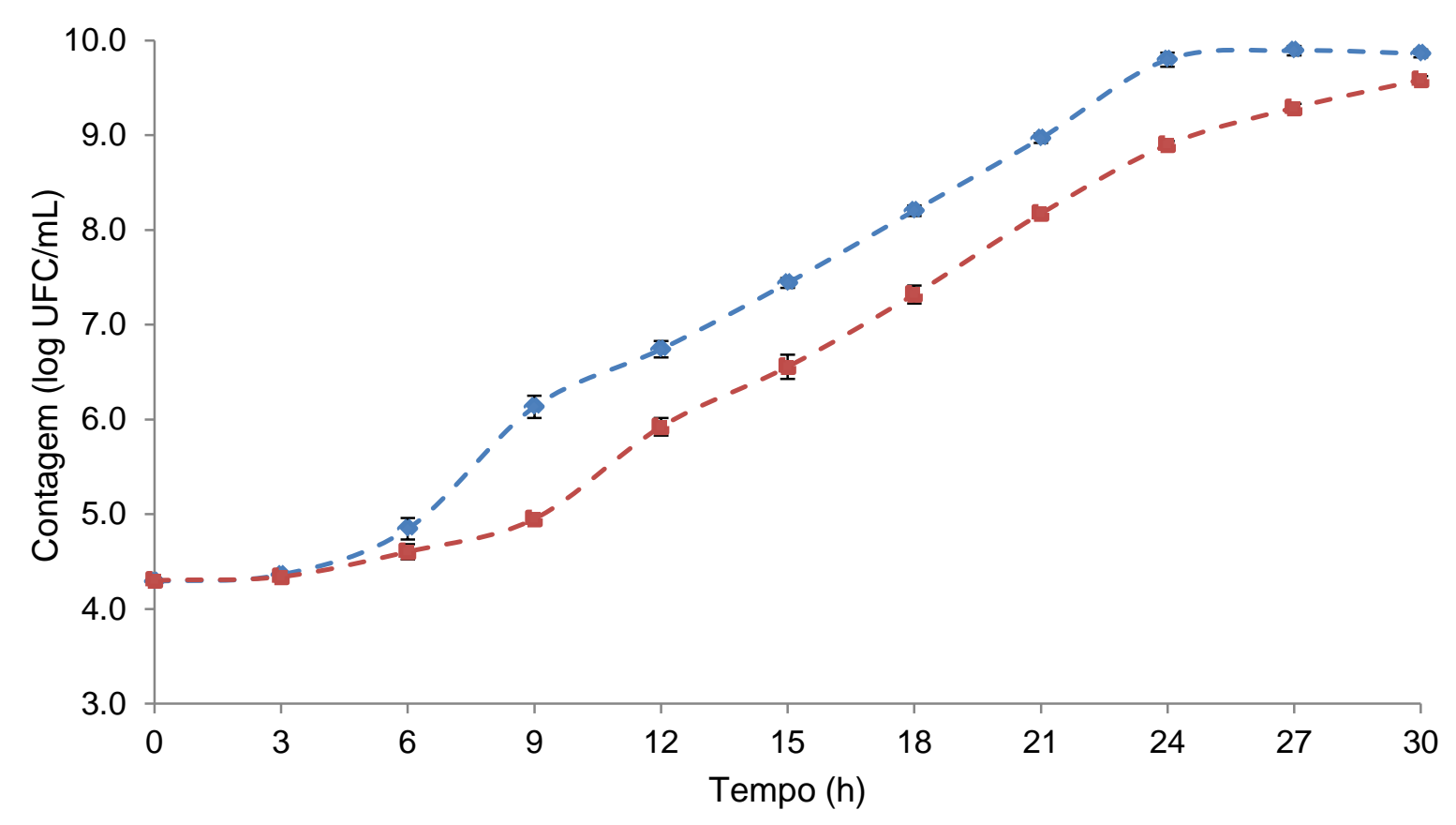

Figura 9. Curva de crescimento das cepas Bifidobacterium lactis ( $\bullet$ e Bifidobacterium animalis (ఐ) utilizando soro de leite suplementado com $1 \%$ de extrato de levedura. 


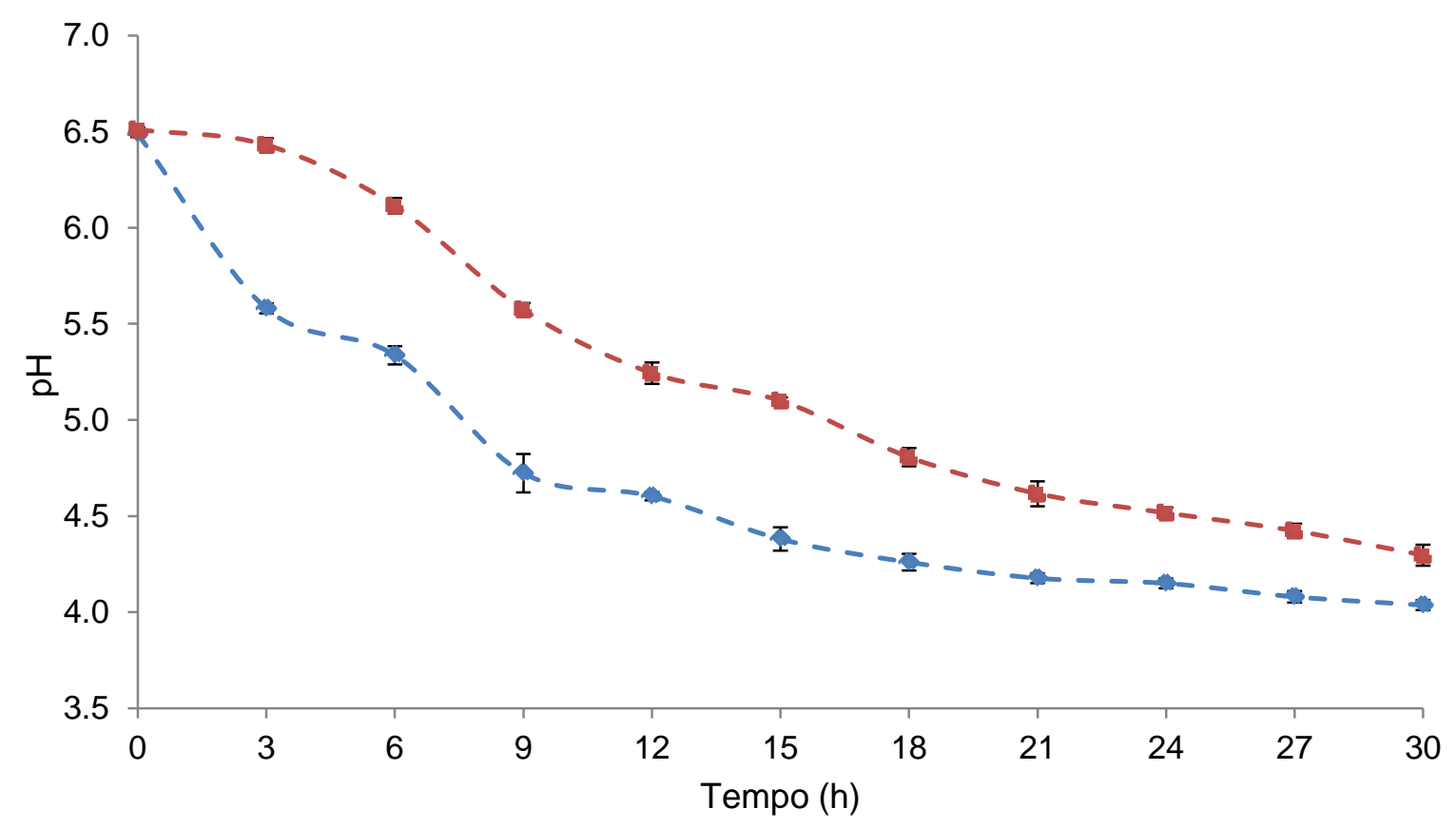

Figura 10. Curva de $\mathrm{pH}$ das cepas Bifidobacterium lactis $(\downarrow)$ e Bifidobacterium animalis ( $\square$ ) utilizando soro de leite suplementado com $1 \%$ de extrato de levedura.

\subsection{Fermentador de bancada}

Para os testes em fermentador de bancada, foi escolhido o meio de cultivo que proporcionou maior concentração de biomassa ao final da fase exponencial de crescimento de $B$. lactis e, associado a este crescimento, a maior atividade de bacteriocina produzida. Buscando estes resultados, as melhores condições e 0 melhor meio de cultivo encontrados para os testes em fermentador de bancada foram: soro de leite no teor de $10 \%(\mathrm{p} / \mathrm{v})$ de sólidos totais, $1 \%(\mathrm{p} / \mathrm{v})$ de extrato de levedura, $50 \mathrm{rpm}$ de agitação e $37^{\circ} \mathrm{C}$ de temperatura.

Nestas condições, a B. lactis mostrou crescimento maior e acelerado em fermentador de bancada, quando comparado ao cultivo em shaker, como pode ser observado na Figura 10. O microrganismo atingiu a fase exponencial, em média, 3 horas mais rápido quando cultivado em fermentador de bancada, situação na qual apresentou concentração celular $(9,57 \log \mathrm{UFC} / \mathrm{mL}) 3$ vezes maior em relação ao cultivo em shaker (8,96 log UFC/mL). Em relação à pós-acidificação (Figura 11), pode-se observar que o comportamento do $\mathrm{pH}$ foi semelhante, tanto em shaker 
como em fermentador de bancada, não havendo diferenças significativas durante as 30 horas de cultivo.

O crescimento de $B$. lactis em meio soro de leite suplementado com extrato de levedura foi superior ao encontrado por Jalili, Razavi e Safari (2010), após 24 horas (7,16 Log UFC/mL), quando o microrganismo foi submetido à condições semelhantes de crescimento e meio de cultivo: soro de leite suplementado por $1 \%$ de extrato de levedura, fermentador de bancada, anaerobiose, $37 \stackrel{\circ}{\mathrm{C}}$, porém a 60 rpm. A fase Log encontrada no estudo feito por Jalili, Razavi e Safari (2010) durou apenas de 12 a 14 horas, enquanto que a encontrada no presente trabalho durou, em média, 18 horas. Apesar do presente trabalho estudar a mesma espécie de bactéria utilizada em Jalili, Razavi e Safari (2010), a diferença nos resultados de crescimento pode estar relacionada à cepa do presente trabalho ter sido modificada geneticamente pela DANISCO, melhorando portanto a sua capacidade de crescimento.

Como foi discutido na seção 5.1 , o crescimento de $B$. lactis é melhor em condições de anaerobiose em relação à microaerofilia. Este comportamento pode ser observado quando essa cepa é cultivada em fermentador de bancada, no qual houve injeção constante de nitrogênio no meio de cultivo. 


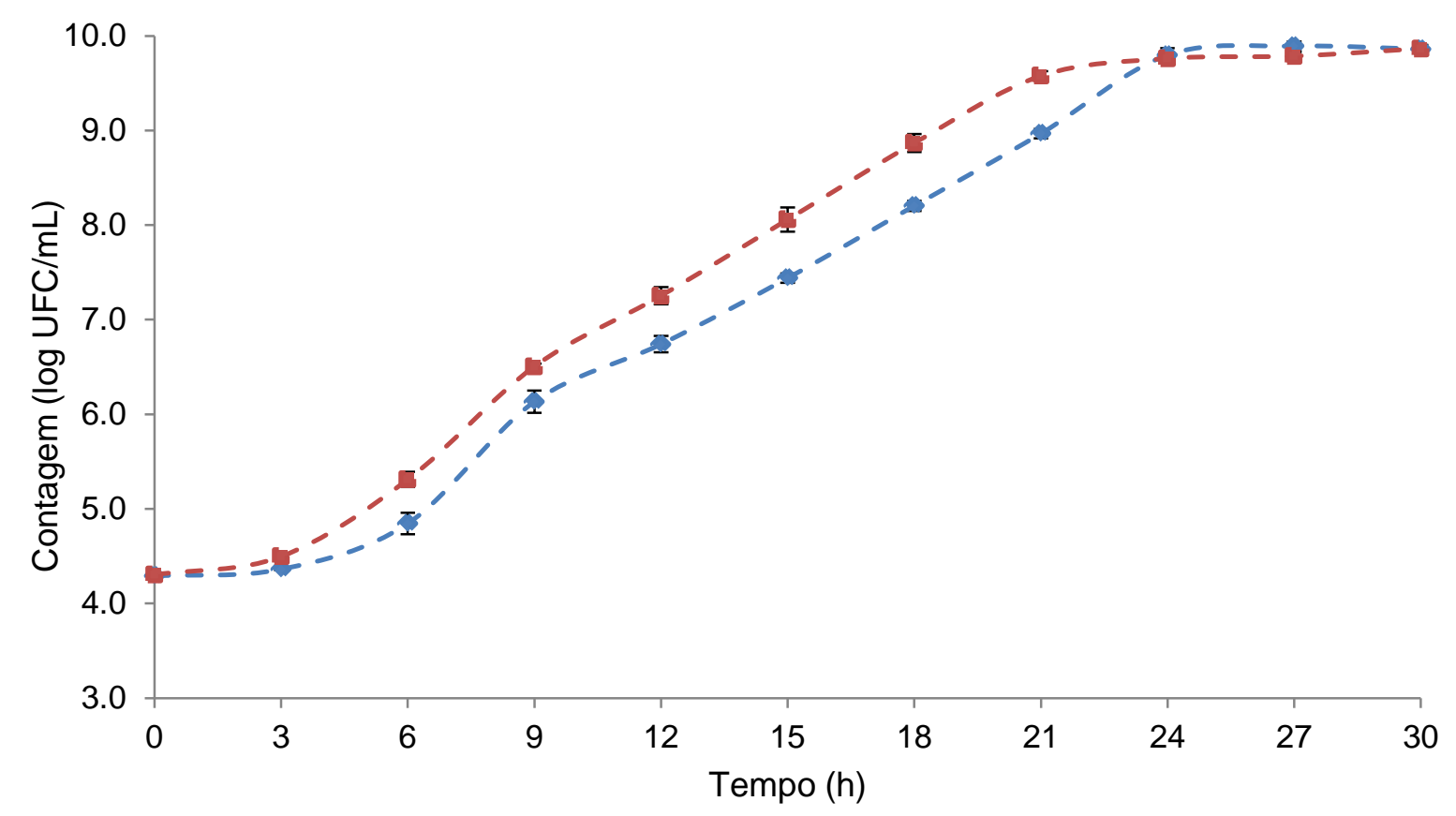

Figura 11. Curva de crescimento de Bifidobacterium lactis em fermentador de bancada $(\square)$ e em shaker $(\checkmark)$ utilizando soro de leite suplementado com $1 \%$ de extrato de levedura.

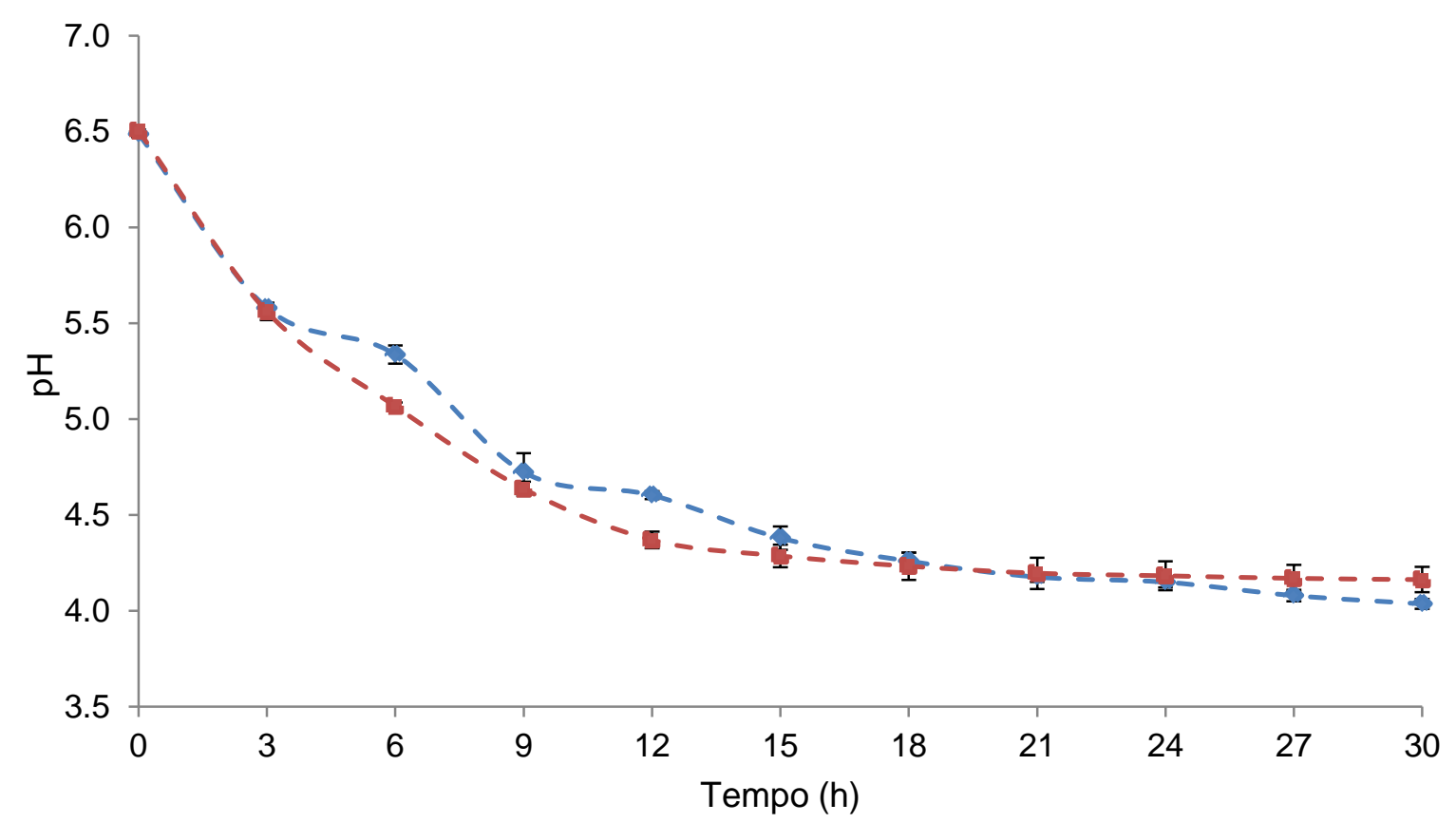

Figura 12. Curva de $\mathrm{pH}$ de Bifidobacterium lactis em fermentador de bancada (匹) e em shaker $(\downarrow)$ utilizando soro de leite suplementado com $1 \%$ de extrato de levedura. 
5.7 Velocidade específica de crescimento $\left(\mu_{\max }\right)$ e tempo de geração $\left(t_{g}\right)$

Em particular, a velocidade específica de crescimento $\left(\mu_{\max }\right)$ foi calculada para $B$. lactis, durante a sua fase de crescimento exponencial, segundo a equação de Monod (1942) à seguir:

$\mu_{\max }=\frac{1}{\left(t_{2}-t_{1}\right)} \ln \frac{X_{2}}{X_{1}}$

em que $X_{2}$ e $X_{1}$ são as contagens (UFC/mL) nos tempos $t_{2}$ e $t_{1}$.

Posteriormente, o tempo de geração $\left(t_{g}\right)$ foi calculado para cada cultura, a partir do valor correspondente de $\mu$, através da equação (POWELL, 1956):

$\mathrm{t}_{\mathrm{g}}=\frac{\ln 2}{\mu_{\max }}$

Os dados de velocidades específicas de crescimento e tempo de geração estão apresentados na Tabela 6. 
Tabela 6. Velocidades específicas de crescimento de Bifidobacterium lactis utilizando os meios de cultivo MRS, BSM e soro de leite (SL) em presença de inulina (I), L-cisteína $(\mathrm{Cl})$, Tween $80\left(\mathrm{~T}_{80}\right)$, extrato de levedura (EL), BA (cultivo de $B$. animalis ATCC 25527 em shaker utilizando soro de leite suplementado com extrato de levedura) e $F$ (cultivo de $B$. lactis em fermentador de bancada utilizando soro de leite suplementado com extrato de levedura).

\begin{tabular}{lcc}
\hline Meio de cultura & $\mu_{\max }\left(\mathbf{h}^{-1}\right)$ & $\mathbf{T}_{\mathbf{g}}(\mathbf{h})$ \\
\hline $\mathrm{BSM}$ & 0,53 & 1,30 \\
$\mathrm{BSM}+\mathrm{T}_{80}$ & 0,56 & 1,23 \\
$\mathrm{BSM}+\mathrm{I}$ & 0,56 & 1,23 \\
$\mathrm{BSM}+\mathrm{Cl}$ & 0,57 & 1,21 \\
$\mathrm{BSM}+\mathrm{EL}$ & 0,56 & 1,23 \\
$\mathrm{MRS}$ & 0,52 & 1,33 \\
$\mathrm{MRS}+\mathrm{T}_{80}$ & 0,54 & 1,28 \\
$\mathrm{MRS}+\mathrm{I}$ & 0,54 & 1,28 \\
$\mathrm{MRS}+\mathrm{Cl}$ & 0,60 & 1,15 \\
$\mathrm{MRS}+\mathrm{EL}$ & 0,62 & 1,11 \\
$\mathrm{SL}$ & 0,54 & 1,28 \\
$\mathrm{SL}+\mathrm{T}_{80}$ & 0,54 & 1,28 \\
$\mathrm{SL}+\mathrm{I}$ & 0,61 & 1,13 \\
$\mathrm{SL}+\mathrm{Cl}$ & 0,54 & 1,28 \\
$\mathrm{SL}+\mathrm{EL}$ & 0,61 & 1,13 \\
$\mathrm{BA}$ & 0,57 & 1,21 \\
$\mathrm{~F}$ & 0,57 & 1,21 \\
\hline
\end{tabular}


Na Tabela 6 , observa-se que a velocidade específica de crescimento $\left(\mu_{\max }\right)$, no meio de cultura MRS suplementado com extrato de levedura, apresentou maior valor $\left(0,62 \mathrm{~h}^{-1}\right)$ em relação aos outros ingredientes adicionados. A menor velocidade específica de crescimento foi observada em caldo MRS sem adição dos suplementos estudados (controle) $\left(0,52 \mathrm{~h}^{-1}\right)$. $O$ efeito redutor do oxigênio no meio de cultivo causado pela adição de L-cisteína é benéfico para o crescimento de $B$. lactis, assim como também foi observado por Karna, Emata e Barraquio (2007), para a bactéria Lactobacillus delbrueckii ssp. bulgaricus. Como pode ser observado nos meios MRS $\left(0,60 \mathrm{~h}^{-1}\right)$ e BSM $\left(0,57 \mathrm{~h}^{-1}\right)$ suplementados com L-cisteína, houve um aumento da velocidade específica de crescimento em relação ao controle.

No entanto, quando utilizado o caldo MRS suplementado com Tween 80 ou inulina, o valor da velocidade específica de crescimento do Bifidobacterium lactis foi de $0.54 \mathrm{~h}^{-1}$, ou seja, menor quando comparado com o valor de L-cisteína. Em particular, o caldo BSM suplementado com Tween 80, extrato de levedura e inulina, as velocidades específicas obtidas foram de $0.56 \mathrm{~h}^{-1}$, ou seja, menores que BSM suplementado por L-cisteína.

Através das velocidades específicas observadas no meio de cultivo sintéticos MRS, pode-se concluir que o principal fator limitante na velocidade de crescimento de $B$. lactis, foi a concentração de proteínas; porém, em caldo BSM, o efeito redutor do oxigênio causado pela L-cisteína mostrou-se superior na influência da velocidade de crescimento em $B$. lactis. Isso se deve, como já foi discutido anteriormente (seção 6.2), à formulação específica do caldo BSM para o gênero Bifidobacterium. Portanto, em caldo BSM, a diminuição da concentração de oxigênio dissolvido no meio exerce maior influência na velocidade específica de crescimento de $B$. lactis em relação à suplementação com fontes de nutrientes diferentes.

Nota-se que quando o soro de leite foi utilizado como meio de cultura, a velocidade específica de crescimento do meio suplementado com L-cisteína ou Tween 80 foi inferior $\left(0.54 \mathrm{~h}^{-1}\right)$, em relação com o que foi observado nos resultados com caldo BSM. No soro de leite suplementado com extrato de levedura e inulina, foi observada velocidade específica maior $\left(0.61 \mathrm{~h}^{-1}\right)$ do que aquela obtida no soro de leite suplementado com Tween $80\left(0.54 \mathrm{~h}^{-1}\right)$. Vale salientar que o soro de leite é um meio de cultivo natural, que contém substâncias nutricionais que favorecem o metabolismo do B. lactis, assim como outras bactérias ácido láticas, resultado já 
observado em trabalhos de outros autores (MARTH, 1973, PENNA; THAMER, 2005).

O soro de leite suplementado com Tween 80, por sua vez, incrementou a velocidade específica de crescimento nos meios de cultivo, se comparado aos meios padrões, apesar de não ter gerado o melhor resultado. $O$ uso do Tween 80 como aditivo em meios de cultura se mostrou promissor em outros trabalhos de produção de bacteriocina encontrados na literatura (COLLADO; HERNÁNDEZ; SANZ, 2005), já que é um agente tensoativo, podendo aumentar na concentração de bacteriocinas, por facilitar a excreção desse peptídeo antimicrobiano.

Por fim, pode-se observar que, no meio de cultivo contendo soro de leite suplementado com extrato de levedura ou inulina, houve maior velocidade de crescimento específica e, consequentemente, menor tempo de geração em relação ao caldo BSM suplementado com o mesmo composto. Somado a este rendimento, o custo do soro de leite como meio de cultura é aproximadamente 10 vezes inferior em relação ao custo do caldo MRS ou BSM. Ressalta-se que não há diferença estatística significativa entre os resultados de velocidade específica de crescimento observados nos caldos BSM e MRS suplementados, porém é observada diferença quando estes são comparados com o meio soro de leite suplementado por inulina ou extrato de levedura. Este comportamento da $B$. lactis já era esperado, pois os caldos BSM e MRS são meios de cultivo sintéticos com formulações semelhantes. De fato, o meio BSM é um meio de cultivo seletivo, ou seja, possui compostos que inibem o crescimento de outros microrganismos que não do gênero Bifidobacterium. Esse meio de cultivo apresenta uma substância chamada "mupirocina" que é um antibiótico e o seu uso implica em problemas éticos, já que bacteriocinas são geralmente aplicadas em alimentos (ASHRAF; SHAH, 2011).

\subsection{Atividade da bacteriocina}

Em relação à atividade antimicrobiana da bacteriocina, a cepa utilizada no presente estudo (Bifidobacterium lactis) expressou quantidade de bacteriocina insuficiente. Porém, esta bactéria probiótica mostrou-se ser bacteriocinogênica. A 
atividade da bacteriocina foi de aproximadamente $120 \mathrm{UA} / \mathrm{mL}$, quando utilizado o caldo MRS suplementado com L-cisteína; $60 \mathrm{UA} / \mathrm{mL}$ (caldo MRS suplementado com Tween 80); $90 \mathrm{UA} / \mathrm{mL}$ no caldo MRS suplementado com inulina; e $140 \mathrm{UA} / \mathrm{mL}$ (caldo MRS suplementado com extrato de levedura). Já no meio BSM, foi observada atividade aproximada de $130 \mathrm{UA} / \mathrm{mL}$, quando adicionado L-cisteína; $130 \mathrm{UA} / \mathrm{mL}$ (Tween 80); $150 \mathrm{UA} / \mathrm{mL}$ (inulina); e $160 \mathrm{UA} / \mathrm{mL}$, quando adicionado extrato de levedura.

Em soro de leite, os valores de atividade foram $100 \mathrm{UA} / \mathrm{mL}$, com suplementação de L-cisteína; $110 \mathrm{UA} / \mathrm{mL}$ (Tween 80); $190 \mathrm{UA} / \mathrm{mL}$ (inulina); e $200 \mathrm{UA} / \mathrm{mL}$ (extrato de levedura). O único microrganismo bioindicador, no qual a Bifidobacterium lactis expressou essas atividades antimicrobianas, nos diferentes meios de cultura, foi a Listeria monocytogenes. Nos ensaios em shaker, os melhores resultados foram apresentados no soro de leite suplementado com inulina e com extrato de levedura, sendo que ambos não apresentaram diferenças significativas entre si.

A atividade da bacteriocina obtida em fermentador de bancada utilizando o soro de leite suplementado com extrato de levedura foi semelhante $(200 \mathrm{AU} / \mathrm{mL})$ à atividade encontrada na bacteriocina produzida no mesmo meio de cultivo em shaker, já que ambos cultivos apresentam a mesma formulação e crescimento celular semelhante. Através dos resultados apresentados na Figura 12, pode-se observar que a atividade da bacteriocina está relacionada principalmente com o crescimento celular, pois se trata de uma biomolécula de metabolismo primário (HUGAS et al., 2002). 


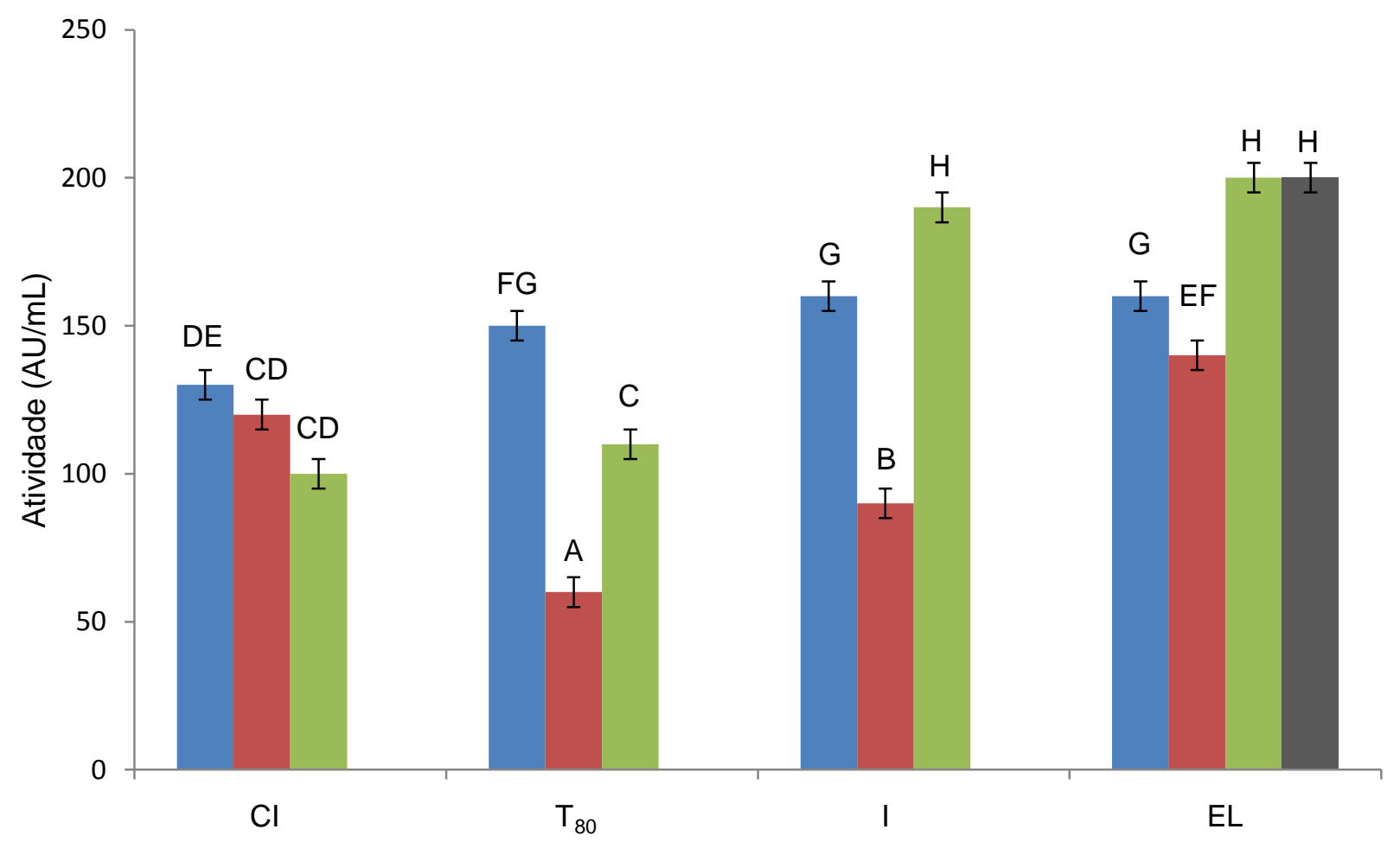

Figura 13. Atividade antimicrobiana da bacteriocina produzida por Bifidobacterium lactis utilizando os meios de cultivo: BSM ( $\square)$, MRS $(\square)$ e soro de leite $(\square)$ e cultivo em fermentador de bancada utilizando o soro de leite $(\square)$ em presença de inulina (I), L-cisteína $(\mathrm{Cl})$, Tween $80\left(\mathrm{~T}_{80}\right)$ e extrato de levedura $(\mathrm{EL})$. Diferentes letras na mesma coluna significam que há diferença estatística entre os valores $(P<0,05)$.

\section{CONCLUSÃO}

O gênero Bifidobacterium é conhecido por possuir espécies anaeróbias estritas e anaeróbias aerotolerantes. A cepa B. lactis mostrou melhor crescimento celular e,consequentemente, expressão da bacteriocina em agitação baixa (50 rpm), quando utilizado agitador rotativo. Além disso, a cepa demonstrou atividade antimicrobiana contra a espécie patogênica Listeria monocytogenes.

O soro de leite suplementado com extrato de levedura ou inulina proporcionou o melhor desempenho de $B$. lactis, em relação ao crescimento celular, e se mostrou um meio de cultivo natural interessante para a produção de bacteriocinas. Com a adição de extrato de levedura, houve aumento significativo na produção desse 
peptídeo antimicrobiano, o que torna este suplemento ideal para os ensaios em fermentador de bancada, nos quais a cepa $B$. lactis se mostrou muito promissora. De fato, o soro de leite, por se tratar de um meio de cultura mais barato que os meios sintéticos MRS e BSM, pode diminuir o custo de produção desta biomolécula de alto valor agregado, de modo que seu uso, portanto, se torna vantajoso.

\section{SUGESTÕES PARA TRABALHOS FUTUROS}

Os resultados do presente trabalho abrem perspectivas para novos projetos no uso da $B$. lactis estudada. Visando o emprego industrial da produção da bacteriocina propõe-se a purificação deste composto, assim como o seu sequenciamento para a identificação e classificação. Outro estudo sugerido é a ampliação da produção de bacteriocina em fermentador de bancada, testando-se novos ingredientes na suplementação do meio soro de leite. Outra proposta que pode ser desenvolvida em trabalhos futuros é o uso combinado de vários ingredientes visando à melhora na produção da bacteriocina.

\section{ATIVIDADES ACADÊMICAS}

\subsection{Participação em Congresso}

No período vigente do mestrado, houve a apresentação do pôster "Bacteriocin Production Using Bifidobacterium animalis in Milk Whey" na "XVII Semana Farmacêutica de Ciência e Tecnologia", realizada na USP (Universidade de São Paulo), no período de 1 a 5 de outubro de 2012. 
No período do presente trabalho (01/03/2012 a 15/07/2013), foram publicados três artigos em forma de review.

1. BALCIUNAS, E. M., MARTINEZ, F. A. C., TODOROV, S. D., FRANCO, B. D. G. M., CONVERTI, A., OLIVEIRA, R. P. S. Novel biotechnological applications of bacteriocins: A review. Food Control, v. 32, p. 134-142, 2013.

2. MARTINEZ, F. A. C., BALCIUNAS, E. M., CONVERTI, A., COTTER, P. D., OLIVEIRA, R. P. S. Bacteriocin production by Bifidobacterium spp. A review. Biotechnology Advances, v. 31, p. 482-488, 2013.

3. MARTINEZ, F. A. C., BALCIUNAS, E. M., SALGADO, M., DOMÍNGUEZ, J., CONVERTI, A., OLIVEIRA, R. P. S. Lactic acid properties, applications and production: A review. Trends in Food Science \& Technology, v. 30, p. 7083, 2013.

4. SABO, S. S., BALCIUNAS, E. M., VITOLO, M., OliVEIRA, R. P. S. Lactobacillus plantarum: a versatile lactic acid bactéria. Food Science and Technology, Artigo submetido.

\section{REFERÊNCIAS}

AHMAD, C., NATASCHA, C., HAIQIN, C., JIANXIN, Z., JIAN, T., HAO, Z., WEI, C.Bifidin I - A new bacteriocin produced by Bifidobacteriuminfantis BCRC 14602: Purification and Partial amino acid sequence. Food Control, v. 21, p. 746-753, 2010.

ANTUNES, A. J. Funcionalidade de Proteínas do Soro de Leite Bovino. 1. ed, São Paulo: Editora Manole, 2003.

ASHRAF, R., SHAH, N. P. Selective and differential enumerations of Lactobacillus delbrueckii subsp. bulgaricus, Streptococcus thermophilus, Lactobacillus 
acidophilus, Lactobacillus casei and Bifidobacterium spp. in yoghurt - A review. International Journal of Food Microbiology, v. 149, p. 194-208, 2011.

AUCHER, W., LACOMBE, C., HÉQUET, A., FRÈRE, J., BERJEAUD, J. M. Influence of amino acid substitutions in the leader peptide on maturation and secretion of mesentericin Y105 by Leuconostoc mesenteroides. Journal of Bacteriology, Washington, v. 187, p. 2218-2223, 2005.

BIAVATI, B., MATTARELLI, P. The family Bifidobacteriaceae. In: M. DWORKIN, S. FALKOW, E. ROSEMBERG, K. H. SCHLEIFER, E. STACKE. (Org.). The prokaryotes: an evolving electronic resource for the microbiological community 3. ed. New York: Springer, 2005.

BIRRI, D. J., BREDE, D. A., FORBERG, T., HOLO, H., NES, I. F. Molecular and genetic characterization of a novel bacteriocin locus in Enterococcus avium isolates from infants. Applied and Environmental Microbiology, v. 76, p. 483-492, 2010.

BORRERO, J., BREDE, D. A., SKAUGEN, M., DIEP, D. B., HERRANZ, C., NES, I. F., CINTAS, L. M., HERNÁNDEZ, P. E. Characterization of garvicin ML, a novel circular bacteriocin produced by Lactococcus garvieae DCC43, isolated 570 from mallard ducks (Anas platyrhynchos). Applied and Environmental Microbiology, v. 77, p. 369-373, 2011.

BRIÃO, V. B. Estudo de prevenção à poluição em uma indústria de laticínios. Maringá. Dissertação de Mestrado apresentada ao Programa de Pós-Graduação em Engenharia Química. Universidade Estadual de Maringá, 2000.

BUDAVAVI, S., O'NEIL, M. J., SMITH, A., HECKELMAN, P. E., KINNEARY, J. F. (Eds.), Merck Index, 1996. An Encyclopedia of Chemicals, Drugs, and Biologicals (twelfth edition) (1996)

BUYONG, N., KOK, J., LUCHANSKY, J. B. Use of a genetically enhanced, pediocinproducing starter culture, Lactococcus lactis subsp. lactis MM 217 to control Listeria monocytogenesin cheddar cheese. Applied and Environmental Microbiology, v. 64, p. 4842-4845, 1998.

CHEEKE, P. R., STANGEL, D. E. Lactose and whey utilization by rats and swine. Journal Anim. Science, v.37, p. 1142, 1973. 
COLLADO, M., HERNÁNDEZ, M., SANZ, Y. Production of bacteriocin-like inhibitory compounds by human fecal Bifidobacterium strains. Journal of food protection, $v$. 68, p. 1034-1040, 2005.

DONKOR, O. N., HENRIKSSON, A., VASILJEVIC, T., SHAH, N. P. a-Galactosidase and proteolytic activities of selected probiotic and dairy cultures in fermented soymilk. Food Chemistry, v. 104, p. 10-20, 2007.

EKLUND, T.The antimicrobial effect of dissociated and undissociated sorbic acid at different pH levels. Journal of Applied Bacteriology, v. 54, p. 383-389, 1983.

ERCOLINI, D., STORIA, A., VILLANI, F., \& MAURIELLO, G. Effect of a bacteriocinactivated polythene film on Listeria monocytogenes as evaluated by viable staining and epifluorescence microscopy. Journal of Applied Microbiology, v.100, p. 765-772, 2006.

FALK, P. G., HOOPER, L. V., MIDTVEDT, T., GORDON, J. I. Creating and maintaining the gastrointestinal ecosystem: What we know and need to know from gnotobiology. Microbiology and Molecular Biology Reviews, v. 62, p. 11571170, 1998.

GAGNON, M., KHEADR, E. E., LE BLAY, G., FLISS, I. In vitro onhibition of Escherichia coli $\mathrm{O} 157: \mathrm{H} 7$ by bifidobacterial strains of human origin. International Journal of Food Microbiology, v. 63, p. 506-512, 2004.

GALVEZ, A., LOPEZ, R. L., ABRIOUEL, H., VALDIVIA, E., OMAR, N. B. Application of bacteriocins in the control of food borne pathogenic and spoilage bacteria. Critical Reviews in Biotechnology, v. 28, p. 125-152, 2008.

GHALEY, A.E., El-TAWEEL, A. A. Kinetic modelling of continuous production of ethanol from cheese whey, Biomass and Bioenergy. v. 12, p. 461-472, 1997.

GIBSON, G. R., WANG, X. Regulatory effects of bifidobacteria on the growth of other colonic bacteria. Journal of Applied Bacteriology, v. 77, p. 412-420, 1994.

GOMES, A. M. P., MALCATA, F. X., KLAVER, F. A. M. Growth Enhancement of Bifidobacterium lactis Boand Lactobacillus acidophilus Ki by Milk Hydrolyzates. Journal of Dairy Science, v. 81, p. 2817-2825, 1998.

GOMES, A. M. P., MALCATA, F. X. Bifidobacterium ssp and Lactobacillus acidophilus: biological, biochemical, technological and therapeutical properties 
relevant for use as probiotics. Trends in Food Science and Technology, v. 10, p. 139-157, 1999.

GUINANE, C. M., COTTER, P. D., HILL, C., ROSS, R. P. Microbial solutions to microbial problems; lactococcal bacteriocins for the control of undesirable biota in food. Journal of Applied Microbiology, v. 98, p. 1316-1325, 2005.

HOFFMANN, A., SCHNEIDER, T., PAG, U., SAHL, H. G. Localization and functional analysis of Pepl, the immunity peptide of Pep 5-producing Staphylococcus epidermidis strain 5. Appliedand Enviromental Microbiology, v. 70, p. 3263-3271, 2004.

HOLZAPFEL, W. H., GEISEN, R., SCHILLINGER, U. Biological preservation of foods with reference to protective cultures, bacteriocins and food-grade enzymes. International Journal of Food Microbiology, v. 24, p. 343-362, 1995.

HOLZAPFEL, W. H. Appropriate starter culture technologies for small-scale fermentation in developing countries. International Journal of Food Microbiology, v. 75, p. 197-212, 2002.

HU, C. B., MALAPHAN, W., ZENDO, T., NAKAYAMA, J., SONOMOTO, K. Enterocin $\mathrm{X}$, a novel two peptidebacteriocin from Enterococcus faecium KU-B5, has an antibacterial spectrum entirely different from those of its component peptides. Applied Environmental Microbiology, v.76, p. 4542-4545, 2010.

HUGAS, M., GARRIGA, M., PASCUAL, M., AYMERICH, M. T., MONFORT, J. M. Enhancement of sakacin $\mathrm{K}$ activity against Listeria monocytogenes in fermented sausages with pepper or manganese as ingredients. Food Microbiology, v. 19, p. 519-528, 2002.

JACK, R. W., TAGG, J. R., RAY, B. Bacteriocins of gram-positive bacteria. Microbiological Reviews, v. 59, p. 171-200, 1995.

JALILI, H., RAZAVI, H., SAFARI, M. Effect of whey permeate and yeast extract on metabolic activity of Bifidobacterium animalis subsp. lactis $\mathrm{Bb} 12$ cultivated in skim milk based media. Iranian Journal of Biotechnology, v. 8, p. 38-45, 2010.

JOZALA, A. F., ANDRADE, M. S., ARAUZ, L. J., PESSOA JR., A., VESSONI PENNA, T. C. Nisin Production Utilizing Skimmed Milk Aiming to Reduce Process Cost. Applied Biochemistry and Biotechnology, v. 136, p. 515-528, 2007. 
KARNA, B. K. L., EMATA, O. C., BARRAQUIO, V. L. Lactic Acid and Probiotic Bacteria from Fermented and Probiotic Dairy Products. Science Diliman, v. 19, p. 23-34, 2007.

KELLY, W. J., ASMUNDSON, R. V., HUANG, C. M. Characterisation of plantaricin KW30, a bacteriocin produced by Lactobacillus plantarum. Journal of Applied Bacteriology, v. 81, p. 657-662, 1996.

KIM, H.O., WEE, Y.J., KIM, J.N., YUN, J.S., RYU, H.W. Production of lactic acid from cheese whey by batch and repeated batch cultures of Lactobacillus sp. RKY2. Applied Biochemestry and Biotechnology, v. 129, p. 694-704, 1995.

KIVIHARJU, K., LEISOLA, M., EERIKÄINEN, T., Optimization of a Bifidobacterium longum production process. Journal of Biotechnology, v. 117, p. 299-308, 2005.

KOSIKOWSKI, F. V. Whey utilization and whey products. Journal of Dairy Science, v.62, n.7, p. 1149-1160, 1979.

KLEEREBEZEM, M., QUADRI, L. E. Peptide pheromone-dependent regulation of antimicrobial peptide production in Gram-positive bacteria: a case of multicellular behavior. Peptides, v. 22, p. 1579-1596, 2001.

LEROY, F., VERLUYTEN, J., DE VUYST, L. Functional meat starter cultures for improved sausage fermentation. International Journal of Food Microbiology, v. 106, p. 270-285, 2006.

LI, Q., CHEN, Q., RUAN, H., ZHU, D., HE, G. Isolation and characterisation of an oxygen, acid and bile resistant Bifidobacterium animalis subsp. lactis Qq08. Journal of the Science of Food and Agriculture, v. 90, p. 1340-1346, 2010.

LIMA, K. G. C., KRUGER, F. M., BEHRENS, J., DESTRO, M. T., LANDGRAF, M., FRANCO, B. D. G. M. Evaluation of culture media for enumeration of Lactobacillus acidophilus, Lactobacillus casei and Bifidobacterium animalis in the presence of Lactobacillus delbrueckii subsp bulgaricus and Streptococcus thermophiles. Food Science and Technology, v. 42, p. 491-495, 2009.

LIU, C., HU, B., LIU, Y. E., CHEN, S. Stimulation of nisin production from whey by a mixed culture of Lactococcuslactis and Saccharomyces cerevisiae. Applied Biochemistry and Biotechnology, v. 129, p. 751-761, 2006.

LOQUASTO, J. R., BARRANGOU, R., DUDLEY, E. G., ROBERTS, R. F. Short communication: The complete genome sequence of Bifidobacterium animalis 
subspecies animalis ATCC 25527 T and comparative analysis of growth in milk with B. animalis subspecies lactis DSM 10140T. Journal of Dairy Science, v. 94, p. 5864-5870, 2011.

MADIGAN, M. T., MARTINKO, J. M., PARKER, J. Brock Biology of Microorganisms, 10. ed. . New Jersey: Prentice Hall, 2003.

MARTH, E. H., Utilization of whey through fermentations, Marschall Italian \& Specialty Cheese Seminars. 1973.

MATTILA-SANDHOLM, T., MYLLÄRINEN, P., CRITTENDEN, R., MOGENSEN, G., FONDÉN, R., SAARELA, M. Technological challenges for future probiotic foods. International Dairy Journal, v. 12, p. 173-182, 2002.

MÄTTÖ, J., ALAKOMI, H. L., VAARI, A., VIRKAJÄRVI, I., SAARELA, M. Influence of processing conditions on Bifidobacterium animalis subsp. lactis functionality with a special focus on acid tolerance and factors affecting it. International Dairy Journal, v. 16, p. 1029-1037, 2006.

MARTinez, F. A. C., BAlCiUnAS, E. M., CONVERTI, A., COTTER, P. D., OLIVEIRA, R. P. S. Bacteriocin production by Bifidobacterium spp. A review. Biotechnology Advances, v. 31, p. 482-488, 2013.

MAURIELLO, G., ERCOLINI, D., LA STORIA, A., CASABURI, A., VILLANI, F. Development of polythene films for food packaging activated with an antilisterial bacteriocin from Lactobacillus curvatus 32Y. Journal of Applied Microbiology, v. 97, p. 314-322, 2004.

MAYO, B., ALEKSANDRZAK-PIEKARCZYK, T., FERNÁNDEZ, M., KOWALCZYK, M., PABLO ÁLVAREZ- MARTÍN, P., BARDOWSKI, J. Updates in the metabolism of lactic acid bacteria, In: MOZZI, F., RAYA, R. R., VIGNOLO, G. M. (Org.). Biotechnology of Lactic Acid Bacteria: Novel Applications, lowa: Wiley-Blackwell, p. 3-33, 2010.

MONOD, J. Recherches sur la croissance des cultures bacmnes. Paris: Hermann et Cie, 1942.

MORENO, M. R. F., SARANTINOPOULOS, P., TSAKALIDOU, E., DE VUYST, L. The role and application of enterococci in food and health.International Journal of Food Microbiology, v. 106, p. 1-24, 2006. 
NES, I. F., EIJSINK, V. G. H. Regulation of group II peptide bacteriocin synthesis by quorum-sensing mechanisms. In: DUNNY, G. M.; WINANS, S. C. (Org.). Cell-cell signalling in bacteria,Washinton: American Society for Microbiology, 1999. p.175192.

NILSEN, T., NES, I. F., HOLO, H. An exported inducer peptide regulates bacteriocin production in Enterococcus faecium CTC492. Journal of Bacteriology, v. 180, p. 1848-1854, 1998.

ODAMAKI, T., XIAO, J. Z., YONEZAWA, S., IWATSUKI, K. Improved viability of bifidobacteria in fermented milk by cocultivation with Lactococcus lactis subspecies lactis. Journal of Dairy Science, v. 94, p. 1112-1121, 2011.

OLIVEIRA, R. P. S., PEREGo, P., CONVERTI, A., OLIVEIRA, M. N. Effect of inulin on growth and acidification performance of different probiotic bacteria in cocultures and mixed culture with Streptococcus thermophilus. Journal of Food Engineering, v. 91, p. 133-139, 2009a.

OliveirA, R. P. S., Florence, A., SILVA, R., PEREGo, P., CONVERTI, A., GIOIELLI, L., OLIVEIRA, M. N. Effect of different prebiotics on the fermentation kinetics, probiotic survival and fatty acids profiles in nonfat symbiotic fermented milk. International Journal of Food Microbiology, v. 128, p. 467-472, 2009b.

OliVeirA, R. P. S., PEREGo, P., CONVERTI, A., OLIVEIRA, M. N. The effect of inulin as a prebiotic on the production of probiotic fibre-enriched fermented milk. International Journal of Dairy Technology, v. 62, p. 195-203, 2009c.

OLIVEIRA, R. P. S., PEREGO, P., OLIVEIRA, M. N., CONVERTI, A. Effect of inulin as prebiotic and synbiotic interactions between probiotics to improve fermented milk firmness. Journal of Food Engineering, v. 107, p. 36-40, 2011.

O'MAHONY, T., REKHIF, N., CAVADINI, C., FITZGERALD, G. F. The application of a fermented food ingredient containing "variacin", a novel antimicrobial produced by Kocuriavarians, to control the growth of Bacillus cereus in chilled dairy products. Journal of Applied Microbiology, v. 90, p. 106-114, 2001.

PARKIN, M. F., MARSHALL, K. R. Spray irrigation disposal of dairy factory effluent: a review of current practice in New Zealand. New Zealand Journal of Dairy Science and Technology, v.11, p. 196-205, 1976. 
PELÁEZ, C., REQUENA, T. Exploiting the potential of bacteria in the cheese ecosystem. International Dairy Journal, v. 15, p. 831-844, 2005.

PHILLIPS, J. D., GRIFFTHS, M. W., MUIR, D. D. Effect of nisin on the shelf-life of pasteurized double cream. The Journal of the Society of the Dairy Technology, v. 36, p. 17-21, 1983.

PENNA, A. L. B., THAMER, K. G. Efeito do teor de soro, açúcar e de frutooligossacarídeos sobre a população de bactérias lácticas probióticas em bebidas fermentadas. Revista Brasileira de Ciências Farmacêuticas, v. 41, 2005.

PFEILER, E. A., KLAENHAMMER, T. R. The genomics of lactic acid bacteria.Trends in Microbiology, v. 15, p. 546-553, 2007.

POWELL, E. O. Growth Rate and Generation Time of Bacteria, with Special Reference to Continuous Culture. Microbiology, v. 15, p. 492-511, 1956.

REDDY, K. V. R., YEDERY, R. D., GUPTA, S. M. Antimicrobial peptides: premises and promises. International Journal of Antimicrobial Agents, v. 24, p. 536-547, 2009.

RILLA, N., MARTINEZ, B., RODRIGUEZ, A. Inhibition of a methicillin-resistant Staphylococcus aureus strain in Afuega'l Pitu cheese by the nisin Z producing strain Lactococcus lactis subsp. lactis IPLA 729. Journal of Food Protection, v. 67, p. 928-933, 2004.

ROBBINS, C. W., HANSEN, C. L., ROGINSKE, M. F., SORENSEN, D. L. Extractable potassium and soluble calcium, magnesium and potassium in two whey-treated calcareous soils. Journal of Environmental Quality, v.25, p. 791-795, 1996.

ROGERS, L. A., WHITTIER, E. D. Limiting factors in lactic fermentation. Journal of Bacteriology, v. 16, p. 211-229, 1928.

ROSS, R. P., MORGAN, S., HILL, C. Preservation and fermentation: past, present and future. International Journal of Food Microbiology, v. 79, p. 3-16, 2002.

ROSS, S. S., FIEGEL, J., Nutrient dispersion enhances conventional antibiotic activity against Pseudomonas aeruginosabiofilms International Journal of Antimicrobial Agents, v. 40, p. 177-181, 2012.

ROY, D. Media for the isolation and enumeration of bifidobacteria in dairy products. International Journal of Food Microbiology, v. 69, p. 167-182, 2001. 
SARANTINOPOULOS, P., LEROY, F., LEONTOPOULOU, E., GEORGALAKI, M. D., KALANTZOPOULOS, G., TSAKALIDOU, E., VUYST, L. Bacteriocin production by Enterococcus faecium FAIR-E 198 in view of its application as adjunct starter in Greek Feta cheese making. International Journal of Food Microbiology, v. 72, p. 125-136, 2002.

SARIKA, A. R., LIPTON, A. P., AISHWARYA, M. S. Bacteriocin Production by a New Isolate of Lactobacillus rhamnosus GP1 under Different Culture Conditions. Advance Journal of Food Science and Technology, v. 2, p. 291-297, 2010.

SCHILLINGER, U., GEISEN, R., HOLZAPFEL, W. H. Potential of antagonistic microorganisms and bacteriocins for the biological preservation of foods. Trends Food Science and technology, v. 7, p. 158-164, 1996.

SIMHA, B. V., SOOD, S. K., KUMARIYA, R., GARSA, A. K. Simple and rapid purification of pediocin PA-1 from Pediococcus pentosaceous NCDC 273 suitable for industrial application. Microbiological Research, v. 167, p. 544-549, 2012.

SIMPSON, P. J., FITZGERALD, G. F., STANTON, C., ROSS, R. P. The evaluation of a mupirocin-based selective medium for the enumeration of bifidobacteria from probiotic animal feed. Journal of Microbiological Methods, v. 57, p.9-16, 2004.

STEPPER, J., SHASTRI, S., LOO, T. S., PRESTON, J. C., NOVAK, P., MAN, P., MOORE, C. H., HAVLÍČEK, V., PATCHETT, M. L., NORRIS, G. E. Cysteine $S$ glycosylation, a new post-translational modification found in glycopeptide bacteriocins. FEBS Letters, v. 585, p. 645-650, 2011.

STILES, M. E.Biopreservation by lactic acid bacteria. Antonie van Leeuwenhoek, v. 70, p. 331-345, 1996.

TAMIME A. Y. Probiotic dairy products. Dairy Science and Technology. Consultant Ayr, UK: Blackwell Publishing Ltd, 2005.

TANG, I., YANG, S. T., OKOS, M. R. Acetic acid production from whey lactose by the co-culture of Streptococcus lactis and Clostridium formicoaceticum. Applied Microbiology and Biotechnology, v. 28, p. 138-143, 1988.

TOURE, R., KHEADR, E., LACROIX, C., MORONI, O., FLISS, I. Production of antibacterial substances by bifidobacterial isolates from infant stool active against Listeria monocytogenes. Journal of Applied Microbiology, v. 95, p. 1058-1069, 2003. 
TWOMEY, D., ROSS, R. P., RYAN, M., MEANEY, B., HILL, C. Lantibiotics produced by lactic acid bacteria: structure, function and applications. Antonie van Leeuwenhoek, v. 82, p. 165-185, 2002.

UELIVON, A. H. Identification of Bifidobacterium thermophilum RBL67 isolated from baby faeces and partial purification of its bacteriocin. PhD thesis, Swiss Federal Institute of Technology, Zurich, Switzerland, 2006.

VENTURA, M., O'CONNELL-MOTHERWAY, M., LEAHY, S., MORENO-MUNOZ, J. A., FITZGERALD, G., VAN SINDEREN, D. From bacterial genome to functionally; case bifidobacteria. International Journal of Food Microbiology, v. 120, p. 2-12, 2007.

VIÑAS, M., BORZACCONI, L., MARTíneZ, J., MALlO, M., GALISTEO, M. Simultaneous degradation of carbohydrates and proteins in anaerobic treatment. VII International Symposium on Anaerobic Digestion, January 23-27, Cape Town, South Africa, p. 345-348, 1994.

XIE, L., VAN DER DONK, W. A. Post-translational modifications during lantibiotic biosynthesis. Current Opinion in Chemical Biology, v. 8, p. 498-507, 2004.

YILDIRIM, Z., JOHNSON, M. G. Characterization and antimicrobial spectrum of bifidocin B, a bacteriocin produced by Bifidobacterium bifidum NCFB 1454 . Journal of Food Protection, v. 61, p. 47-51, 1998.

YILDIRIM, Z., WINTERS, D. K., JOHNSON, M. G. Purification, amino acid sequence and mode of action of bifidocin B produced by Bifidobacterium bifidum NCFB 1454. Journal of Applied Microbiology, v. 86, p. 45-54, 1999.

YOSHIDA, C. M. P., ANTUNES, A. J. Application of whey protein films. Ciência e Tecnologia de Alimentos, v. 29, p. 420-430, 2009. 
ANEXOS 
Review

\title{
Novel biotechnological applications of bacteriocins: A review
}

\author{
Eduardo Marcos Balciunas ${ }^{\mathrm{a}}$, Fabio Andres Castillo Martinez ${ }^{\mathrm{a}}$, Svetoslav Dimitrov Todorov ${ }^{\mathrm{b}}$, \\ Bernadette Dora Gombossy de Melo Franco ${ }^{\mathrm{b}}$, Attilio Converti ${ }^{\mathrm{c}}$, Ricardo Pinheiro de Souza Oliveira ${ }^{\mathrm{a}, *}$

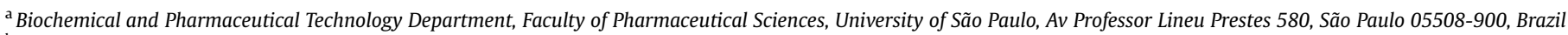 \\ ${ }^{\mathrm{b}}$ Food and Experimental Nutrition Department, Faculty of Pharmaceutical Sciences, University of São Paulo, São Paulo 05508-900, Brazil \\ ${ }^{\mathrm{c}}$ Department of Chemical and Process Engineering, Genoa University, Genoa I-16145, Italy
}

\section{A R T I C L E I N F O}

\section{Article history:}

Received 7 August 2012

Received in revised form

5 November 2012

Accepted 13 November 2012

\section{Keywords:}

Bacteriocins

Biotechnological applications

Food additives

Lactic acid bacteria

Purification

Biosafety

\begin{abstract}
A B S T R A C T
Nowadays, consumers are aware of the health concerns regarding food additives; the health benefits of "natural" and "traditional" foods, processed without any addition of chemical preservatives, are becoming more attractive. One of the alternatives to satisfy this request are bacteriocins, which are antimicrobial peptides produced by a large number of bacteria, including lactic acid bacteria, normally acting against closely related and some spoilage and disease-causing Gram-positive pathogens. For this reason they are used in several applications, among which are biopreservation, shelf-life extension, clinical antimicrobial action and control of fermentation microflora. Toxicological studies showed that nisin intake does not cause any toxic effect to humans having an estimated lethal dose of $6950 \mathrm{mg} / \mathrm{kg}$; thus, it is one of the bacteriocins mostly applied in the food industry as antibotulinic agent in cheese and liquid eggs, sauces and canned foods. It exhibits a wide-spectrum antimicrobial action against Listeria monocytogenes, Staphylococcus aureus, Bacillus cereus and other pathogens. Food-grade substrates such as milk or whey can be supplemented with ex situ produced bacteriocin preparations obtained by fermentation. Preparations can be added as partially purified or purified concentrates requiring specific approval as preservatives from the legislative viewpoint. Demand for new antibacterial compounds has brought great interest for new technologies able to enhance food microbiological safety. Also the dramatic rise in antibiotic-resistant pathogens has stimulated renewed efforts to identify, develop or redesign antibiotics active against multi-resistant bacteria. Numerous antibacterial agents are now being re-considered for application, among others are bacteriophages, probiotics, antimicrobial peptides and bacteriocins. To optimally exploit their desired activities, chemical or genetic engineering methods are often employed. In this review we focus on recent classification of bacteriocins, their mode of action, biotechnological applications in food and pharmaceutical industries, purification techniques and biosafety, as well as recent attempts to generate custom-designed bacteriocins using genetic engineering techniques.
\end{abstract}

(C) 2012 Elsevier Ltd. All rights reserved.

\section{Contents}

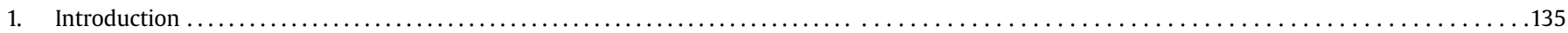

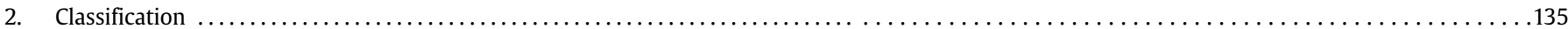

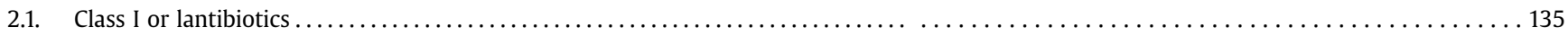

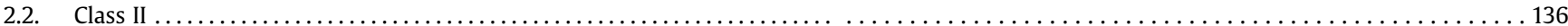

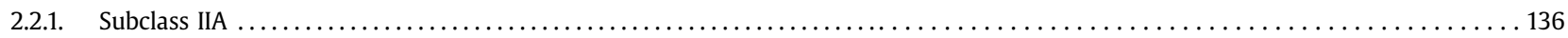

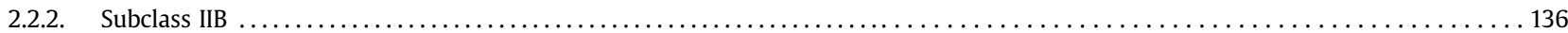

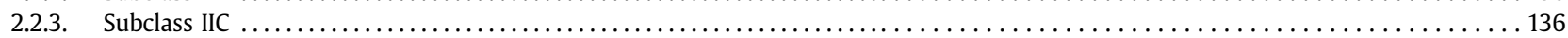

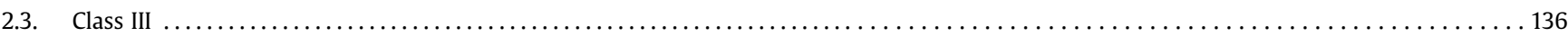

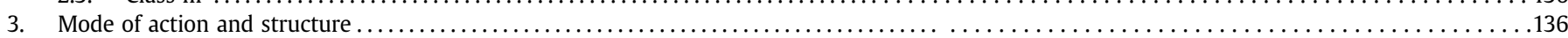

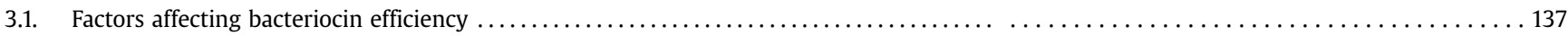

\footnotetext{
* Corresponding author. Tel.: +55 113091 2478; fax: +55 1138156386 .

E-mail address: rpsolive@usp.br (R.P.S. Oliveira).
} 


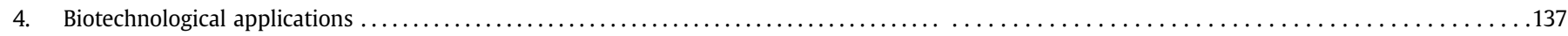

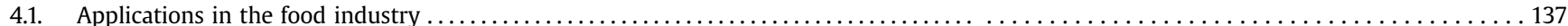

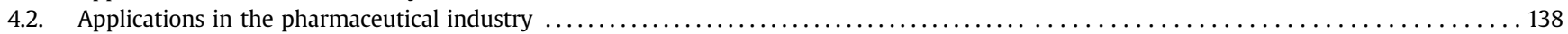

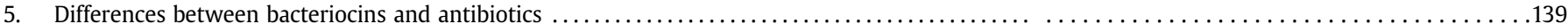

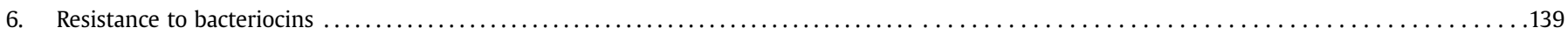

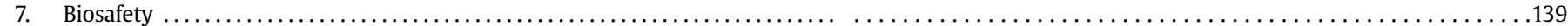

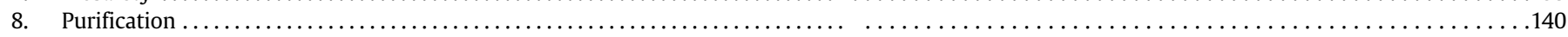

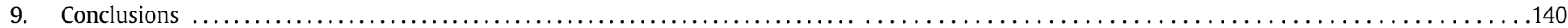

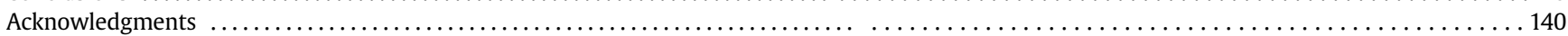

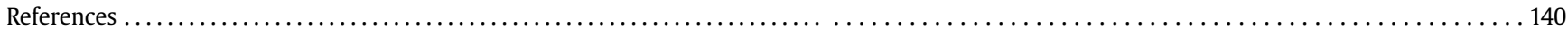

\section{Introduction}

Lactic acid bacteria (LAB) are a diverse and very useful group of bacteria that, while not adhering to a strict taxonomic group, are gathered on the basis of shared properties (Oguntoyinbo \& Narbad, 2012) and have the common trait of producing lactic acid (LA) as a major or sole fermentation product. For these reasons, LAB have historically been associated with the fermentation of foods, and as a result many LAB, like Lactococcus, Oenococcus, Lactobacillus, Leuconostoc, Pedicoccus and Streptococcus sp., are generally recognized as safe (GRAS) and/or probiotics (Mayo et al., 2010).

The desirable property of a probiotic strain is the ability to produce antimicrobial substances such as bacteriocins that offer the potential to provide an advantage in competition and colonization of the gastrointestinal tract. Bacteriocins are generally defined as peptides produced by bacteria that inhibit or kill other related and unrelated microorganisms. Bacteriocin was firstly identified by Gratia (1925) as an antimicrobial protein produced by Escherichia coli and named colicin. The interest in bacteriocins produced by GRAS microorganisms has been leading to considerable interest for nisin, being the first bacteriocin to gain widespread commercial application since 1969. As a result, the field has developed increasingly, resulting in the discovery and detailed characterization of a great number of bacteriocins from LAB in the last few decades (Collins, Cotter, Hill, \& Ross, 2010).

Nowadays, consumers are aware of the health concerns regarding food additives; the health benefits of "natural" and "traditional" foods, processed without any addition of chemical preservatives, are becoming more attractive. Thus, because of recent consumer demand for higher quality and natural foods, as well as of strict government requirements to guarantee food safety, food producers have faced conflicting challenges (Franz, Cho, Holzapfel, \& Gálvez, 2010). Chemical additives have generally been used to combat specific microorganisms. The application of bacteriocins as biopreservatives for vegetable food matrices started approximately 25 years ago. In these years, a lot of studies have focused on the inhibition of spoilage and/or human pathogens associated with vegetable foods and beverages by bacteriocins, and their application appeared as a good alternative to chemical compounds and antibiotics. When deliberately added or produced in situ, bacteriocins have been found to play a fundamental role in the control of pathogenic and undesirable flora, as well as in the establishment of beneficial bacterial populations (Collins et al., 2010).

Traditionally, new bacteriocins have been identified by screening bacterial isolates for antimicrobial activity followed by purification and identification of the bacteriocin and its genetic determinants. Such a strategy is still fundamental for detection and identification of powerful bacteriocins of various subclasses, and recent examples of this include a) a class Ila bacteriocin named avicin A that was identified from Enterococcus avium strains isolated from faecal samples of healthy human infants from both Ethiopia and Norway
(Birri, Brede, Forberg, Holo, \& Nes, 2010), b) a circular bacteriocin named garvicin ML produced by a Lactococcus garvieae strain isolated from mallard duck (Borrero et al., 2011), c) a class IIb bacteriocin named enterocin $\mathrm{X}$ isolated from an Enterococcus faecium strain from sugar apples (Hu, Malaphan, Zendo, Nakayama, \& Sonomoto, 2010) and d) a glycosylated bacteriocin (glycocin F) from Lactobacillus plantarum isolated from fermented corn (Kelly, Asmundson, \& Huang, 1996).

In the next sections, we will present bacteriocin classification, their mode of action and structure, biotechnological applications in food and pharmaceutical industries and problems associated with resistance and purification.

\section{Classification}

According to Klaenhammer (1993), bacteriocins can be divided into four classes. The class I of lantibiotics, represented by nisin, gathers very low molecular weight $(<5 \mathrm{kDa})$ thermostable peptides characterized by the presence of lanthionine and derivatives. The class II is composed of small thermostable peptides $(<10 \mathrm{kDa})$ divided into three subclasses: Ila (pediocin and enterocin), IIb (lactocin G) and IIc (lactocin B). The class III is represented by high molecular weight $(>30 \mathrm{kDa})$ thermolabile peptides such as the helveticin J, while in the class IV we can find large peptides complexed with carbohydrates or lipids. However, Cleveland, Montville, Nes, and Chikindas (2001) believe that these structures are artifacts of partial purification and not a new class of bacteriocins.

Cotter, Hill, and Ross (2005) suggested a new classification where bacteriocins are divided into two categories: lantibiotics (class I) and not containing lanthionine lantibiotics (class II), while high molecular weight thermolabile peptides, which are formally components of the above class III, would be separately designated as "bacteriolysins". These authors also suggested that the above class IV should be extinguished. Finally, Drider, Fimland, Hechard, Mcmullen, and Prevost (2006) divided bacteriocins into three major classes according to their genetic and biochemical characteristics (Table 1), and we will refer to such a classification in the following.

\subsection{Class I or lantibiotics}

Lantibiotics are small peptides (19-38 amino acid residues) with rare thermostable amino acids in their composition, which may result from the combination of two alanine linked by a disulfide bond as for lanthionine, or from an amino butyric acid linked to an alanine by a disulfide bond as for $\beta$-methyl-lanthionine (Jarvis, Jeffcoat, \& Cheeseman, 1968).

The main representative of this class is nisin, which is produced by some strains of Lactococcus lactis subsp. lactis and is composed of 34 amino acid residues. Two variants of nisin are nisin A and nisin Z, which differ structurally in only one amino acid, but have similar 
Table 1

Classification of bacteriocins.

\begin{tabular}{|c|c|c|c|}
\hline Classification & Features & Subcategories & Examples \\
\hline Class I or lantibiotics & Lantionine or peptides containing $\beta$-lantionine & $\begin{array}{l}\text { Type A (linear molecules) } \\
\text { Type B (globular molecule) }\end{array}$ & $\begin{array}{l}\text { Nisin, subtilin, epidermine } \\
\text { Mersacidin }\end{array}$ \\
\hline Class II & Heterogeneous class of small thermostable peptides & $\begin{array}{l}\text { Subclass IIa (antilisterial-pediocine bacteriocins type) } \\
\text { Subclass IIb (composed of two peptides) } \\
\text { Subclass IIc (other bacteriocins) }\end{array}$ & $\begin{array}{l}\text { Pediocin, enterocin, sakacin } \\
\text { Plantaricin, lactacin F } \\
\text { Lactococcin }\end{array}$ \\
\hline Class III & Large thermolabile peptides & & Helveticin J, millericin B \\
\hline
\end{tabular}

Source: Adapted from Drider et al. (2006).

activity (Mulders, Boerrigter, Rollema, Siezen, \& Vos, 1991). Due to the acidic nature of its molecule, nisin is completely stable in solution at $\mathrm{pH} 2.0$ and can be stored for long time in the temperature range of $2-7{ }^{\circ} \mathrm{C}$, while above $\mathrm{pH} 7.0$ inactivation occurs even at room temperature (Delves-Broughton, 1990).

Toxicological studies showed that nisin intake does not cause any toxic effect to humans with an estimated lethal dose $\left(\mathrm{LD}_{50}\right)$ as high as $6950 \mathrm{mg} / \mathrm{kg}$ (close to that of salt) when administered orally (Jozala, Andrade, Arauz, Pessoa Jr., \& Vessoni-Penna, 2007). In general, some authors have ascribed the high $\mathrm{LD}_{50}$ values of bacteriocins to digestive enzymes capable of rapidly inactivating trypsin and chymotrypsin produced in the pancreas (Vaucher et al., 2011).

Nisin has been largely using in the food industry as antibotulinic agent in cheese and liquid eggs, sauces and canned foods. It exhibits a wide-spectrum antimicrobial action against L. monocytogenes, Staphylococcus aureus, Bacillus cereus and other pathogens and LAB species (Rilla, Martinez, \& Rodriguez, 2004), which is mediated by a dual action mechanism encompassing interference with cell wall synthesis and promotion of pore formation in cell membrane. The resulting changes in permeability, with outflow of essential compounds ( $\mathrm{K}^{+}$ion, amino acids and ATP) through the pores, are responsible for cell death (Breukink et al., 1999).

Nisin is the only bacteriocin approved for food applications being considered to be safe by the Food and Agriculture Organization/World Health Organization (FAO/WHO) in 1969. According to Ross, Morgan, and Hill (2002), dairy products can contain nisin as a food additive for processed cheese at concentration up to $12.5 \mathrm{mg} / \mathrm{kg}$ pure nisin. In addition, it was also included as biopreservative ingredient in the European food additive list, where it was assigned the number E234.

\subsection{Class II}

This subclass is composed of small thermostable peptides $(<10 \mathrm{kDa})$ with an amphiphilic helical structure that allows for their insertion in the cytoplasmic membrane of the target cell, thereby promoting membrane depolarization and cell death. Three subdivisions are proposed for this class, according to Drider et al. (2006).

\subsubsection{Subclass IIA}

The subclass Ila is composed of bacteriocins showing high specificity against $L$. monocytogenes. Its representatives have 37-48 amino acid residues with an $\mathrm{N}$-terminal portion with pleated sheet configuration and a $\mathrm{C}$ terminus containing one or two $\alpha$-helices (Fimland, Johnsen, Dalhus, \& Nissen-Meyer, 2005). The bacteriocins of this class fall into the cell membrane of the target microorganism by the $\mathrm{C}$ terminus, promoting the formation of pores and consequent dissipation of proton motive force (Kaiser \& Montville, 1996). In the attempt to maintain or restore the proton motive force, there is acceleration in the consumption of ATP and consequently cell death.

Pediocin PA-1, which is composed of 44 amino acid residues, is the only bacteriocin belonging to the subclass Ila that is synthesized not only by different species, but also by different genera of LAB. It was initially detected in Pediococcus acidilactici (Bhunia, Johnson, \&
Ray, 1987). Since then, other strains and species of pediococci were described as producers of pediocin (Díez et al., 2012). Ennahar et al. (1996) isolated a strain of $L$. plantarum in Munster cheese able to produce pediocin $\mathrm{AcH}$, a bacteriocin with an antagonistic effect on pathogenic and deteriorating microorganisms, including L. monocytogenes, S. aureus and Clostridium perfringens (Bhunia et al., 1987; Loessner, Guenther, Steffan, \& Scherer, 2003).

The first enterocin was identified by Kjems (1955) and subsequently classified as a member of the pediocin family. Since then, several enterocins have been described, that have representatives in more than one class of bacteriocins. Usually they are thermostable $\left(121^{\circ} \mathrm{C} / 15 \mathrm{~min}\right)$ and resistant to lyophilization and storage at $-20^{\circ} \mathrm{C}$ for long periods. According to Cintas, Casaus, Havarstein, Hernandez, and Nes (1997), these compounds have selective antimicrobial activity, do not show antagonism with Leuconostoc and Lactococcus, but attack C. perfringens, Clostridium botulinum, S. aureus and especially species of the genus Listeria.

\subsubsection{Subclass IIB}

This subclass includes heterodimeric bacteriocins, i.e. bacteriocins that require the combined activity of two peptides. Normally, genes are located in the same operon and expressed simultaneously, and the two peptides act in combination frequently showing an important synergistic action. Their mechanism of action also involves the dissipation of membrane potential and a decrease in the intracellular ATP concentration. These peptides have very low activity when individually employed (Garneau, Martin, \& Vederas, 2002).

\subsubsection{Subclass IIC}

Bacteriocins belonging to this subclass have a covalent bond between $\mathrm{C}$ and $\mathrm{N}$ terminals, resulting in a cyclic structure (Kawai et al., 2004). Enterocin AS-48, circularin A and reutericin 6 are representatives of this subclass.

\subsection{Class III}

This class gathers large thermolabile bacteriocins ( $>30 \mathrm{kDa}$ ) that have complex activity and protein structure. Their action mechanism is different from those of other bacteriocins, in that they promote lysis of the cell wall of the target microorganism. Their $\mathrm{N}$ terminal portion is homologous to an endopeptidase involved in cell wall synthesis, while the C-terminal portion is responsible for recognition of the target cell (Lai, Tran, \& Simmonds, 2002).

\section{Mode of action and structure}

Bacteriocins are usually synthesized as inactive pre-peptides that have an N-terminal sequence guide (Macwana \& Muriana, 2012). These precursors are transported to the cell surface during the exponential growth phase and enzymatically converted into their active forms. The carriers contain an $\mathrm{N}$-terminal peptidic portion responsible for the guide peptide cleavage as well as a Cterminal portion responsible for ATP hydrolysis and energy supply 
(Aucher, Lacombe, Héquet, Frère, \& Berjeaud, 2005). For class II, accessory proteins are used to facilitate the membrane translocation and/or cleave the peptide tab.

The system regulating the production of bacteriocins is composed of three components: an inducing peptide (or pheromone-activating factor), the transmembrane histidine kinase (pheromone receptor) and a response regulator (Nes \& Eijsink, 1999). The peptide inducer is synthesized in the ribosome at low levels as a pre-peptide, which is cleaved and secreted in the outer environment by the carrier system. When this compound reaches a threshold concentration, it activates transmembrane histidine kinase, which leads to autophosphorylation of the histidine residue, thus transferring phosphate to a response regulator protein. The phosphorylated regulator activates the transcription of the bacteriocin in addition to the elements that make up the regulatory system, initiating a positive feedback (Nes \& Eijsink, 1999). Regulation of the production of lantibiotics such as nisin and subtilin is done by the bacteriocin itself, which acts as a pheromone inducing their production at high levels (Kleerebezem \& Quadri, 2001).

The mechanism of immunity of bacteriocin-producing bacteria makes distinction between bacteriocin produced by themselves and by other microorganisms. The protection can be promoted by a specific protein and/or the conveyor system. The mechanism by which they work is similar, by kidnapping the structural protein or by antagonistic competition for receptor of the bacteriocin (Hoffmann, Schneider, Pag, \& Sahl, 2004).

\subsection{Factors affecting bacteriocin efficiency}

The activity of bacteriocins produced by different LAB is not uniform and constant and depends on the chemical composition and physical conditions of food; it mainly depends on $\mathrm{pH}$ and is reduced by bacteriocin binding to food components, adsorption to cell or protein, activity of proteases and other enzymes (Schillinger, Geisen, \& Holzapfel, 1996). A correlation between nisin degradation and extent of proteolysis in pasteurized cream was found by Phillips, Griffths, and Muir (1983). Buyong, Kok, and Luchansky (1998) ascribed the reduction in pediocin activity from 64,000 to $2,000 \mathrm{U} / \mathrm{g}$ after six months of maturation of Cheddar cheese to the action of proteases and peptidases. $\mathrm{NaCl}$ at certain concentrations can reduce the growth of LAB and consequently the production of bacteriocins, besides protecting the target bacteria such as $L$. monocytogenes from their action (Hugas, Garriga, Pascual, Aymerich, \& Monfort, 2002). Sarantinopoulos et al. (2002) observed reductions in bacteriocin activity and $E$. faecium FAIR-E 198 growth rate after addition of $2 \% \mathrm{NaCl}$ to MRS broth. Nilsen, Nes, and Holo (1998) ascribed this phenomenon to the interference of $\mathrm{NaCl}$ in the production factor binding the inductor to the receptor.

Aside from interacting with food components, bacteriocins may be adversely affected by processing and storage conditions such as $\mathrm{pH}$ and temperature of the product. According Drosinos, Mataragas, Nasis, Galiotou, and Metaxopoulos (2005), the optimal pH for bacteriocin production (5.5) does not match that for microbial growth (6.5). Because of their maximum stability under acidic conditions, nisin activity is increased when used in acidic foods. Therefore, effective applications of nisin require that the $\mathrm{pH}$ of food is less than 7 to ensure satisfactory solubility, stability during processing and storage period (Hernandez et al., 1993). Leroy and De Vuyst (1999) reported that bacteriocin activity decreases with increasing temperature owing to increased activity of proteases.

The inhibitory efficiency of bacteriocins is also related to the level of food contamination by the target organism. If the initial contamination is too high, bacteriocin activity is low and unable to prevent the development of contaminating microorganisms. Rilla et al. (2004) investigated the action of Lc. lactis subsp. lactis IPLA
729 against $S$. aureus at two different concentrations, specifically $1.8 \times 10^{4}$ and $7.2 \times 10^{6} \mathrm{CFU} \mathrm{mL}^{-1}$ : after $24 \mathrm{~h}$ of incubation, they did not detect $S$. aureus in the more dilute sample, while the other showed a still high count $\left(5.0 \times 10^{4} \mathrm{CFU} \mathrm{\textrm {mL } ^ { - 1 }}\right)$.

\section{Biotechnological applications}

There are potentially significant benefits to employing modern cutting-edge bioengineering to progress the traditional peptide discovery, description and production because of the gene-encoded nature of bacteriocins. One of the greatest advantages of bioengineering in the lantibiotic field involves the creation of strains producing larger amounts of lantibiotic peptides (Suda et al., 2010). Another strategy to improve lantibiotic-producing strains is to conjugate multiple large bacteriocin-encoding plasmids into a single strain (Collins et al., 2010), thereby making it able to kill the undesired target more effectively than the wild type (O'Sullivan, Ryan, Ross, \& Hill, 2003). It is also possible to achieve this goal through the amplification and cloning of lantibiotic-encoding genes into shuttle vectors and heterologous production in other strains. Such an approach was used to improve the production of lacticin 3147 by an Enterococcus host (Ryan, Mcauliffe, Ross, \& Hill, 2001).

Bioengineering of existing peptides could also lead to the creation of lantibiotics with improved power and/or suitable for specific applications (Collins et al., 2010). A number of studies allowed for better comprehension of the structure/function relationships of specific lantibiotics and pointed out the significance of nisin and related peptides within the hinge region, whose discrete alterations resulted in mutants with no mutacin II activity (Chen et al., 1998), or improved nisin Z activity, or even enhanced stability at high temperature and/or under neutral or alkaline conditions (Yuan, Zhang, Chen, Yang, \& Huan, 2004). In addition, to improve the activity or inhibitory spectrum, peptides were developed with enhanced characteristics. For example, nisin Z studies that solubility and stability were significantly improved by peptide engineering without dramatically reducing specific activity (Rollema, Kuipers, Both, De Vos, \& Siezen, 1995).

It is also possible to drastically alter lantibiotic and nonlantibiotic peptides by altering existing or introducing new posttranslational modifications through the application of specific enzymes. To provide some examples, the cyclase of nisin (NisC) was utilized to cyclize and protect non-lantibiotic peptides against peptidases and proteases (Rink et al., 2007), a property which is particularly useful from a drug design standpoint, while the dehydratase of nisin (NisB) to introduce dehydro residues making the formation of thioether bridges into various peptides easier (Kluskens et al., 2005).

According to Mills, Stanton, Hill, and Ross (2011), bioengineering of bacteriocins is not limited to lantibiotics. Much effort has been devoted to the subclass IIA of bacteriocins to determine the structure-function relationships. Though variants generated in these types of studies are useful from an academic standpoint, none of them display increased activity against several microorganisms (Kazazic, Nissen-Meyer, \& Fimland, 2002).

\subsection{Applications in the food industry}

Foods products can be supplemented with ex situ produced bacteriocin preparations obtained by cultivation of the producer strain in an industrial fermenter followed by adequate recovery. Bacteriocins can be added as partially purified or purified concentrates, which would require specific approval as preservatives from the legislative viewpoint. So far, nisin and pediocin PA-1 are bacteriocins licensed as food preservatives (Simha, Sood, Kumariya, \& Garsa, 2012). Many preliminary studies on the activity of bacteriocins in vitro or in food 
systems are carried out with partially-purified preparations obtained from culture broths, but in the most cases a low concentration of bacteriocin is often recovered (Schillinger et al., 1996; Stiles, 1996), which demonstrates the significance to address many efforts in this direction.

Foods can also be supplemented with bacteriocins ex situ produced that can be added in the form of raw concentrates obtained by cultivation of the producer strain in a food-grade substrate (such as milk or whey). The resulting preparations may be regarded as food additives or ingredients from the legal viewpoint, since some of their components may play a recognized function in the food (such as increase in protein content or thickening). They also contain the cell-derived antimicrobial metabolites (such as LA) and bacteriocins, affording an additional bioprotectant function. Other milk-based preparations have been described, in addition to already-marketed concentrates such as ALTA ${ }^{\mathrm{TM}} 2341$ or Microgard $^{\mathrm{TM}}$, such as lacticin 3147 (Guinane, Cotter, Hill, \& Ross, 2005) and variacin (O’Mahony, Rekhif, Cavadini, \& Fitzgerald, 2001). Bacteriocins ex situ produced can also be applied in the form of immobilized preparations, in which the partially-purified bacteriocin is bound to a carrier. The carrier acts as a reservoir and diffuser of the concentrated bacteriocin molecules to the food, guaranteeing a gradient-dependent continuous supply of bacteriocin. The carrier may also protect the bacteriocin from inactivation by interaction with food components and enzymatic inactivation. Moreover, the application of bacteriocin molecules on the food surface requires much lower amounts of bacteriocin (compared to application in the whole food volume), decreasing the processing costs. In most cases, immobilized bacteriocin preparations are applied on the surface of the processed food, avoiding post-process contamination and surface proliferation of unwanted bacteria. A recent advance in this field is the use of immobilized bacteriocins in the development of antimicrobial packaging (Ercolini, Storia, Villani, \& Mauriello, 2006).

In situ, bacteriocin production offers several advantages compared to ex situ production, concerning both legal aspects and costs. Lowering the costs of biopreservation processes may be highly attractive, especially for small economies and developing countries, where food safety may be seriously compromised (Holzapfel, 2002). Several studies demonstrate the effectiveness of these compounds in food biopreservation, as shown in Table 2.

Many studies have also focused on the selection and development of protective bacteriocinogenic cultures for food applications (Leroy, Verluyten, \& De Vuyst, 2006; Ross et al., 2002) such as inhibition of spoilage and pathogenic bacteria during the shelf life period of non-fermented foods. A protective culture may grow and produce bacteriocin during refrigerated storage of the food, which must have a neutral impact on its physicochemical and organoleptic properties, and/or during temperature abuse conditions, under which it may even act as the predominant spoiler, ensuring that pathogenic bacteria do not grow and that the spoiled food is not consumed (Holzapfel, Geisen, \& Schillinger, 1995).

\subsection{Applications in the pharmaceutical industry}

With the availability of a powerful and effective arsenal of drugs, most pharmaceutical companies abandoned their antimicrobial drug development programs, as there seemed to be little need for new drug compounds (Knowles, 1997). Bacterial resistance to antimicrobials was observed right after their initial wide-scale use (Levin et al., 1998). Since then, the levels of resistance have continued to rise dramatically. It has reached the point that by 2000 the World Health Organization cautioned that infectious diseases might become untreatable as a result of high levels of multiply resistant pathogens. At first, antibiotic resistance was thought to be confined to hospital settings, where the use of antibiotics was most intensive; approximately one third of all hospitalized patients receive antibiotics with at least half of those prescriptions being unnecessary, poorly chosen or incorrectly administered (Van Houten, Luinge, Laseur, \& Kimpen, 1998).

Compounding the problem further, an almost exclusive reliance on broad-spectrum antibiotic agents has contributed to a rapid emergence of multiresistant pathogens (Wester et al., 2002). The increasing threat of antibiotic resistance is also the result of antibiotic use in agricultural and food production settings. In the agricultural industry, the use of antibiotics for disease control, prophylactic agents and growth promotion, has contributed significantly to the emergence of resistant bacteria pathogenic to animals (Barton \& Hart, 2001) and plants (Mcmanus, Stockwell, Sundin, \& Jones, 2002). Additionally, bacteria isolated from animals in environments unrelated to clinical or agricultural management settings have been shown to naturally acquire high levels of antibiotic resistance (Sherley, Gordon, \& Collignon, 2000). Ironically, it is likely that the extensive benefits of antibiotic use has contributed to the limited array of effective drugs available today for treating multi-resistant bacteria.

Only recently the alarming nature of this problem has motivated research efforts to find alternatives to our increasingly limited antibiotic resources. Numerous antibacterial agents are now being considered such as bacteriophages (Alisky, Iczkowski, Rapoport, \& Troitsky, 1998), probiotic bacteria (Macfarlane \& Cummings, 2002), antimicrobial peptides (Joerger, 2003), and bacteriocins (Twomey, Ross, Ryan, Meaney, \& Hill, 2002). In order to optimally exploit the desired activities of these varied antimicrobial leads, researchers often employ chemical or genetic engineering methods (Lien \& Lowman, 2003). Examples of some bacteriocins and their pharmaceutical applications are shown in Table 3.

The use of microcins is a possible alternative to control Gramnegative bacteria (Duquesne, Destoumieux-Garzón, Peduzzi, \& Rebuffat, 2007). Similarly to pediocin-like bacteriocins, microcins belonging to class IIa such as microcin $\mathrm{V}$ are linear polypeptides, and the removal of the leader peptide is the unique posttranslational modification that they undergo before being secreted by the cells (Duquesne et al., 2007; Pons, Lanneluc, Cottenceau, \& Sable, 2002). Three different proteins may serve as

Table 2

Application of bacteriocins in food biopreservation.

\begin{tabular}{|c|c|c|c|c|c|}
\hline Bacteriocin & Culture producer & Target microorganism & Food & $\begin{array}{l}\text { Reduction } \\
\left(\log \mathrm{CFU} \mathrm{g}^{-1}\right)\end{array}$ & References \\
\hline Nisin & Lactococcus lactis & Brochothrix thermosphacta & Pork & 3.5 & Nattress, Yost, \& Baker, 2001 \\
\hline Nisin & L. lactis & Listeria monocytogenes & Fermented milk & 6.0 & Benkerroum et al. (2002) \\
\hline AcH Pediocin & Lactobacillus plantarum & L. monocytogenes & Cheese & $1.0-2.0$ & Loessner et al., 2003 \\
\hline Enterocin & Enterococcus faecium & L. monocytogenes & Milk & 2.0 & $\begin{array}{l}\text { Elotmani, Revol-Junelles, Assobhei, } \\
\text { \& Milliére, } 2002\end{array}$ \\
\hline Enterocin & Enterococcus faecalis & Staphylococcus aureus & Sausage & 5.3 & $\begin{array}{l}\text { Ananou, Maqueda, Martínéz-Bueno, } \\
\text { Gálvéz, \& Valdivia, } 2005\end{array}$ \\
\hline Nisin Z & Lactococcus lactis lactis & S. aureus & Afuega'l pitu cheese & 2.0 & Rilla et al. (2004) \\
\hline
\end{tabular}

Source: Adapted from Nascimento, Moreno, and Kuaye (2008). 
Table 3

Examples of some bacteriocins and their pharmaceutical applications.

\begin{tabular}{ll}
\hline Group of bacteriocins & Pharmaceutical applications \\
\hline Lantibiotics & Blood pressure treatment \\
& Inflammations and allergies treatment \\
& Skin infections treatment \\
& Mastitis infections treatment \\
& Herpes treatment \\
& Dental carries treatment \\
& Peptic ulcer treatment \\
& Urinogenital infection \\
Colicins & Hemorrhagic colitis treatment \\
& Hemolytic uremic syndrome treatment \\
& Antibacterial agent \\
Microcins & Salmonellosis treatment \\
\hline
\end{tabular}

Source: Adapted from Gillor, Nigro, and Riley (2005).

a specific receptor for linear microcins, namely the membrane component $\mathrm{F}_{0}$ of the ATP synthase, $\mathrm{SdaC}$, and the mannose permease, required by $\mathrm{MccH} 47, \mathrm{MccV}$, and MccE492, respectively (Biéler, Silva, \& Belin, 2010; Gérard, Pradel, \& Wu, 2005). Because of the Gram-negative envelope structure, an additional step is required by class Ila microcins, i.e. an OM transporter system is used for these peptides to reach the plasma membrane receptor. The enterocin CRL35, a pediocin-like bacteriocin isolated from Argentinean regional cheese, has a potent antilisterial activity but is inactive against Gram-negative bacteria (Farías, Farías, de Ruiz Holgado, \& Sesma, 1996). On the other hand, microcin V, previously known as colicin V, is specifically active against Gramnegative bacteria (Gratia, 1925). In order to obtain a peptide with a broader antimicrobial spectrum, Acuña, Picariello, Sesma, Morero, and Bellomio (2012) fused by asymmetrical PCR the required portions of genes encoding enterocin CRL35 and microcin V, namely munA and $c v a C$. The hybrid bacteriocin purified from $E$. coli extracts, named Ent35-MccV, showed inhibitory activity against enterohemorrhagic E. coli, L. monocytogenes, and other pathogenic Gram-positive and Gram-negative bacteria (Acuña et al., 2012).

\section{Differences between bacteriocins and antibiotics}

In contrast to the currently used antibiotics, bacteriocins are often considered more natural because they are thought to have been present in many of the foods eaten since ancient times. Bacteriocins are inactivated by enzymes, such as trypsin and pepsin, found in the gastrointestinal tract and therefore, they do not alter the microbiota of the digestive tract (Cleveland et al., 2001). If bacteriocins are considered antibiotics, they may not be used in human food, since the use of antibiotics in food is illegal (Collins et al., 2010). Nisin is the only bacteriocin considered by the Codex Alimentarius committee FAO (Food and Agriculture Organization) as GRAS (Generally Regarded As Safe) and can be used as a food additive in the inhibition of post-germination spores and toxin formation by $C$. botulinum in pasteurized processed cheese. Antibiotics for use in animal feed have been first approved in 1951 by the U.S. Food and Drug Administration that now maintains a list of currently approved products. Over the years and especially more recently, a number of strategies for improvements in animal health, productivity, and microbial food safety that did not involve antibiotics have been explored, like probiotics and bacteriocins (Joerger, 2003).

Antibiotics and bacteriocins have different mechanisms of action. When nisin is combined with some antibiotics, antimicrobial synergy may occur. The mechanisms of resistance to nisin and antibiotics are different. Antibiotic-resistant cells are sensitive to nisin and nisin-resistant cells are sensitive to antibiotics (Cleveland et al., 2001; Fernández, Delgado, Herrero, Maldonado, \& Rodríguez, 2008). More recently, microencapsulated nisin in nanovesicles prepared from partially purified soy lecithin was shown to be as effective as free nisin to inhibit $L$. monocytogenes growth in whole and skim milk at low temperatures over 14 days (da Silva-Malheiros, Daroit, da Silveira, \& Brandelli, 2010). Naghmouchi, Le Lay, Baah, and Drider (2012) determined the synergistic effect of bacteriocins and antibiotics on sensitive and resistant variants of strains. In particular, a synergistic effect against Pseudomonas fluorescens was observed with $90 \%$ of the combinations of the class I or subclass IIa bacteriocins with antibiotics and $60 \%$ of the combinations of colistin with antibiotics. So, in the future, combination of antibiotics with antimicrobial peptides could allow for reduced use of antibiotics in medical applications and could help to prevent the emergence of bacteria resistant to antibiotics.

\section{Resistance to bacteriocins}

The resistance of spontaneous mutants to bacteriocins may be related to changes in membrane and cell wall, such as alterations in the electrical potential, fluidity, membrane lipid composition and load or cell wall thickness (Mantovani \& Russel, 2001), or even a combination of all factors. According to Van Schaik, Gahan, and Hill (1999), these changes may occur following cell exposure to low concentrations of bacteriocins or as part of an adaptive response to some other stress. The mechanism of resistance of cells to nisin is not yet well understood. According to Abee (1995), the resistance of $L$. monocytogenes to nisin is related to variation in fatty acid composition of cell membranes, reducing the concentration of phospholipids, hindering the formation of pores.

Gravesen, Axelsen, Silva, Hansen, and Knochel (2002) reported that the frequency of resistance may vary between $10^{-2}$ and $10^{-7}$, depending on the strain of $L$. monocytogenes. The mechanism of resistance to subclass Ila bacteriocins appears to be linked to reduced expression of mannose permease of the phosphotransferase system (Vadyvaloo, Hastings, Van Der Merwe, \& Rautenbach, 2002)

\section{Biosafety}

Microorganisms like Lactobacillus spp., Lactococcus spp. and Streptococcus thermophilus have been used in food processing, and consumption of foods containing them or their metabolites has taken place for a long time (Ishibashi \& Yamazaki, 2001). The safety of these microorganisms has not been questioned and reports of harmful effects of these bacteria have been very rare. Some LAB have proven to be associated with human infections, like endocarditis by Lactobacillus fermentum isolated in the mitral valve (Gallemore, Mohon, \& Ferguson, 1995), pancreatitis by Lactobacillus rhamnosus isolated in the intra-abdomen and blood (Brahimi, Mathern, Fascia, Afchain, \& Lucht, 2008), urinary tract infection by P. acidilactici, Lactobacillus gasseri and Leuconostoc mesenteroides (Taneja et al., 2005), and several other diseases. In addition, some LAB has been associated with resistance to antibiotics, but according to Songisepp et al. (2012), L. plantarum Tensia is not resistant to tetracycline.

However, various clinical studies have been conducted to assess the safety of probiotics in small groups of specific HIV infected patients, and the findings of these studies support the safety of probiotics consumed by such groups (Cunningham-Rundles et al., 2000). 


\section{Purification}

Bacteriocin-producers are LAB that need complex nutritional exigencies to grow, and this not only increases the production cost, but also makes the purification of bacteriocins more difficult ( $\mathrm{Li}$, Bai, Cai, \& Ouyang, 2002). Since bacteriocins form an extremely heterogeneous group of substances, specific purification protocols generally need to be designed for each of them, which may explain why only few bacteriocins have been purified to homogeneity like nisin. Three major methods for the purification of LAB bacteriocins can be distinguished according to their biochemical structure. First, purification can be done by a conventional method that is based on a rather laborious series of subsequent steps of ammonium sulfate precipitation, ion exchange, hydrophobic interaction, gel filtration, and reversed-phase high-pressure liquid chromatography (Parente \& Ricciardi, 1999). Second, a simple three-step protocol has been developed, including (1) ammonium sulfate precipitation, (2) chloroform/methanol extraction/precipitation, and (3) reversedphase high-pressure liquid chromatography, as the sole chromatographic step involved (Callewaert et al., 1999). Third, bacteriocins can be isolated through a unique unit operation, i.e. expanded bed adsorption, using a hydrophobic interaction gel, after maximizing the bioavailable bacteriocin titer through $\mathrm{pH}$ adjustment of the crude fermentation medium (Foulquié-Moreno, Callewaert, \& De Vuyst, 2001).

Following the last two methods, which are more rapid and successful than the first conventional one, several bacteriocins with interesting industrial potential have been purified such as amylovorin L (produced by Lactobacillus amylovorus DCE 471 and belonging to the class II), several enterocins (produced by the E. faecium RZS C5, RZS C13 and FAIR-E 406 strains) and the lantibiotic macedocin (produced by Streptococcus macedonicus ACA-DC 198) (Callewaert et al., 1999; Georgalaki et al., 2002). Nisin, for example, has been purified using immunoaffinity chromatography (Prioult, Turcotte, Labarre, Lacroix, \& Fliss, 2000), expanded bed ion exchange (Cheigh, Kook, Kim, Hong, \& Pyun, 2004) and reversedphase high-performance liquid chromatography (López et al., 2007). However, these methodologies greatly increase the cost of nisin, which is the most consumed bacteriocin in the world.

\section{Conclusions}

Bacteriocins have the potential to cover a very broad field of application, including both the food industry and the medical sector. They are a diverse group of antimicrobial proteins/peptides; therefore, they are expected to behave differently on different target bacteria and under different environmental conditions. Since the efficacy of bacteriocins is dictated by environmental factors, there is a need to determine more precisely the most effective conditions for application of each particular bacteriocin. For uses involving purified bacteriocins, cost of the compounds can become a significant barrier. Production of all but the smallest bacteriocins is currently only imaginable by culture of natural or genetically engineered producer organisms. Investments in research and development can be expected to be high, and the size of the market is difficult to predict, but the fact that nisin has found commercial uses indicates that economic aspects are not insurmountable barriers to bacteriocin applications.

\section{Acknowledgments}

The authors are grateful for the financial support of this work to the FAPESP (Fundação de Amparo à Pesquisa do Estado de São Paulo) (process numbers: 11/50195-7 and 11/14048-0) and CAPES Coordenação de Aperfeiçoamento de Pessoal de Nível Superior.

\section{References}

Abee, T. (1995). Pore-forming bacteriocins of Gram-positive bacteria and selfprotection mechanisms of producer organism. FEMS Microbiology Letters, 129, $1-9$.

Acuña, L., Picariello, G., Sesma, F., Morero, R. D., \& Bellomio, A. (2012). A new hybrid bacteriocin, Ent35-MccV, displays antimicrobial activity against pathogenic Gram-positive and Gram-negative bacteria. Federation of European Biochemical Societies Open BIO, 12-19.

Alisky, J., Iczkowski, K., Rapoport, A., \& Troitsky, N. (1998). Bacteriophages show promise as antimicrobial agents. Journal of Infection, 36, 5-15.

Ananou, S., Maqueda, M., Martínéz-Bueno, M., Gálvéz, A., \& Valdivia, E. (2005) Control of Staphylococcus aureus in sausages by enterocin AS-48. Meat Science, 71, 549-556.

Aucher, W., Lacombe, C., Héquet, A., Frère, J., \& Berjeaud, J. M. (2005). Influence of amino acid substitutions in the leader peptide on maturation and secretion of mesentericin Y105 by Leuconostoc mesenteroides. Journal of Bacteriology, 187, 2218-2223.

Barton, M. D., \& Hart, W. S. (2001). Public health risks: antibiotic resistance - Review. Asian-Australasian Journal of Animal Sciences, 14, 414-422.

Benkerroum, N., Ghouati, Y., Ghalfi, H., Elmejdoub, T., Roblain, D., Jacques, P., et al. (2002). Biocontrol of Listeria monocytogenes in a model cultured milk (lben) by in situ bacteriocin production from Lactococcus lactis ssp. lactis. International Journal of Dairy Technology, 55, 145-151.

Bhunia, A. K., Johnson, M. C., \& Ray, B. (1987). Direct detection of an antimicrobial peptide of Pediococcus acidilactici in sodium dodecyl sulfate-polyacrylamide ge electrophoresis. Journal of Industrial Microbiology E Biotechnology, 2, 319-322.

Biéler, S., Silva, F., \& Belin, D. (2010). The polypeptide core of microcin E492 stably associates with the mannose permease and interferes with mannose metabolism. Research in Microbiology, 161, 706-710.

Birri, D. J., Brede, D. A., Forberg, T., Holo, H., \& Nes, I. F. (2010). Molecular and genetic characterization of a novel bacteriocin locus in Enterococcus avium isolates from infants. Applied and Environmental Microbiology, 76, 483-492.

Borrero, J., Brede, D. A., Skaugen, M., Diep, D. B., Herranz, C., Nes, I. F., et al. (2011). Characterization of garvicin ML, a novel circular bacteriocin produced by Lactococcus garvieae DCC43, isolated from mallard ducks (Anas platyrhynchos). Applied and Environmental Microbiology, 77, 369-373.

Brahimi, M., Mathern, P., Fascia, P., Afchain, J. M., \& Lucht, F. (2008). Two cases of Lactobacillus rhamnosus infection and panctreatitis. Médecine et Maladies Infectieuses, 38, 29-31.

Breukink, E., Wiedemann, I., Van Kraaij, C., Kuipers, O. P., Sahl, H. G., \& Kruijff, B. (1999). Use of the cell wall precursor lipid II by a pore-forming peptide antibiotic. Science, 286, 2361-2364.

Buyong, N., Kok, J., \& Luchansky, J. B. (1998). Use of a genetically enhanced, pediocin-producing starter culture, Lactococcus lactis subsp. lactis MM 217 to control Listeria monocytogenes in cheddar cheese. Applied and Environmental Microbiology, 64, 4842-4845.

Callewaert, R., Holo, H., Devreese, B., Van Beeumen, J., Nes, I., \& De Vuyst, L. (1999). Characterization and production of amylovorin L471, a bacteriocin purified from Lactobacillus amylovorus DCE 471 by a novel three-step method. Microbiology, 145, 2559-2568.

Cheigh, C. I., Kook, M. C., Kim, S. B., Hong, Y. H., \& Pyun, Y. R. (2004). Simple one-step purification of nisin $\mathrm{Z}$ from unclarified culture broth of Lactococcus lactis subsp. lactis A164 using expanded bed ion exchange chromatography. Biotechnology Letters, 26, 1341-1345.

Chen, P., Novak, J., Kirk, M., Barnes, S., Qi, F., \& Caufield, P. W. (1998). Structure-activity study of the lantibiotic mutacin II from Streptococcus mutans T8 by a gene replacement strategy. Applied and Environmental Microbiology, 64, 2335-2340.

Cintas, L. M., Casaus, P., Havarstein, L. S., Hernandez, P. E., \& Nes, I. F. (1997). Biochemical and genetic characterization of enterocin P, a novel sec-dependent bacteriocin from Enterococcus faecium P13 with a broad antimicrobial spectrum. Applied and Environmental Microbiology, 63, 4321-4330.

Cleveland, J., Montville, T. J., Nes, I. F., \& Chikindas, M. L. (2001). Bacteriocins: safe, natural antimicrobials for food preservation. International Journal of Food Microbiology, 71, 1-20.

Collins, B., Cotter, P. D., Hill, C., \& Ross, R. P. (2010). Applications of lactic acid bacteria-produced bacteriocins. In F. Mozzi, R. R. Raya, \& G. M. Vignolo (Eds.), Biotechnology of lactic acid bacteria: Novel applications (pp. 89-109).

Cotter, P. D., Hill, C., \& Ross, P. (2005). Bacteriocins: developing innate immunity for food. Nature Reviews Microbiology, 3, 777-788.

Cunningham-Rundles, S., Ahrne, S., Bengmark, S., Johann-Liang, R., Marshall, F, Metakis, L., et al. (2000). Probiotics and immune response. American Journal of Gastroenterology, 95, 22-25.

Delves-Broughton, J. (1990). Nisin and its application as a food preservative. Journal of the Society of Dairy Technology, 43, 73-76.

Díez, L., Rojo-Bezares, B., Zarazaga, M., Rodríguez, J. M., Torres, C., \& Ruiz-Larrea, F. (2012). Antimicrobial activity of pediocin PA-1 against Oenococcus oeni and other wine bacteria. Food Microbiology, 31, 167-172.

Drider, D., Fimland, G., Hechard, Y., Mcmullen, L. M., \& Prevost, H. (2006). The continuing story of class Ila bacteriocins. Microbiology and Molecular Biology Reviews, 70, 564-582.

Drosinos, E. H., Mataragas, M., Nasis, P., Galiotou, M., \& Metaxopoulos, J. (2005) Growth and bacteriocin production kinetics of Leuconostoc mesenteroides E131. Journal of Applied Microbiology, 99, 1314-1323. 
Duquesne, S., Destoumieux-Garzón, D., Peduzzi, J., \& Rebuffat, S. (2007). Microcins, gene-encoded antibacterial peptides from enterobacteria. Natural Product Reports, 24, 708-734.

Elotmani, F., Revol-Junelles, A. M., Assobhei, O., \& Milliére, J. (2002) Characterization of anti-Listeria monocytogenes bacteriocins from Enterococcus faecalis, Enterococcus faecium and Lactococcus lactis strains isolated from Raib, a Moroccan traditional fermented milk. Current Microbiology, 44, 10-17.

Ennahar, S., Aoude-Werner, D., Sorokine, O., Dorsselaer, A. V., Bringel, F., Hubert, J. C. et al. (1996). Production of pediocin AcH by Lactobacillus plantarum WHE92 isolated from cheese. Applied and Environmental Microbiology, 62, 4381-4387.

Ercolini, D., Storia, A., Villani, F., \& Mauriello, G. (2006). Effect of a bacteriocinactivated polythene film on Listeria monocytogenes as evaluated by viable staining and epifluorescence microscopy. Journal of Applied Microbiology, 100 765-772.

Farías, M. E., Farías, R. N., de Ruiz Holgado, A. P., \& Sesma, F. (1996). Purification and N-terminal amino acid sequence of enterocin CRL 35, a "pediocin-like" bacteriocin produced by Enterococcus faecium CRL 35. Letters in Applied Microbiology, 22, 417-419.

Fernández, L., Delgado, S., Herrero, H., Maldonado, A., \& Rodríguez, J. M. (2008). The bacteriocin nisin, as effective agent for the treatment of Staphylococcal mastitis during lactation. Journal of Human Lactation, 24, 311-316.

Fimland, G., Johnsen, L., Dalhus, B., \& Nissen-Meyer, J. (2005). Pediocin-like antimicrobial peptides (class Ila bacteriocins) and their immunity proteins: biosynthesis, structure and mode of action. Journal of Peptide Science, 11, 688-696.

Foulquié-Moreno, M. R., Callewaert, R., \& De Vuyst, L. (2001). Isolation of bacteriocins through expanded bed adsorption using a hydrophobic interaction medium. Bioseparation, 10, 45-50.

Franz, C. M. A. P., Cho, G. S., Holzapfel, W. H., \& Gálvez, A. (2010). Safety of lactic acid bacteria. In F. Mozzi, R. R. Raya, \& G. M. Vignolo (Eds.), Biotechnology of lactic acid bacteria: Novel applications (pp. 341-359).

Gallemore, G. H., Mohon, R. T., \& Ferguson, D. A. (1995). Lactobacillus fermentum endocarditis involving a native mitral valve. Journal of the Tennessee Medical Association, 88, 306-308.

Garneau, S., Martin, N. I. \& Vederas, J. C. (2002). Two-peptide bacteriocins produced by lactic acid bacteria. Biochimie, 84, 577-592.

Georgalaki, M. D., Van Den Berghe, E., Kritikos, D., Devreese, B., Van Beeumen, J. Kalantzopoulos, G., et al. (2002). Macedocin, a food-grade lantibiotic produced by Streptococcus macedonicus ACA-DC 198. Applied and Environmental Microbiology, 68, 5891-5903.

Gérard, F., Pradel, N., \& Wu, L. F. (2005). Bactericidal activity of colicin V is mediated by an inner membrane protein, SdaC, of Escherichia coli. Journal of Bacteriology, 187, 1945-1950.

Gillor, O., Nigro, L. M., \& Riley, M. A. (2005). Genetically engineered bacteriocins and their potential as the next generation of antimicrobials. Current pharmaceutica design, 11, 1067-1075.

Gratia, A. (1925). Sur un remarquable exemple d'antagonisme entre deux souches de coilbacille. Comptes Rendus des Séances et Mémoires de la Société de Biologie 93, 1040-1041.

Gravesen, A., Axelsen, A. M. J., Silva, J. M., Hansen, T. B., \& Knochel, S. (2002) Frequency of bacteriocin resistance development and associated fitness costs in Listeria monocytogenes. Applied and Environmental Microbiology, 68, 756-764.

Guinane, C. M., Cotter, P. D., Hill, C., \& Ross, R. P. (2005). Microbial solutions to microbial problems; lactococcal bacteriocins for the control of undesirable biota in food. Journal of Applied Microbiology, 98, 1316-1325.

Hernandez, P. E., Rodriguez, J. M., Cintas, L. M., Moreira, W. L., Sobrino, O. J., Fernandez, M. F., et al. (1993). Utilización de bactérias lácticas en el control de microorganismos patógenos de los alimentos. Microbiologia SEM, 9, 37-48.

Hoffmann, A., Schneider, T., Pag, U., \& Sahl, H. G. (2004). Localization and functional analysis of PepI, the immunity peptide of Pep 5-producing Staphylococcus epidermidis strain 5. Applied and Environmental Microbiology, 70, 3263-3271.

Holzapfel, W. H. (2002). Appropriate starter culture technologies for small-scale fermentation in developing countries. International Journal of Food Microbiology, 75, 197-212.

Holzapfel, W. H., Geisen, R., \& Schillinger, U. (1995). Biological preservation of foods with reference to protective cultures, bacteriocins and food-grade enzymes. International Journal of Food Microbiology, 24, 343-362.

Hu, C. B., Malaphan, W., Zendo, T., Nakayama, J., \& Sonomoto, K. (2010). Enterocin X, a novel twopeptide bacteriocin from Enterococcus faecium KU-B5, has an antibacterial spectrum entirely different from those of its component peptides. Applied and Environmental Microbiology, 76, 4542-4545.

Hugas, M., Garriga, M., Pascual, M., Aymerich, M. T., \& Monfort, J. M. (2002). Enhancement of sakacin K activity against Listeria monocytogenes in fermented sausages with pepper or manganese as ingredients. Food Microbiology, 19, 519-528.

Ishibashi, N., \& Yamazaki, S. (2001). Probiotics and safety. American Journal of Clinical Nutrition, 73, 465-470.

Jarvis, B., Jeffcoat, J., \& Cheeseman, G. C. (1968). Molecular weight distribution of nisin. Biochemical Biophysiologie Acta, 168, 153-155.

Joerger, R. D. (2003). Alternatives to antibiotics: bacteriocins, antimicrobial peptides and bacteriophages. Poultry Science, 82, 640-647.

Jozala, A. F., Andrade, M. S., Arauz, L. J., Pessoa, A., Jr., \& Vessoni-Penna, T. C. (2007). Nisin production utilizing skimmed milk aiming to reduce process cost. Applied Biochemical Biotechnology, 136, 515-528.

Kaiser, A. L., \& Montville, T. J. (1996). Purification of the bacteriocin bavaricin MN and characterization of its mode of action against Listeria monocytogenes Scott A cells and lipid vesicles. Applied and Environmental Microbiology, 62, 4529-4535.
Kawai, Y., Ishii, Y., Arakawa, K., Uemura, K., Saitoh, B., Nishimura, J., et al. (2004). Structural and functional differences in two cyclic bacteriocins with the same sequences produced by lactobacilli. Applied and Environmental Microbiology, 70, 2906-2911.

Kazazic, M., Nissen-Meyer, J., \& Fimland, G. (2002). Mutational analysis of the role of changed residues in target-cell binding, potency and specificity of the pediocinlike bacteriocin sakacin P. Microbiology, 148, 2019-2027.

Kelly, W. J., Asmundson, R. V., \& Huang, C. M. (1996). Characterization of plantaricin KW30, a bacteriocin produced by Lactobacillus plantarum. Journal of Applied Bacteriology, 81, 657-662.

Kjems, E. (1955). Studies on streptococcal bacteriophages: I. Techniques for isolating phage producing strains. Pathology and Microbiology Scandinavia, 36, 433-440.

Klaenhammer, T. R. (1993). Genetics of bacteriocins produced by lactic acid bacteria. FEMS Microbiological Review, 12, 39-85.

Kleerebezem, M., \& Quadri, L. E. (2001). Peptide pheromone-dependent regulation of antimicrobial peptide production in Gram-positive bacteria: a case of multicellular behavior. Peptides, 22, 1579-1596.

Kluskens, L. D., Kuipers, A., Rink, R., De Boef, E., Fekken, S., Driessen, A. J., et al. (2005). Posttranslational modification of therapeutic peptides by NisB, the dehydratase of the lantibiotic nisin. Biochemistry, 44, 12827-12834.

Knowles, D. J. C. (1997). New strategies for antibacterial drug design. Trends in Microbiology, 5, 379-383.

Lai, A. C., Tran, S., \& Simmonds, R. S. (2002). Functional characterization of domains found within a lytic enzyme produced by Streptococcus equi subsp. zooepidemicus. FEMS Microbiology Letters, 215, 133-138.

Leroy, F., \& De Vuyst, L. (1999). The presence of salt and a curing agent reduces bacteriocin production by Lactobacillus sakei CTC 494, a potential starter culture for sausage fermentation. Applied and Environmental Microbiology, 65, $5350-5356$

Leroy, F., Verluyten, J., \& De Vuyst, L. (2006). Functional meat starter cultures for improved sausage fermentation. International Journal of Food Microbiology, 106, 270-285.

Levin, B. R. Antia, R., Berliner, E., Bloland, P., Bonhoeffer, S., \& Cohen, M. (1998). Resistance to antimicrobial chemotherapy: a prescription for research and action. American Journal of the Medical Sciences, 315, 87-94.

Li, C., Bai, J., Cai, Z., \& Ouyang, F. (2002). Optimization of a cultural medium for bacteriocin production by Lactococcus lactis using response surface methodology. Journal of Biotechnology, 93, 27-34.

Lien, S., \& Lowman, H. B. (2003). Therapeutic peptides. Trends in Biotechnology, 21, 556-562.

Loessner, M., Guenther, S., Steffan, S., \& Scherer, S. (2003). A pediocin-producing Lactobacillus plantarum strain inhibits Listeria monocytogenes in a multispecies cheese surface microbial ripening consortium. Applied and Environmental Microbiology, 69, 1854-1857.

López, R. L., García, M. T., Abriouel, H., Omar, N. B., Grande, M. J., MartínezCañamero, M., et al. (2007). Semi-preparative scale purification of enterococcal bacteriocin enterocin EJ97, and evaluation of substrates for its production. Journal of Industrial Microbiology \& Biotechnology, 34, 779-785.

Macfarlane, G. T., \& Cummings, J. H. (2002). Probiotics, infection and immunity. Current Opinion in Infectious Diseases, 15, 501-506.

Macwana, S., \& Muriana, P. M. (2012). Spontaneous bacteriocin resistance in Listeria monocytogenes as a susceptibility screen for identifying different mechanisms of resistance and modes of action by bacteriocins of lactic acid bacteria. Journal of Microbiological Methods, 88, 7-13.

Mantovani, H. C., \& Russel, J. B. (2001). Nisin resistance of Sreptococcus bovis. Applied and Environmental Microbiology, 67, 808-813.

Mayo, B., Aleksandrzak-Piekarczyk, T., Fernández, M., Kowalczyk, M., ÁlvarezMartín, P., \& Bardowski, J. (2010). Updates in the metabolism of lactic acid bacteria. In F. Mozzi, R. R. Raya, \& G. M. Vignolo (Eds.), Biotechnology of lactic acid bacteria: Novel applications (pp. 3-33). Iowa, USA: Wiley-Blackwell.

Mcmanus, P. S., Stockwell, V. O., Sundin, G. W., \& Jones, A. L. (2002). Antibiotic use in plant agriculture. Annual Review of Phytopathology, 40, 443-465.

Mills, S., Stanton, C., Hill, C., \& Ross, R. P. (2011). New developments and applications of bacteriocins and peptides in foods. Annual Review of Food Science and Technology, 2, 299-329.

Mulders, J. W., Boerrigter, I. J., Rollema, H. S., Siezen, R. J., \& Vos, W. M. (1991). Identification and characterization of the lantibiotic nisin $\mathrm{Z}$, a natural nisin variant. European Journal of Biochemistry, 201, 581-584.

Naghmouchi, K., Le Lay, C., Baah, J., \& Drider, D. (2012). Antibiotic and antimicrobial peptide combinations: synergistic inhibition of Pseudomonas fluorescens and antibiotic-resistant variants. Research in Microbiology. http://dx.doi.org/10.1016/ j.resmic.2011.11.002

Nascimento, M. S., Moreno, I., \& Kuaye, A. Y. (2008). Bacteriocinas em alimentos: uma revisão. Brazilian Journal of Food Technology, 11, 120-127.

Nattress, F. M., Yost, C. K., \& Baker, L. P. (2001). Evaluation of the ability of lysozyme and nisin to control meat spoilage bacteria. International Journal of Food Microbiology, 70, 111-119.

Nes, I. F., \& Eijsink, V. G. H. (1999). Regulation of group II peptide bacteriocin synthesis by quorum-sensing mechanisms. In G. M. Dunny, \& S. C. Winans (Eds.), Cell-cell signalling in bacteria (pp. 175-192). American Society for Microbiology.

Nilsen, T., Nes, I. F., \& Holo, H. (1998). Na exported inducer peptide regulates bacteriocin production in Enterococcus faecium CTC 492. Journal of Bacteriology, $180,1848-1854$ 
Oguntoyinbo, F. A., \& Narbad, A. (2012). Molecular characterization of lactic acid bacteria and in situ amylase expression during traditional fermentation of cereal foods. Food Microbiology, 31, 254-262.

O'Mahony, T., Rekhif, N., Cavadini, C., \& Fitzgerald, G. F. (2001). The application of a fermented food ingredient containing 'variacin', a novel antimicrobial produced by Kocuria varians, to control the growth of Bacillus cereus in chilled dairy products. Journal of Applied Microbiology, 90, 106-114.

O’Sullivan, L., Ryan, M. P., Ross, R. P., \& Hill, C. (2003). Generation of foodgrade lactoccal starters which produce the lantibiotics lacticin 3147 and lacticin 481. Journal of Applied and Environmental Microbiology, 69, 36813685.

Parente, E., \& Ricciardi, A. (1999). Production, recovery and purification of bacteriocins from lactic acid bacteria. Journal of Applied Microbiology and Biotechnology, 52, 628-638.

Phillips, J. D., Griffths, M. W., \& Muir, D. D. (1983). Effect of nisin on the shelf-life of pasteurized double cream. The Journal of the Society of the Dairy Technology, 36, 17-21.

Pons, A. M., Lanneluc, I., Cottenceau, G., \& Sable, S. (2002). New developments in non-post translationally modified microcins. Biochimie, 84, 531-537.

Prioult, G., Turcotte, C., Labarre, L., Lacroix, C., \& Fliss, I. (2000). Rapid purification of nisin $\mathrm{Z}$ using specific monoclonal antibody-coated magnetic beads. International Dairy Journal, 10, 627-633.

Rilla, N., Martinez, B., \& Rodriguez, A. (2004). Inhibition of a methicillin-resistant Staphylococcus aureus strain in Afuega'I Pitu cheese by the nisin Z producing strain Lactococcus lactis lactis IPLA 729. Journal of Food Protection, 67, 928-933.

Rink, R., Kluskens, L. D., Kuipers, A., Driessen, A. J., Kuipers, O. P., \& Moll, G. N. (2007). NisC, the cyclase of the lantibiotic nisin, can catalyze cyclization of designed nonlantibiotic peptides. Biochemistry, 46, 13179-13189.

Rollema, H. S., Kuipers, O. P., Both, P., De Vos, W. M., \& Siezen, R. J. (1995) Improvement of solubility and stability of the antimicrobial peptide nisin by protein engineering. Journal of Applied and Environmental Microbiology, 61, 2873-2878.

Ross, R. P., Morgan, S., \& Hill, C. (2002). Preservation and fermentation: past, present and future. International Journal of Food Microbiology, 79, 3-16.

Ryan, M. P., Mcauliffe, O., Ross, R. P., \& Hill, C. (2001). Heterologous expression of lacticin 3147 in Enterococcus faecalis: comparison of biological activity with cytolysin. Letters in Applied Microbiology, 32, 71-77.

Sarantinopoulos, P., Leroy, F., Leontopoulou, E., Georgalaki, M. D., Kalantzopoulos, G., Tsakalidou, E., et al. (2002). Bacteriocin production by Enterococcus faecium FAIR-E 198 in view of its application as adjunct starter in Greek Feta cheese making. International Journal of Food Microbiology, 72, 125-136.

Schillinger, U., Geisen, R., \& Holzapfel, W. H. (1996). Potential of antagonistic microorganisms and bacteriocins for the biological preservation of foods. Trends Food Science and Technology, 7(5), 158-164.
Sherley, M., Gordon, D. M., \& Collignon, P. J. (2000). Variations in antibiotic resistance profile in Enterobacteriaceae isolated from wild Australian mammals. Environmental Microbiology, 2, 620-631.

da Silva-Malheiros, P., Daroit, D. J., da Silveira, N. P., \& Brandelli, A. (2010). Effect of nanovesicle-encapsulated nisin on growth of Listeria monocytogenes in milk. Food Microbiology, 27, 175-178.

Simha, B. V., Sood, S. K., Kumariya, R., \& Garsa, A. K. (2012). Simple and rapid purification of pediocin PA-1 from Pediococcus pentosaceous NCDC 273 suitable for industrial application. Microbiological Research, . http://dx.doi.org/10.1016/ j.micres.2012.01.001.

Songisepp, E., Hütt, P., Rätsep, M., Shkut, E., Kõljalg, S., Truusalu, K., et al. (2012) Safety of a probiotic cheese containing Lactobacillus plantarum Tensia according to a variety of health indices in different age groups. Journal of Dairy Science, 95 , 5495-5509.

Stiles, M. E. (1996). Biopreservation by lactic acid bacteria. Antonie Van Leeuwenhoek, 70, 331-345.

Suda, S., Westerbeek, A., O'Connor, P. M., Ross, R. P., Hill, C., \& Cotter, P. D. (2010). Effect of bioengineering lacticin 3147 lanthionine bridges on specific activity and resistance to heat and proteases. Chemistry $\mathcal{E}$ Biology, 17, 1151-1160.

Taneja, N., Rani, P., Emmanuel, R., Khudaier, B. Y., Sharma, S. K., Tewari, R., et al. (2005). Nosocomial urinary tract infection due to Leuconostoc mesenteroides at a tertiary care centre in north india. Indian Journal of Medical Research, 122 $178-179$.

Twomey, D., Ross, R. P., Ryan, M., Meaney, B., \& Hill, C. (2002). Lantibiotics produced by lactic acid bacteria: structure, function and applications. Antonie Van Leeuwenhoek, 82, 165-185.

Vadyvaloo, V., Hastings, J. W., Van Der Merwe, M. J., \& Rautenbach, M. (2002) Membranes of class Ila bacteriocin-resistant $L$. monocytogenes cells contain increased levels of desaturated and snort-acyl-chain phosphatidylglycerols. Applied and Environmental Microbiology, 68, 5223-5230.

Van Houten, M. A., Luinge, K., Laseur, M., \& Kimpen, J. L. (1998). Antibiotic utilisation for hospitalised paediatric patients. International Journal of Antimicrobial Agents, 10, 161-164.

Van Schaik, W., Gahan, C. G., \& Hill, C. (1999). Acid-adapted Listeria monocytogenes displays enhanced tolerance against the lantiobiotics nisin and lacticin 3147 Journal of Food Protection, 62, 536-540.

Vaucher, R. A., Gewehr, C. C. V., Correa, A. P. F., Sant'Anna, V., Ferreira, J., \& Brandelli, A. (2011). Evaluation of the immunogenicity and in vivo toxicity of the antimicrobial peptide P34. International Journal of Pharmaceutics, 421, 94-98.

Wester, C. W., Durairaj, L., Evans, A. T., Schwartz, D. N., Husain, S., \& Martinez, E. (2002). Antibiotic resistance - a survey of physician perceptions. Archives of Internal Medicine, 162, 2210-2216.

Yuan, J., Zhang, Z. Z., Chen, X. Z., Yang, W., \& Huan, L. D. (2004). Site-directed mutagenesis of the hinge region of nisin $\mathrm{Z}$ and properties of nisin $\mathrm{Z}$ mutants. Applied Microbiology and Biotechnology, 64, 806-815. 
Research review paper

\title{
Bacteriocin production by Bifidobacterium spp. A review
}

\author{
Fabio Andres Castillo Martinez a , Eduardo Marcos Balciunas a , Attilio Converti ${ }^{\text {b }}$, Paul D. Cotter ${ }^{\text {, }}$, \\ Ricardo Pinheiro de Souza Oliveira ${ }^{\mathrm{a}, *}$ \\ a Biochemical and Pharmaceutical Technology Department, Faculty of Pharmaceutical Sciences, University of São Paulo, Av. Lineu Prestes 580, São Paulo 05508-900, Brazil \\ ${ }^{\mathrm{b}}$ Department of Civil, Chemical and Environmental Engineering, Pole of Chemical Engineering, Genoa University, I-16145 Genoa, Italy \\ c Teagasc Food Research Centre, Moorepark, Fermoy and Alimentary Pharmabiotic Centre, Cork, Ireland
}

\section{A R T I C L E I N F O}

\section{Article history:}

Received 4 December 2012

Received in revised form 24 January 2013

Accepted 24 January 2013

Available online 4 February 2013

\section{Keywords:}

Bacteriocins

Bifidobacterium spp.

Antimicrobial compounds

Lactic acid bacteria

\begin{abstract}
A B S T R A C T
Bacteriocins are ribosomally-synthesized antibacterial peptides. These compounds are produced by a broad variety of different bacteria belonging mainly to the genus Bifidobacterium, to which health promoting properties have frequently been attributed. However, despite the fact that the identification of Bifidobacteriumassociated bacteriocins was first reported in 1980 and that they exhibit antimicrobial activity against pathogenic microorganisms such as Listeria monocytogenes, Clostridium perfringens, and Escherichia coli, relatively little information is still available about the antimicrobial compounds produced by strains of this genus. More detailed understanding of the action mechanisms of these antimicrobials could allow us to determine the extent to which their production contributes to the probiotic properties of specific bifidobacteria strains and, potentially, be of crucial significance for ultimate preservation of functional foods or pharmaceutical applications. Here we review what is already known about their structure, classification, mode of action, functionality, immunity, production and purification.
\end{abstract}

(C) 2013 Elsevier Inc. All rights reserved.

\section{Contents}

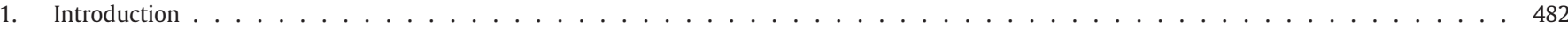

2. Antimicrobial compounds from Bifidobacterium spp. . . . . . . . . . . . . . . . . . . . . . . . . . . . . . 483

2.1. Antimicrobial compounds: production time and phases . . . . . . . . . . . . . . . . . . . . . . . . . . . . . . . . . . . . . .

2.2. Antimicrobial compounds: enzymes, $\mathrm{pH}$ and heat stability . . . . . . . . . . . . . . . . . . . . . . . . . . . . . 484

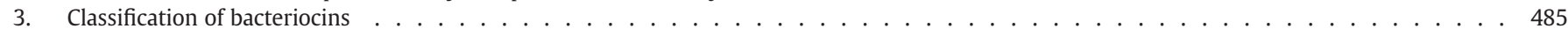

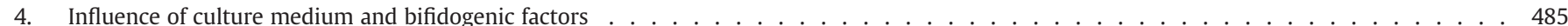

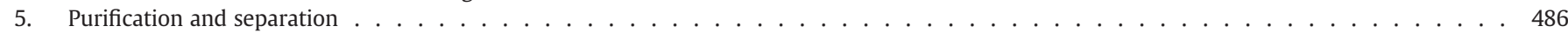

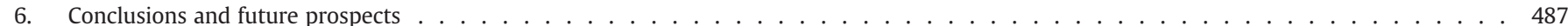

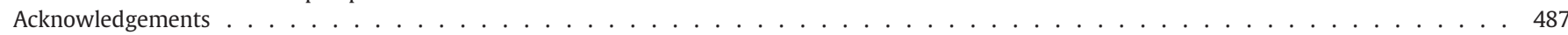

References $\ldots \ldots \ldots \ldots$

\section{Introduction}

Bifidobacteria are high GC, Gram-positive, non-spore-forming, non-motile and catalase-negative anaerobic bacteria belonging to the phylum of Actinobacteria (Ishibashi et al., 1997). They are able to ferment glucose to lactic and acetic acids via a metabolic pathway that is characterized by the presence of the enzyme fructose-6-phosphate phosphoketolase (F6PPK) (Ballongue, 2004; Gomes and Malcata, 1999). These microorganisms were first isolated by Tissier (1900),

\footnotetext{
* Corresponding author. Tel.: +55 113091 0123; fax: +55 1138156386 .

E-mail address: rpsolive@usp.br (R.P. de Souza Oliveira).
}

described as pleomorphic rods with different shapes, including curved, short and bifurcated Y shapes, and initially classified as Bacillus bifidus communis. Subsequently, they were renamed Lactobacillus bifidus before De Vries and Stouthamer (1967) suggested that they should be reclassified as a distinct genus (Bifidobacterium) because of the presence of F6PPK and the simultaneous absence of glucose-6-phosphatase dehydrogenase and aldolase, i.e. two enzymes present in lactobacilli (Ballongue, 2004; Cheikhyoussef et al., 2008; Ishibashi et al., 1997).

Bifidobacteria are an important group of human gut commensal bacteria, accounting for around $3-7 \%$ of the microbiota in adults and, according to some reports, up to $91 \%$ in newborns (Ballongue, 2004; Cheikhyoussef et al., 2009a). Some strains of Bifidobacterium 
possess traits that have resulted in them being employed as probiotics. According to the Food and Agriculture Organization (FAO) and the World Health Organization (WHO) (FAO/WHO, 2001), probiotics are living microorganisms that, when ingested in sufficient quantities, exert health-promoting benefits to the host. Among the many probiotic traits that have been attributed to bifidobacteria are a) the induction of immunoglobulin production, b) improvement of food nutritional value by assimilation of substrates not metabolized by the host, c) anti-carcinogenic activity and d) folic acid synthesis (Bevilacqua et al., 2003; Cheikhyoussef et al., 2009a; Collado et al., 2005a; Gomes and Malcata, 1999; Touré et al., 2003). Interestingly for the purposes of this review, some bifidobacteria are also known to produce antimicrobials (Cheikhyoussef et al., 2009b; Gibson and Wang, 1994b; Gomes and Malcata, 1999; Ibrahim and Salameh, 2001) and, more specifically, bacteriocins (Anand et al., 1984, 1985; Cheikhyoussef et al., 2010; von Ah, 2006; Yildirim and Johnson, 1998; Yildirim et al., 1999).

Bacteriocins are ribosomally-synthesized antimicrobial peptides produced by bacteria that are active against other bacteria, either belonging to the same species (narrow spectrum) or even across genera (broad spectrum). Producing organisms are immune to their own bacteriocin(s), a property that is mediated by specific immunity proteins (Cotter et al., 2005b). Bacteriocin production takes place most frequently during the late exponential or early stationary phases of growth, is often influenced by quorum sensing and stress signaling (Klaenhammer, 1988; Kotelnikova and Gelfand, 2002; Riley and Chavan, 2007; Tagg et al., 1976), and is regarded as a probiotic trait (Dobson et al., 2012; O'Shea et al., 2012) contributing to the suppression of intestinal pathogens. In addition, the rise in demand for natural foods that do not contain chemical preservatives has increased the interest in their application as preservatives to ensure food quality and safety. Since the discovery of bacteriocins (Cascales et al., 2007; Cotter et al., 2005a), in-depth studies have been undertaken to get detailed information on their physicochemical properties, mechanisms of action and genetic determinants (Cotter et al., 2005a; Drider et al., 2006; Ennahar et al., 2000; Riley and Wertz, 2002; Tagg et al., 1976), all of which are of great significance for the ongoing attempts to commercialize them more extensively. A considerable part of research on bacteriocins has focused on the production and investigation of peptides from lactic acid bacteria (LAB) such as Lactococcus spp., Leuconostoc spp., Enterococcus spp., and Pediococcus spp., with a view to their potential application as natural preservatives of foods (Cheikhyoussef et al., 2009a; Deegan et al., 2006; Riley and Chavan, 2007). Despite the potential of bifidobacteria to suppress the growth of both Gram-negative and Gram-positive bacteria, their ability to produce bacteriocins has so far been underestimated, being their antimicrobial activity often ascribed to the inhibitory action of organic acids and the related pH decrease (Ballongue, 2004; Makras and De Vuyst, 2006; von Ah, 2006). However, exceptions exist.

Here we review the literature relating to bifidobacteria able to produce bacteriocins, with a focus on their distinctive features, factors influencing their production, purification, mechanisms of action and classification.

\section{Antimicrobial compounds from Bifidobacterium spp.}

Bifidobacteria have the capacity to synthesize organic acids and other antimicrobial compounds such as bacteriocins. Although some reports have suggested that the production of organic acids, via the heterofermentative pathways, is partially responsible for the inhibitory activity of bifidobacteria (Bruno and Shah, 2002; Ibrahim and Salameh, 2001), it is well accepted that at least some bifidobacteria also produce bacteriocins. In some cases, the antimicrobial activity was associated with the production of peptides, but the exact nature of the active substance was not determined (Anand et al., 1984, 1985; Bernet et al., 1993; Liévin et al., 2000; Meghrous et al., 1990); in other cases, the peptides involved were definitively identified.
Table 1 contains a list of known Bifidobacterium-associated bacteriocins and putative bacteriocins as well as their main characteristics. In general, it can be stated that research of Bifidobacterium-associated bacteriocins has been relatively unsatisfying and has provided more questions than answers. The following paragraphs provide information regarding a significant number of putative bacteriocins about which frustratingly little is known.

The first putative Bifidobacterium-associated bacteriocin found is bifidin produced by Bifidobacterium bifidum NCDC 1452 . The antimicrobial activity of this strain was found to be the greatest when grown in skim milk, and from this medium it was extracted with methanol-acetone and partially purified by Sephadex G-15 chromatography. The purified product was refrigerated for 3 months or more without exhibiting any activity loss (Anand et al., 1984, 1985). Amino acid analysis of the peptide revealed high contents of phenylalanine and glutamic acid and, in less extent, threonine, aspartic acid, serine, glycine, proline, isoleucine and leucine. However, the study on bifidin did not progress since the mid-1980s.

A number of years later, Kang et al. (1989) described a Bifidobacterium longum strain that produced an uncharacterized antimicrobial, referred to as bifilong, that inhibited some Gram-negative and Gram-positive bacteria and was stable over a pH range of 2.5 to 5.0. Similarly, Meghrous et al. (1990) discovered thermoresistant proteinaceous compounds in the supernatant of B. bifidum cultures, which inhibited the growth of Streptococcus, Lactococcus and Clostridium spp. However, as the authors were specifically targeting antimicrobials able to inhibit Gram-negative bacteria, the active compounds were not isolated. Liévin et al. (2000) were successful in demonstrating the antiSalmonella typhimurium activity of a highly lipophilic, low molecular weight ( $<3500 \mathrm{Da})$ compound produced by Bifidobacterium strains, which was precipitated with ammonium sulfate and partially purified by methanol-chloroform extraction and dialysis. However, once again, this compound was not further characterized. Following the same theme, Toure et al. (2003) isolated bifidobacteria strains from infants that displayed antagonistic activity against Listeria monocytogenes. Using methanol-acetone extraction, they purified the most hydrophilic proteinaceous antimicrobials, which were found to be resistant to high temperature $\left(100{ }^{\circ} \mathrm{C}\right.$ for $\left.5 \mathrm{~min}\right)$ but sensitive to proteases. Saleh and El-Sayed (2004) provided a somewhat more detailed report on the production, in MRS broth with $0.05 \%$ L-cysteine. $\mathrm{HCl}$, of putative bacteriocins, designated as bifilact $\mathrm{Bb}-12$ and bifilong Bb-46, by Bifidobacterium lactis $\mathrm{Bb}-12$ and $\mathrm{B}$. longum $\mathrm{Bb}-46$, respectively. These two bacteriocins were shown to exhibit strong activity against Staphylococcus aureus, S. typhimurium, Bacillus cereus and Escherichia coli. While the minimal inhibition concentrations (MICs) of partially purified bifilact Bb-12 and bifilong Bb-46 were found to be 40 and $20 \mathrm{mg} / \mathrm{mL}$ for $S$. aureus and 20 and $16 \mathrm{mg} / \mathrm{mL}$ for E. coli, respectively, one can expect that purified peptides, if obtained, would be even more active. Additional antimicrobials from six Bifidobacterium strains were found to exhibit broad inhibitory spectra against both Gram-negative and Gram-positive bacteria, namely Clostridium difficile, Brochothrix thermosphacta, L. monocytogenes, S. aureus, Helicobacter pylori, S. typhimurium, Arcobacter butzleri, and some pathogenic yeasts. These heat-stable compounds were sensitive to proteinases and resistant to $\mathrm{pH}$ in the range from 3 to 10 (Collado et al., 2005b), but were neither purified nor subject to further investigation. Finally, von Ah (2006) identified, recovered by methanol/acetone extraction and reversed-phase HPLC and partly characterized thermophilicin B67, a bacteriocin produced by Bifidobacterium thermophilum RBL67 that exhibited a narrow inhibition spectrum towards three Listeria strains and Lactobacillus acidophilus.

Ultimately, despite the many reports on Bifidobacterium-associated bacteriocins, bifidocin B from B. bifidum NCFB 1454 (Yildirim et al., 1999), bifidin I from Bifidobacterium infantis BCRC 14602 (partially sequenced) (Cheikhyoussef et al., 2010) and the lantibiotic bisin from B. longum DJO10A are the only bacteriocins that were in-depth 
Table 1

Bacteriocins from Bifidobacterium spp. and their main characteristics.

\begin{tabular}{|c|c|c|c|c|c|c|c|c|}
\hline Bacteriocin & $\begin{array}{l}\text { Species and } \\
\text { strain }\end{array}$ & $\begin{array}{l}\text { Mol. wt. } \\
\text { (kDa) }\end{array}$ & $\begin{array}{l}\text { Heat range } \\
\text { stability }\end{array}$ & $\begin{array}{l}\text { pH range } \\
\text { stability }\end{array}$ & $\begin{array}{l}\text { Production } \\
\text { phase }\end{array}$ & $\begin{array}{l}\text { Optimal } \\
\text { production }\end{array}$ & Inhibitory spectrum & Reference \\
\hline Bifidin & $\begin{array}{l}\text { B. bifidum } \\
\text { NCDC } 1452\end{array}$ & $(-)$ & $\left(100{ }^{\circ} \mathrm{C}-30 \mathrm{~min}\right)$ & $4.8-5.5$ & After $48 \mathrm{~h}$ & pH: 4.8 & $\begin{array}{l}\text { Gram-positive and Gram-negative } \\
\text { bacteria }\end{array}$ & $\begin{array}{l}\text { Anand et al. } \\
(1984,1985)\end{array}$ \\
\hline Bifidocin B & $\begin{array}{l}\text { B. bifidum } \\
\text { NCFB } 1454\end{array}$ & 3.3 & $\left(121^{\circ} \mathrm{C}-15 \mathrm{~min}\right)$ & $2-12$ & $(12-18 \mathrm{~h})$ & $\begin{array}{l}37^{\circ} \mathrm{C}, \\
\mathrm{pH} 5.0-6.0\end{array}$ & $\begin{array}{l}\text { Bacillus cereus, Enterococcus faecalis, } \\
\text { Listeria monocytogenes, Pediococcus } \\
\text { acidolactici, Streptococcus faecalis, etc. }\end{array}$ & $\begin{array}{l}\text { Yildirim and Johnson } \\
\text { (1998); Yildirim et al. } \\
\text { (1999) }\end{array}$ \\
\hline Bifilong & B. longum & 120 & $\left(100{ }^{\circ} \mathrm{C}-30 \mathrm{~min}\right)$ & $2.5-5.0$ & $(-)$ & $(-)$ & $\begin{array}{l}\text { Gram-positive and Gram-negative } \\
\text { bacteria }\end{array}$ & Kang et al. (1989) \\
\hline Bifilact Bb-46 & $\begin{array}{l}\text { B. longum } \\
\text { Bb-46 }\end{array}$ & $25-127$ & $\left(121{ }^{\circ} \mathrm{C}-15 \mathrm{~min}\right)$ & $4-7$ & $(-)$ & $(-)$ & $\begin{array}{l}\text { Staphylococcus aureus, Salmonella } \\
\text { typhimurium, Bacillus cereus, E. coli }\end{array}$ & $\begin{array}{l}\text { Saleh and El-Sayed } \\
(2004)\end{array}$ \\
\hline Bifilact Bb-12 & B. lactis Bb-12 & $25-89$ & $\begin{array}{l}\text { Unstable for high } \\
\text { temperatures }\end{array}$ & $4-7$ & $(-)$ & $(-)$ & $\begin{array}{l}\text { Staphylococcus aureus, Salmonella } \\
\text { typhimurium, Bacillus cereus, E. coli }\end{array}$ & $\begin{array}{l}\text { Saleh and El-Sayed } \\
\text { (2004) }\end{array}$ \\
\hline $\begin{array}{l}\text { Thermophilicin } \\
\text { B67 }\end{array}$ & $\begin{array}{l}\text { B. thermophilum } \\
\text { RBL67 }\end{array}$ & $5-6$ & $\left(100{ }^{\circ} \mathrm{C}-5 \mathrm{~min}\right)$ & $2-10$ & $24 \mathrm{~h}$ & $\begin{array}{l}\mathrm{pH} 6 \text { and } \\
40{ }^{\circ} \mathrm{C}\end{array}$ & Listeria sp., Lactobacillus acidophilus & von Ah (2006) \\
\hline Bifidin I & $\begin{array}{l}\text { B. infantis BCRC } \\
14602\end{array}$ & 3 & $\left(121{ }^{\circ} \mathrm{C}-15 \mathrm{~min}\right)$ & $4-10$ & $18 \mathrm{~h}$ & $(-)$ & $\begin{array}{l}\text { LAB strains, Staphylococcus, Bacillus, } \\
\text { Streptococcus, Salmonella, Shigella, E. coli. }\end{array}$ & $\begin{array}{l}\text { Cheikhyoussef } \\
\text { et al. (2009a, 2010) }\end{array}$ \\
\hline $\begin{array}{l}\text { Lantibiotic } \\
\quad \text { (Bisin) }\end{array}$ & B. longum DJO10A & $(-)$ & $(-)$ & $(-)$ & $1-8 \mathrm{~h}$ & $\begin{array}{l}\text { Auto-induction } \\
\text { by crude } \\
\text { lantibiotic }\end{array}$ & $\begin{array}{l}\text { Streptococcus thermophilus ST403, } \\
\text { Clostridium perfringens, Staphylococcus } \\
\text { epidermidis, Bacillus subtilis, Serratia } \\
\text { marcescens, E. coli DH5a. }\end{array}$ & Lee et al. (2011) \\
\hline
\end{tabular}

(-): not available.

characterized and whose amino acid sequence was at least partially elucidated. The (predicted) amino acid sequence of these bacteriocins is shown in Table 2. Bifidocin B and bifidin I show homology in the $\mathrm{N}$-terminal region to Class Ila bacteriocins, also known as pediocin PA1-like bacteriocins (bacteriocin classification is detailed in Section 3), which contain a -Tyr-Gly-Asn-Gly-Val-Xaa-Cys (or YGNGV) consensus region and that are known for their potent antilisterial activity (Drider et al., 2006; Lozano et al., 1992). Bifidocin B is produced by B. bifidum NCFB 1454 and shows activity against Listeria, Lactobacillus, Enterococcus, Pediococcus, Staphylococcus, Clostridium, Leuconostoc and Bacillus strains (Yildirim and Johnson, 1998). Its bactericidal activity brought about a 99\% decrease in $\mathrm{CFU} / \mathrm{mL}$ of all these sensitive indicator strains after only 30 min (Cheikhyoussef et al., 2009a; Yildirim et al., 1999). Bifidin I was purified in 2010 by Cheikhyoussef and coworkers from B. infantis BCRC 14602 I using a three-step purification procedure. Initial studies, using Lactobacillus plantarum BCRC 11697 as a target, established that bifidin I (1000 Activity Units [AU]/mL) brought about 93 and 95\% growth inhibition after 2 and 6 h, respectively (Cheikhyoussef et al., 2009a). Further investigations established that bifidin I has a broad activity spectrum, including Gram-positive bacteria such as Streptococcus, Staphylococcus and Clostridium, and Gram-negative ones such as Salmonella, Shigella and E. coli (Cheikhyoussef et al., 2009b). Bisin was found to be effective against several indicator strains of Streptococcus thermophilus, Bacillus subtilis, Serratia marcescens and S. aureus, among others (Lee et al., 2008, 2011).

Therefore, since some of these bacteriocins may affect starter and probiotic cultures, care should be taken when selecting bacteriocin producing strains for inclusion in fermented foods, to make sure that pathogens rather than important LABs are the targets of their bacteriocins.

\subsection{Antimicrobial compounds: production time and phases}

The production of bacteriocins is generally associated with late logarithmic phase and early stationary phase of growth, but the concentrations obtained are often low, which makes their purification and subsequent application difficult. Therefore, a precise knowledge of the growth phase during which bacteriocin production is optimal can be critical. Unfortunately, since bacteriocin producing bifidobacteria can be grown in a variety of different growth media (the importance of which is highlighted below) and the activity of bacteriocins is measured in a number of different ways (different indicator microorganisms, assays etc.), a systematic comparison between different studies on bacteriocin production is quite difficult (Pongtharangkul and Demirci, 2004; von Ah, 2006). Although considerable variation exists, it is not possible to ascertain to what extent it is the result of different producing strains or assays employed. For instance, the antimicrobial production by B. bifidum NCDC 1452 appeared after $30 \mathrm{~h}$ of growth and reached a maximum after $48 \mathrm{~h}$ (Anand et al., 1985), whereas bifidocin B was produced by B. bifidum NCFB 1454 between the late logarithmic and early stationary phases (12-18 h) (Cheikhyoussef et al., 2008) and decreased in concentration along the stationary one (by 50 and $75 \%$ after 18 and $72 \mathrm{~h}$, respectively) (Yildirim and Johnson, 1998). Furthermore, Collado et al. (2005a) observed that, in the presence of Tween 80 , the antimicrobial activity of a variety of different Bifidobacterium strains reached a maximum in the early stationary phase (around $16 \mathrm{~h}$ of fermentation) but decreased or was absent thereafter (Deraz et al., 2005). Thus, while there is a general consensus with respect to the importance of the growth phase, the time lasted by a specific bacteriocin-producing strain to enter the idiophase can be quite variable.

\subsection{Antimicrobial compounds: enzymes, $\mathrm{pH}$ and heat stability}

The characteristics of Bifidobacterium-associated bacteriocins can vary considerably as shown in the following and more synthetically in Table 1. Bifidin from B. bifidum NCDC 1452 was optimally produced at $\mathrm{pH} 4.8$, displayed maximal inhibitory potential between 4.8 and 5.5 , and was stable even after exposure to $100{ }^{\circ} \mathrm{C}$ for $30 \mathrm{~min}$

Table 2

The (predicted) amino acids sequence of Bifidobacterium spp. bacteriocins.

\begin{tabular}{|c|c|c|c|}
\hline Bacteriocin & Amino acid sequence & Amino acid residues & References \\
\hline Bifidin I & KYGDVPLY (partial sequence) & Unknown & Cheikhyoussef et al. (2010) \\
\hline Bifidocin B & KYYGNGVTCGLHDCRVDRGKATCGIINNGGMWGDIG & 36 & Yildirim et al. (1999) \\
\hline Bisin prepeptide & MSINEKSIVGESFEDLSAADMAMLTGRNDDGVAPASLSFAVSVLSVSFSACSVTVVTRLASCGNCK & $66^{\mathrm{a}}$ & Lee et al. (2011) \\
\hline
\end{tabular}

\footnotetext{
a Prior to leader cleavage.
} 
(Anand et al., 1984, 1985). Bifidocin B from B. bifidum NCFB 1454 retained its biological activity between $\mathrm{pH} 2$ and 12 and was more stable under acidic than alkaline conditions. Whereas it retained full activity when stored at $-20{ }^{\circ} \mathrm{C}$ or $-70{ }^{\circ} \mathrm{C}$ for 1 or 3 months, a decrease from 51,200 to $30,000 \mathrm{AU} / \mathrm{mL}$ took place when samples were stored at $-4{ }^{\circ} \mathrm{C}$ for $1-3$ months, and 25 and $50 \%$ activity decreases were observed when crude extracts were heated at $90{ }^{\circ} \mathrm{C}$ for 30 and $60 \mathrm{~min}$, respectively (Yildirim and Johnson, 1998; Yildirim et al., 1999). Bifidocin B was also found to be inactivated by proteases such as trypsin, $\alpha$-chymotrypsin, papain, or pepsin, whereas lysozyme, ribonuclease A, glucose oxidase, lipase, amylase, dextranase and catalase had no effect (Yildirim and Johnson, 1998). Bifidin I from B. infantis BCRC 14602 was found to be stable over wide ranges of $\mathrm{pH}$ (from 4 to 10 , maximum activity at $\mathrm{pH} 4.8$ ) and temperature (30 min at $50{ }^{\circ} \mathrm{C}$ and $15 \mathrm{~min}$ at $121{ }^{\circ} \mathrm{C}$ ), but was totally inactivated by protease and proteinase $\mathrm{K}$, partially inactivated by alcalase 2.4 LFG (50\% activity reduction) and almost not affected by $\alpha$-amylase, lysozyme and lipase (Cheikhyoussef et al., 2009a). The activities of bifilact Bb-12 from B. lactis Bb-12 and bifilong Bb-46 from B. longum $\mathrm{Bb}-46$ reached optimum values at $\mathrm{pH} 4$ and 7 and decreased at $\mathrm{pH} \leq 3$ and $\geq 9$, respectively, at $-20^{\circ} \mathrm{C}$ for $24 \mathrm{~h}$ or when sterilized at $121{ }^{\circ} \mathrm{C}$ for $15 \mathrm{~min}$. In addition, although resistant to $\alpha$-amylase or lipase, these antimicrobials were found to be sensitive to pepsin and trypsin (Saleh and El-Sayed, 2004). Finally, thermophilicin B67 from $B$. thermophilum RBL 67 showed activity over broad ranges of $\mathrm{pH}$ (4-8) and temperature $\left(25-47{ }^{\circ} \mathrm{C}\right)$, with a maximum $(256 \mathrm{AU} / \mathrm{mL})$ at pH 5.5 and $35^{\circ} \mathrm{C}$ (von Ah, 2006).

\section{Classification of bacteriocins}

Bacteriocins can be classified into two main classes (Cotter et al., 2005b). Class I (molecular weight $<5 \mathrm{kDa}$ ) includes the lantibiotics and are distinguished by the fact they undergo post-translational modification. Class II bacteriocins are unmodified peptides that can be divided into four subgroups, i.e. Class IIa-d. Class IIa (or pediocin PA1-like) peptides often exhibit potent antilisterial activity, consist of 37 to 48 amino acids and are positively charged (Drider et al., 2006). These bacteriocins share a conserved sequence motif in their $\mathrm{N}$-terminal region consisting of Tyr-Gly-Asn-Gly-Val-X-Cys-XXXXVal-X-Val (or YGNGVXCXXXXVXV, with X being any amino acid), which is stabilized by two cysteines forming a disulfide bridge, and a hydrophobic and/or amphiphilic C-terminal part consisting of one or two $\alpha$-helices (Eijsink et al., 2002; von Ah, 2006). Bifidocin B from $B$. bifidum NCFB 1454 belongs to this class of bacteriocins having a N-terminal domain containing a Tyr-Gly-Asn-Gly-Val-X-Cys motif (Yildirim et al., 1999), while bifidin I from B. infantis BCRC 146, whose N-terminal domain although not completely sequenced contains a similar, but distinct Tyr-Gly-Asp-Val stretch (Cheikhyoussef et al., 2010), has its classification still under consideration (Table 2).

With regard to the $\mathrm{N}$-terminal motif of the class II peptides, residues Lys-1, Lys-11 and His-12 (or their equivalents) have been reported as mediators of non-specific bacteriocin binding to target membranes, while residues Val-7, Cys-9, Cys-14, Val-16 and Trp-18 to be involved in membrane insertion processes (Eijsink et al., 2002; Ennahar et al., 2000). Indeed, modifications in the consensus sequence drastically reduce bacteriocin activity (Drider et al., 2006). On the other hand, it has been suggested that the C-terminal region of pediocin-like bacteriocins is responsible for target cell specificity (Johnsen et al., 2005).

Lee et al. (2008) described the production of the Class I lantibiotic bisin by B. longum DJO10A, which was found to be effective against both Gram-positive and Gram-negative bacteria. Bisin is encoded by a typical lantibiotic-associated gene cluster consisting of genes encoding, in two-component signal transduction system (lanR2 and $\operatorname{lan} K)$, a lantibiotic prepeptide ( $\operatorname{lan} A)$, a lantibiotic response regulator (lanR1), lantibiotic modification enzymes (lanD and lanM), a lantibiotic immunity protein (lanI) and a lantibiotic transporter with predicted protease activity (lanT) (Lee et al., 2008, 2011). Its production was detected when the producing strain was grown on agar, but not in broth due to repression of lanA transcription; however, the lantibiotic, when added to broth (at 160 AU antimicrobial activity), acted as an induction factor improving the production. Interestingly, the bacteriocin-producing phenotype of this strain is quite unstable as the $10.2 \mathrm{~kb}$ gene cluster, located between two IS30 elements, can be lost during serial subculturing (Lee et al., 2008).

Although the bifidocin B gene cluster has still to be identified, it has been established, through the use of acriflavin and the isolation of mutants unable to produce the bacteriocin, that its production by B. bifidum NCFB 1454 is associated with a plasmid of about $8 \mathrm{~kb}$ in size, whereas this plasmid is not required for immunity or sugar fermentation. The presence of a gene encoding bifidocin $B$ on the $8 \mathrm{~kb}$ plasmid was confirmed by Southern blotting using an oligonucleotide based on the N-terminal amino acid sequence (Yildirim et al., 1999).

As noted above, there are several situations where further investigation is required to elucidate the nature of putative bacteriocins. In addition to peptides $(<10 \mathrm{kDa})$, there are some reports on larger antimicrobial proteins (bifilact Bb-46, bifilact Bb-12 and bifilong) (Cheikhyoussef et al., 2010; Collado et al., 2005a,b) that are potentially belonging to the bacteriolysin family of antimicrobials (Cotter et al., 2005b).

\section{Influence of culture medium and bifidogenic factors}

The availability of simple and inexpensive methods and reagents for the cultivation of Bifidobacterium spp. will be important for production of bacteriocins and their commercial applications. Most of Bifidobacterium-specific culture media have a complex composition, often containing antibiotics or induction factors, and imply long incubation times. Many nutritious culture media also negatively impact on the production of antimicrobials by the selected strains (Nebra and Blanch, 1999).

Bifidobacteria show high growth rates in rich synthetic media such as Trypticase-Peptone-Yeast extract (TPY) and MRS broths, but can also grow in simple media containing only lactose, free amino acids, mainly cysteine, glycine and tryptophan, and some nucleotides, vitamins and minerals (Gomes and Malcata, 1999). Ballongue (2004) highlighted the advantages of adding bifidogenic growth factors such as N-acetyl-D-glucosamine or cysteine, azide and China ink to MRS agar medium to differentiate bifidobacteria species, or vitamins such as pyridoxine (B6), thiamine (B1), cyanocobalamine (B12), folic acid (B9) and nicotinic acid (PP) or different selective agents such as polymyxin, propionate and linoleate. The control of magnesium, manganese and iron levels was shown to be essential for optimal growth of bifidobacteria or bacteriocin production, as a result of nutritional stress or induction, according to circumstances (Kang and Fung, 2000; O'Sullivan, 2001).

Most of bifidobacteria strains were also shown to grow effectively in milk-based media, which constitutes a great advantage taking in mind the high cost of synthetic media. So, several protein sources such as liver, meat or yeast extract, peptones, horse blood, tomato juice or human milk, along with antioxidant compounds such as cysteine, ascorbic acid, or sodium sulfite have also been successfully added to these media (Gomes and Malcata, 1999; Russell et al., 2011).

In addition to the components described above, many species of bifidobacteria can also utilize complex biopolymers able to improve cell growth and production of antimicrobials, including bifitose, fructooligosaccharides (FOS) and xylooligosaccharides, among others. These compounds, which are generally carbohydrates or their derivatives, are metabolized by bifidobacteria, but not by the host or the majority of other bacteria (Gomes and Malcata, 1999); among them, the different types of linear and branched FOS, oligofructose and 
lactulose-based oligosaccharides show particularly high induction rates. Dietary fibers have also been found to be effective in promoting the intestinal growth of bifidobacteria (Dubey and Mistry, 1996; Ishibashi et al., 1997). However, not all strains have the same nutritional requirements.

There are also a number of nutritional and biological factors that influence antimicrobial production by bifidobacteria including, as mentioned above, nutrient shortage as well as the presence of a competing microbiota (O'Shea et al., 2012). Touré et al. (2003) reported that a co-culture of $L$. monocytogenes and Bifidobacterium spp. was able to stimulate bacteriocin production by the latter and, in some cases, the addition of surfactants such as Tween 80 increased the concentration of bacteriocins produced as a consequence of cell growth acceleration. Surfactants may also enhance the sensitivity of the indicator strain and form micelles with proteinaceous compounds, thus stabilizing the bacteriocins (Carolissen-Mackay et al., 1997; Cheikhyoussef et al., 2008; Collado et al., 2005b).

Finally, bifidobacteria are usually cultivated under anaerobic conditions. However, some studies have reported that some strains of Bifidobacterium spp. can decompose and detoxify oxygen metabolites by certain enzymes such as superoxide dismutase and catalase, and that oxygen sensitivity differs according to the species or strains. Thus, several oxygen-tolerant bifidobacteria have been reported by various authors (Chou and Hou, 2000; Li et al., 2010; Yang et al., 1998).

\section{Purification and separation}

Bacteriocin purification is usually difficult because these low molecular weight, hydrophobic peptides are often produced only in small amounts (Berjeaud and Cenatiempo, 2004). From an industrial point of view, several bacteriocins have been purified and characterized (De Vuyst and Leroy, 2007), but no bacteriocin from Bifidobacterium spp. has yet been prepared on an industrial scale. Table 3 gives a summary of the approaches used to date to (partially) purify Bifidobacteriumassociated bacteriocins.

In many cases, the first step of the process is the precipitation of antimicrobials from culture supernatants usually adding ammonium sulfate. Such a salting out operation (60\% saturation) followed by chloroform-methanol extraction was successfully employed by Cheikhyoussef et al. (2008) to concentrate the antimicrobials present in cell free supernatants of two strains of bifidobacteria (CA1 and F9), yielding a product effective against $S$. typhimurium SL1344 and E. coli
C1845. Other alternatives include the use of acid or organic solvents as precipitating agents (Gibson and Wang, 1994a). Dialysis and ultrafiltration can also be used to further concentrate and purify bacteriocins, even though some Bifidobacterium-associated studies pointed out large product losses due to incomplete precipitation (Collado et al., 2005b; Liévin et al., 2000). The final purification step generally consists of reversed phase high-performance liquid chromatography (RP-HPLC) with acetonitrile gradient, which can be followed by sodium dodecyl sulfate-polyacrylamide gel electrophoresis (SDS-PAGE) or mass spectrometry for molecular size determination.

Bifidocin B from B. bifidum NCFB 1454 was purified by precipitation with $70 \%$ ammonium sulfate followed by dialysis through a 1000 molecular weight cutoff dialysis membrane, which resulted in an 18-fold increase in antimicrobial activity of the dialysis product $(58,200 \mathrm{AU} / \mathrm{mL})$ compared to the cell-free culture supernatant (3200 AU/mL) (Yildirim and Johnson, 1998). Subsequently, Yildirim et al. (1999) developed a purification method based on a rapid and simple three-step process including freeze drying, Micro-Cel adsorption/ desorption and cation exchange chromatography with a carboxymethyl cellulose column, which allowed increasing the specific activity from $285 \mathrm{AU} / \mathrm{mg}$ in the cell-free supernatant to $29,880 \mathrm{AU} / \mathrm{mg}$ after the Micro-Cel step, and to 540,000 AU/mg after the cation exchange chromatography, corresponding to a 1895-fold overall concentration effect (Table 3).

Bifidin I from $B$. infantis BCRC 14602 was partially purified by a two-step purification process (Table 3 ). Initial precipitation with ammonium sulfate, which resulted in an $80 \%$ yield and 4.56 -fold concentration, was followed by dialysis using a 1000 Da molecularweight cutoff and, finally, by freeze-drying. Such a process allowed obtaining a final preparation with specific activity of 31,605 AU/mg, corresponding to overall 120 -fold purification and $64 \%$ yield (Cheikhyoussef et al., 2009a). A new method has recently been developed by Cheikhyoussef et al. (2010), whereby bifidin I was purified/ concentrated by a three-step process. The purification protocol started with its recovery by adsorption/desorption onto/from silicic acid, which resulted in a preparation with specific activity of $67,696 \mathrm{AU} / \mathrm{mg}$, corresponding to 257 -fold concentration and $80 \%$ yield. This active preparation was then subject to cation exchange separation on SP-Sepharose at $\mathrm{pH} 7.6$ and final purification by RP-HPLC (in the process establishing the cationic nature of bifidin I), which allowed increasing the specific activity up to $115,315 \mathrm{AU} / \mathrm{mg}$ (64\% yield) and 36,571 AU/mg (25.6\% yield), corresponding to 438 and 1390 -fold concentrations, respectively.

Table 3

Summary of approaches taken to (partially) purify Bifidobacterium associated bacteriocins.

\begin{tabular}{|c|c|c|c|c|c|c|c|c|c|c|}
\hline $\begin{array}{l}\text { Bifidobacterium } \\
\text { species and strain }\end{array}$ & Bacteriocin & $\begin{array}{l}\text { Purification } \\
\text { steps }^{\text {a }}\end{array}$ & $\begin{array}{l}\text { Volume } \\
(\mathrm{mL})\end{array}$ & $\begin{array}{l}\text { Total } \\
\text { activity } \\
(\mathrm{AU})\end{array}$ & $\begin{array}{l}\text { Protein } \\
\text { concentration } \\
(\mathrm{mg} / \mathrm{mL})\end{array}$ & $\begin{array}{l}\text { Total protein } \\
(\mathrm{mg})\end{array}$ & $\begin{array}{l}\text { Specific activity } \\
(\mathrm{AU} / \mathrm{mg})\end{array}$ & $\begin{array}{l}\text { Purification } \\
\text { factor }\end{array}$ & Yield (\%) & Reference \\
\hline $\begin{array}{l}\text { B. bifidum NCFB } \\
1454\end{array}$ & Bifidocin B & ADPC & $(-)$ & $(-)$ & $(-)$ & $(-)$ & 58,200 & 18 & $(-)$ & $\begin{array}{l}\text { Yildirim and Johnson } \\
\text { (1998) }\end{array}$ \\
\hline \multirow{4}{*}{$\begin{array}{l}\text { B. bifidum NCFB } \\
1454\end{array}$} & \multirow[t]{4}{*}{ Bifidocin B } & CFCs & 1500 & $4,800,000$ & $(-)$ & 16,855 & 285 & 1 & 100 & \multirow[t]{4}{*}{ Yildirim et al. (1999) } \\
\hline & & FD & 150 & $4,704,000$ & $(-)$ & 16,774 & 281 & 0.99 & 98 & \\
\hline & & MC & 15 & $3,600,000$ & $(-)$ & 121 & 29,880 & 104 & 75 & \\
\hline & & CMC & 1.5 & 864,000 & $(-)$ & 1.6 & 540,000 & 1895 & 18 & \\
\hline \multirow{3}{*}{$\begin{array}{l}\text { B. thermophilum } \\
\text { RBL67 }\end{array}$} & Thermophilicin & CFCs & 2170 & 17,360 & 0.065 & 141.1 & 123 & 1 & 100 & \multirow[t]{3}{*}{ von Ah (2006) } \\
\hline & $\mathrm{B} 67$ & MEA & 217 & 17,344 & 0.532 & 115.4 & 120 & 1 & 99.9 & \\
\hline & & FD & 7 & 5971 & 0.416 & 2912 & 2051 & 16.7 & 34.4 & \\
\hline \multirow{3}{*}{$\begin{array}{l}\text { B. infantis BCRC } \\
14602\end{array}$} & Bifidin I & CFCs & 500 & $80 \times 10^{4}$ & $(-)$ & 3040 & 263 & 1 & 100 & \multirow{3}{*}{$\begin{array}{l}\text { Cheikhyoussef et al. } \\
\text { (2009b) }\end{array}$} \\
\hline & & FD & 50 & $64 \times 10^{4}$ & $(-)$ & 2800 & 228 & 0.86 & 80 & \\
\hline & & ADPC & 5 & $51 \times 10^{4}$ & $(-)$ & 16.2 & 31,605 & 120 & 64 & \\
\hline \multirow{4}{*}{$\begin{array}{l}\text { B. infantis BCRC } \\
14602\end{array}$} & Bifidin I & NCFS & 500 & 800,000 & $(-)$ & 3040 & 263 & 1 & 100 & \multirow{4}{*}{$\begin{array}{l}\text { Cheikhyoussef et al. } \\
\text { (2010) }\end{array}$} \\
\hline & & ADSA & 50 & 640,000 & $(-)$ & 9.44 & 67,696 & 257 & 80 & \\
\hline & & SPSFF & 5 & 512,000 & $(-)$ & 4.44 & 115,315 & 438 & 64 & \\
\hline & & RP-HPLC & 1 & 204,800 & $(-)$ & 0.56 & 365,714 & 1390 & 25.6 & \\
\hline
\end{tabular}

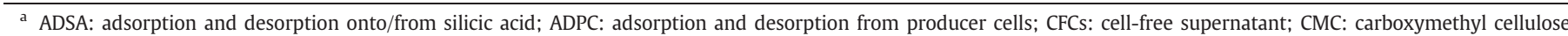

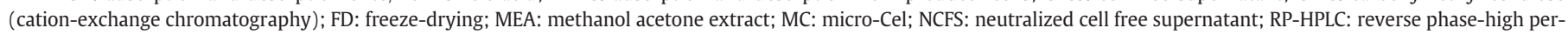
formance liquid chromatography; SPSFF: sulfopropyl sepharose fast flow; $(-)$ : not determined. 
Bifidin, bifilong (Kang et al., 1989) and thermophilicin B67 (von Ah, 2006) were also purified/concentrated from the cell free supernatants of producing strains using methanol-acetone extraction followed by partial purification by chromatographic methods (Anand et al., 1985). In the case of thermophilicin B67, the specific activity of the methanol-acetone extract $(853 \mathrm{AU} / \mathrm{mL})$ pointed out a 17 -fold purification compared with the freeze-dried supernatant (von Ah, 2006).

Finally, a crude lantibiotic preparation was collected from B. longum DJ010A agar cultures by methanol extraction and size fractionation. Although the lantibiotic activity $(160 \mathrm{AU} / \mathrm{mL})$ was low, it was sufficient for microtiter plate-based experiments (Lee et al., 2011).

Other nutritional factors can influence the purification process. For instance, high concentrations of peptides in the growth medium, resulting from the addition of beef or yeast extract, may interfere with various purification processes. Nonetheless, several investigations have demonstrated that the use of complex growth media with a high peptide content is necessary to ensure high bacteriocin productivity (Carolissen-Mackay et al., 1997), and thus a tradeoff is required. Similarly, if from one hand the addition of Tween 80 can enhance bacteriocin production, from the other it can affect the purification process through, for example, the formation of precipitates in the culture supernatants (Collado et al., 2005b).

\section{Conclusions and future prospects}

Despite the potential paramount importance and value of bacteriocin production by bifidobacteria, only a few of such bacteriocins have been purified and characterized. This review summarizes what is already known about Bifidobacterium-associated bacteriocins, with particular concern to those that have been explored in greatest depth, i.e. bifidocin B, bifidin I, thermophilicin B67 and bisin, thereby providing an overview of our understanding about their classification, mode of action, genetic determinants, spectra of activity and factors influencing their production. In addition, some bacteriocins from Bifidobacterium genus may affect starter and probiotic cultures; therefore, care must be taken when selecting bacteriocin producing strains for inclusion in fermented foods to make sure that important LABs are not the targets of their bacteriocins. The route of future application/ commercialization of these Bifidobacterium-associated bacteriocins, as well as those still to be identified, will be dependent on whether the application will involve the use of the producing strain as a probiotic or will require the peptides in a (partially) purified or concentrated form. Therefore, it is important to emphasize that it is necessary to deepen the study of bacteriocins produced by Bifidobacterium spp., which proved to advantageously contribute to functional food properties and pharmaceutical applications.

\section{Acknowledgements}

We are grateful for CAPES and FAPESP (process numbers 2011/ 50195-7 and 2011/14048-0) for financial support.

\section{References}

Anand SK, Srinivasan RA, Rao LK. Antimicrobial activity associated with Bifidobacterium bifidum-I. Cult Dairy Prod J 1984;2:6-7.

Anand SK, Srinivasan RA, Rao LK. Antibacterial activity associated with Bifidobacterium bifidum-II. Cult Dairy Prod J 1985;2:21-3.

Ballongue J. Bifidobacteria and probiotic action. In: Salminen S, von Wright A, Ouwehand A, editors. Lactic acid bacteria microbiological and functional aspects. New York: Marcel Dekker Inc.; 2004. p. 67-124.

Berjeaud JM, Cenatiempo Y. Purification of antilisterial bacteriocins. Methods Mol Bio 2004;268:225-33.

Bernet MF, Brassart D, Neeser JR, Servin AL. Adhesion of human bifidobacterial strain to cultured human intestinal epithelial cells and inhibition of enteropathogen-cell interactions. Appl Environ Microbiol 1993;59:4121-8.

Bevilacqua L, Ovidi M, Di Mattia E, Trovatelli LD, Canganella F. Screening of Bifidobacterium strains isolated from human faeces for antagonistic activities against potentially bacterial pathogens. Microbiol Res 2003;158:179-85.
Bruno F, Shah NP. Inhibition of pathogenic and putrefactive microorganisms by Bifidobacterium sp. Milchwissenschaft 2002;57:617-21.

Carolissen-Mackay V, Arendse G, Hastings JW. Purification of bacteriocins of lactic acid bacteria: problems and pointers. Int J Food Microbiol 1997;34:1-16.

Cascales E, Buchanan SK, Duché D, Kleanthous C, Lloubès R, Postle K, et al. Colicin biology. Microbiol Mol Biol Rev 2007;71:158-229.

Cheikhyoussef A, Pogori N, Chen W, Zhang H. Antimicrobial proteinaceous compounds obtained from bifidobacteria: from production to their application. Int J Food Microbiol 2008;125:215-22.

Cheikhyoussef A, Pogori N, Chen H, Tian F, Chen W, Tang J, et al. Antimicrobial activity and partial characterization of bacteriocin-like inhibitory substances (BLIS) produced by Bifidobacterium infantis BCRC 14602. Food Control 2009a;20:553-9.

Cheikhyoussef A, Pogori N, Chen H, Zhao J, Tang J, Chen W, et al. Comparison of three different methods for the isolation of bacteriocin-like inhibitory substances from Bifidobacterium infantis BCRC 14602. J Rapid Methods Autom Microbiol 2009b;17: 182-94.

Cheikhyoussef A, Cheikhyoussef N, Chen H, Zhao J, Tang J, Zhang H, et al. Bifidin I - a new bacteriocin produced by Bifidobacterium infantis BCRC 14602: purification and partial amino acid sequence. Food Control 2010;21:746-53.

Chou CC, Hou JW. Growth of bifidobacteria in soymilk and their survival in the fermented soymilk drink during storage. Int J Food Microbiol 2000;56:113-21.

Collado M, González A, González R, Hernández M, Ferrús M, Sanz Y. Antimicrobial peptides are among the antagonistic metabolites produced by Bifidobacterium against Helicobacter pylori. Int J Antimicrob Agents 2005a;25:385-91.

Collado M, Hernández M, Sanz Y. Production of bacteriocin-like inhibitory compounds by human fecal Bifidobacterium strains. J Food Prot 2005b;68:1034-40.

Cotter PD, Hill C, Ross RP. Bacterial lantibiotics: strategies to improve therapeutic potential. Curr Protein Pept Sci 2005a;6:61-75.

Cotter PD, Hill C, Ross RP. Bacteriocins: developing innate immunity for food. Nat Rev Microbiol 2005b;3:777-88.

De Vries W, Stouthamer AH. Pathway of glucose fermentation in relation to the taxonomy of bifidobacteria. J Bacteriol 1967;93:574-6.

De Vuyst L, Leroy F. Bacteriocins from lactic acid bacteria: production, purification, and food applications. J Mol Microbiol Biotechnol 2007;13:194-9.

Deegan LH, Cotter PD, Hill C, Ross P. Bacteriocins: biological tools for bio-preservation and shelf-life extension. Int Dairy J 2006;16:1058-71.

Deraz SF, Karlsson EN, Hedström M, Andersson MM, Mattiasson B. Purification and characterisation of acidocin D20079, a bacteriocin produced by Lactobacillus acidophilus DSM 20079. J Biotechnol 2005;117:343-54.

Dobson A, Cotter PD, Ross RP, Hill C. Bacteriocin production: a probiotic trait? Appl Environ Microbiol 2012;78:1-6.

Drider D, Fimland G, Héchard Y, Mcmullen LM, Prévost $\mathrm{H}$. The continuing story of class Ila bacteriocins. Microbiol Mol Biol Rev 2006;70:564-82.

Dubey UK, Mistry VV. Effect of bifidogenic factors on growth characteristics of bifidobacteria in infant formulas. J Dairy Sci 1996;79:1156-63.

Eijsink VGH, Axelsson L, Diep DB, Håvarstein LS, Holo H, Nes IF. Production of class II bacteriocins by lactic acid bacteria; an example of biological warfare and communication. Antonie Van Leeuwenhoek 2002;81:639-54.

Ennahar S, Sashihara T, Sonomoto K, Ishizaki A. Class Ila bacteriocins: biosynthesis, structure and activity. FEMS Microbiol Rev 2000;24:85-106.

FAO/WHO. Health and nutritional properties of probiotics in food including powder milk with live lactic acid bacteria. Report of a joint FAO/WHO expert consultation on evaluation of health and nutritional properties of probiotics in food including powder milk with live lactic acid bacteria; 2001.

Gibson G, Wang X. Regulatory effects of bifidobacteria on the growth of other colonic bacteria. J Appl Bacteriol 1994a;77:412-42.

Gibson G, Wang X. Bifidogenic properties of different types of fructo-oligosaccharides. Food Microbiol 1994b;11:491-8.

Gomes AM, Malcata FX. Bifidobacterium spp. and Lactobacillus acidophilus: biological, biochemical, technological and therapeutical properties relevant for use as probiotics. Trends Food Sci Technol 1999;10:139-57.

Ibrahim S, Salameh M. Simple and rapid method for screening antimicrobial activities of Bifidobacterium species of human isolates. J Rapid Methods Autom Microbiol 2001:9:53-62.

Ishibashi $\mathrm{N}$, Yaeshima $\mathrm{T}$, Hayasawa $\mathrm{H}$. Bifidobacteria: their significance in human intestinal health. Malays J Nutr 1997;3:149-59.

Johnsen L, Fimland G, Nissen-Meyer J. The C-terminal domain of pediocin-like antimicrobial peptides (class Ila bacteriocins) is involved in specific recognition of the C-terminal part of cognate immunity proteins and in determining the antimicrobial spectrum. J Biol Chem 2005;280:9243-50.

Kang D, Fung DC. Stimulation of starter culture for further reduction of foodborne pathogens during Salami fermentation. J Food Prot 2000;63:1492-5

Kang KH, Shin HJ, Park YH, Lee TS. Studies on the antibacterial substances produced by lactic acid bacteria: purification and some properties of antibacterial substance "Bifilong" produced by B. longum. Korean Dairy Sci 1989;1:204-16.

Klaenhammer TR. Bacteriocins of lactic acid bacteria. Biochimie 1988;70:337-49.

Kotelnikova EA, Gelfand MS. Bacteriocin production by Gram-positive bacteria and the mechanisms of transcriptional regulation. Russ J Genet 2002;38:628-41.

Lee JH, Karamychev VN, Kozyavkin SA, Mills D, Pavlov AR, Pavlova NV, et al. Comparative genomic analysis of the gut bacterium Bifidobacterium longum reveals loci susceptible to deletion during pure culture growth. BMC Genomics 2008;9:1-16.

Lee JH, Li X, O'Sullivan DJ. Transcription analysis of a lantibiotic gene cluster from Bifidobacterium longum DJO10A. Appl Environ Microbiol 2011;77:5879-87.

Li Q, Chen Q, Ruan H, Zhu D, He G. Isolation and characterisation of an oxygen, acid and bile resistant Bifidobacterium animalis subsp. lactis Qq08. J Sci Food Agric 2010;90: 1340-6. 
Liévin V, Peiffer I, Hudault S, Rochat F, Brassart D, Neeser JR, et al. Bifidobacterium strains from resident infant human gastrointestinal microflora exert antimicrobial activity. Gut 2000;47:646-52.

Lozano JCN, Meyer JN, Sletten K, Peláz C, Nes IF. Purification and amino acid sequence of a bacteriocin produced by Pediococcus acidilactici. J Gen Microbiol 1992;138: 1985-90.

Makras L, De Vuyst L. The in vitro inhibition of Gram-negative pathogenic bacteria by bifidobacteria is caused by the production of organic acids. Int Dairy J 2006:16:1049-57.

Meghrous J, Euloge P, Junelles AM, Ballongue J, Petitdemange H. Screening of Bifidobacterium strains for bacteriocin production. Biotechnol Lett 1990;12:575-80.

Nebra Y, Blanch AR. A new selective medium for Bifidobacterium spp. Appl Environ Microbiol 1999;65:5173-6.

O'Sullivan. Isolated bifidobacteria that produce siderophores which inhibit growth of Lactococcus lactis. United States patent 6746672. 2001

O'Shea EF, Cotter PD, Stanton C, Ross RP, Hill C. Production of bioactive substances by intestinal bacteria as a basis for explaining probiotic mechanisms: bacteriocins and conjugated linoleic acid. Int J Food Microbiol 2012;15:189-205.

Pongtharangkul T, Demirci A. Evaluation of agar diffusion bioassay for nisin quantification. Appl Microbiol Biotechnol 2004;65:268-72.

Riley M, Chavan M. Bacteriocins: ecology and evolution. 1st ed. Heidelberg: Springer; 2007.

Riley M, Wertz JE. Bacteriocins: evolution, ecology, and application. Annu Rev Microbiol 2002; $56: 117-37$

Russell DA, Ross RP, Fitzgerald GF, Stanton C. Metabolic activities and probiotic potential of bifidobacteria. Int J Food Microbiol 2011;14:88-105.
Saleh FA, El-Sayed EM. Isolation and characterization of bacteriocins produced by Bifidobacterium lactis BB-12 and Bifidobacterium longum BB-46. 9th Egyptian Conference for Dairy Science and Technology. Cairo: Research Papers; 2004. p. 323-37.

Tagg JR, Dajani AS, Wannamaker LW. Bacteriocins of Gram-positive bacteria. Bacteriol Rev 1976;40:722-56.

Tissier $\mathrm{H}$. Recherches sur la flore intestinale normale et pathologique du nourrisson (etat normale et pathologique). Paris: Thesis; 1900. p. 1-253.

Touré $\mathrm{R}$, Kheadr $\mathrm{E}$, Lacroix $\mathrm{C}$, Moroni $\mathrm{O}$, Fliss I. Production of antibacterial substances by bifidobacterial isolates from infant stool active against Listeria monocytogenes. J Appl Microbiol 2003;95:1058-69.

von Ah U. Identification of Bifidobacterium thermophilum RBL67 isolated from baby faeces and partial purification of its bacteriocin. Culture. Swiss Federal Institute of Technology. Zurich: PhD Thesis; 2006. p. 1-192.

Yang YS, Chen MC, Liao CC. Bifidobacteria strains with acid, bile salt and oxygen tolerance and their culture method. United States patent 5711977. 1998.

Yildirim Z, Johnson M. Characterization and antimicrobial spectrum of bifidocin B, a bacteriocin produced by Bifidobacterium bifidum NCFB 1454. J Food Prot 1998;61: 47-51.

Yildirim Z, Winters D, Johnson M. Purification, amino acid sequence and mode of action of bifidocin B produced by Bifidobacterium bifidum NCFB 1454. J Appl Microbiol 1999;86:45-54. 


\section{Lactic acid} properties, applications and production: A review

\section{Fabio Andres Castillo Martinez ${ }^{a}$, Eduardo Marcos Balciunas ${ }^{a}$, José Manuel Salgadob, José Manuel Domínguez González ${ }^{b}$, Attilio Convertic and Ricardo Pinheiro de Souza Oliveira $^{\mathrm{a}, *}$}

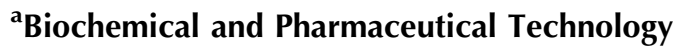
Department, Faculty of Pharmaceutical Sciences, São Paulo University, Av Prof Lineu Prestes, 580, BI 16, 05508-900 São Paulo, Brazil (Tel.: + 5511 30912478; fax: + 5511 38156386; e-mail: rpsolive@usp.br)

${ }^{b}$ Department of Chemical Engineering, Vigo University, Faculty of Sciences, Campus of Ourense, As Lagoas s/n, 32004 Ourense, Spain

'Department of Civil, Chemical and Environmental Engineering, Pole of Chemical Engineering, Genoa University, Via Opera Pia 15, I-16145 Genova, Italy
\end{abstract}

Lactic acid was discovered in 1780 by C.W. Scheele in sour milk, and in 1881 Fermi obtained lactic acid by fermentation, resulting in its industrial production. The yearly world lactic acid production is expected to reach 259,000 metric tons by the year 2012. The interest in lactic acid is related to many aspects, among which is its relatively high added-value. In addition, such a chemical is GRAS (Generally Recognized As Safe), being recognized as harmless by the United States Food and Drug Administration, has a market with great growth potential, can be alternatively produced by fermentation or chemical

\section{* Corresponding author.}

0924-2244/\$ - see front matter $\odot 2012$ Elsevier Ltd. All rights reserved. http://dx.doi.org/10.1016/j.tifs.2012.11.007 synthesis and can employ a large variety of different waste materials as substrates. Lactic acid has many applications. Its existence in the form of two stereoisomers does in fact make the application of one of them or of the racemic mixture of great concern in different fields. In particular, the food and pharmaceutical industries have a preference for the isomer $\mathrm{L}(+)$, the only one that can be metabolized by the human body; however, the chemical industry requires one of the pure isomers or a mixture of both, according to the application. This review describes biotechnological processes to obtain lactic acid from polymeric substrates such as starchy and lignocellulosic materials. Open challenges are related to the technological optimization of the fermentation process and product purification and recovery. In addition, the opportunities and difficulties associated with using raw materials for lactic acid production are discussed.

\section{Introduction}

Because of a number of different properties (AbdelRahman, Tashiro, \& Sonomoto, 2011), lactic acid is an important industrial product that is used as a precursor of small (propylene glycol) or large (acrylic polymers) compounds (San-Martín, Pazos, \& Coca, 1992). Their polymers are biodegradable, used as materials for packaging and labeling (San-Martín et al., 1992), and biocompatible, being useful for the manufacture of prosthetic devices, sutures and internal drug dosing (Chahal, 2000, pp. 1-9). Among them, the polylactic acid (Boswell, 2001; Tsuji, Saeki, Tsukegi, Daimon, \& Fujie, 2008) has several applications in the textile, medical and pharmaceutical industries (Singhvi, Joshi, Adsul, Varma, \& Gokhale, 2010).

In the cosmetic industry, lactic acid is used in the manufacture of hygiene and esthetic products, owing to its moisturizing, antimicrobial and rejuvenating effects on the skin, as well as of oral hygiene products. Lactic acid derivatives such as lactate esters are widely used because of their hygroscopic and emulsifying properties (Gao, Ma, \& $\mathrm{Xu}, 2011)$. In the pharmaceutical industry it is used as a supplement in the synthesis of dermatologic drugs and against osteoporosis (Bai, Zhao, Li, \& Xu, 2004).

Approximately $70 \%$ of lactic acid produced is used in the food industry because of its role in the production of yogurt and cheese (Salminen, Ouwehand, Wright, \& Daly, 1993). In the preparation of yogurts it is the main product of Streptococcus thermophilus and Lactobacillus bulgaricus 
co-fermentation. In the manufacture of cheese, the $\mathrm{pH}$ decrease consequent to lactic acid release triggers the aggregation of casein micelles. Sometimes, depending on the sensory characteristics desired in the final product, direct acidification with lactic acid is exploited to avoid the risk of proliferation of undesirable microorganisms. In the field of grain production, lactic acid forms spontaneously because of the presence of microorganisms that carry out the lactic acid fermentation of the raw material (for example, wet processing of corn), leads to changes in the aroma and taste preparations and causes a decrease in $\mathrm{pH}$ that prevents the growth of pathogenic bacteria (Lee \& Lee, 1993).

As far as the animal nutrition is concerned, controlled lactic fermentation increases the shelf life, palatability and nutritive value of silage. Ammonium lactate is an excellent non-protein nitrogen source, which is preferred in cattle to urea and ammonium citrate because it results in milk with higher nutritive value (Norton, Lacroix, \& Vuillemard, 1994) and does not require any expensive purification.

\section{Physico-chemical properties}

Lactic acid (2-hydroxypropanoic acid) is an organic acid widely distributed in nature. It is the simplest 2hydroxycarboxylic acid with a chiral carbon atom and exists in two enantiomeric forms (Fig. 1). The chemical behavior of lactic acid is determined by its physico-chemical properties, among which are a) acidic character in aqueous medium; b) bifunctional reactivity associated with the presence of a carboxyl and a hydroxyl group, which gives it great reaction versatility; and c) asymmetric optical activity of $\mathrm{C} 2$.

\section{Production technologies and purification}

The worldwide demand of lactic acid in 2007 was estimated to be 130,000-150,000 metric tons per year, with commercial prices of food-grade lactic acid ranging be-

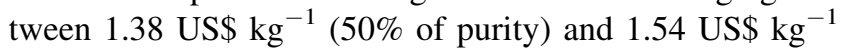
(88\% of purity) (John, Nampoothiri, \& Pandey, 2007). According to forecasts, its production should increase significantly over the coming years mainly to provide the polylactic acid manufacturing sites, and is expected to reach 259,000 metric tons in 2012 (Mujtaba, Iqbal,

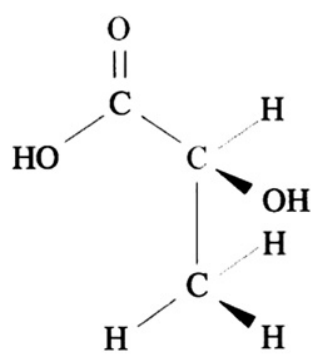

Isomer $\mathbf{L}(+)$

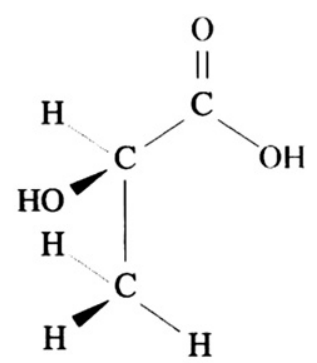

Isomer D(-)
Fig. 1. Structure of $\mathrm{D}(-)$ and $\mathrm{L}(+)$ isomers of the lactic acid.
Edreder, \& Emtir, 2012). The Global Industry Analyst Inc. announced in January 2011 that the global market for lactic acid is forecast to reach approximately 329,000 metric tons by the year 2015 .

\section{Commercial manufacturers}

As regards the world production of lactic acid, several authors reported the most relevant commercial manufacturers (Datta \& Henry, 2006; Datta, Tsai, Bonsignore, Moon, \& Frank, 1995; John, Nampoothiri, et al., 2007). Currently, the major manufacturers of lactic acid include Archer Daniels Midland Company (USA), NatureWorks LLC (USA), Purac (The Netherlands), Galactic S.A. (Belgium) and several Chinese companies, among them are the CCA (Changzhou) Biochemical Co. Ltd., Henan Jindan Lactic Acid Co. Ltd., and Musashino Chemical Co. Ltd.

\section{Chemical synthesis}

For lactic acid chemical synthesis, acetaldehyde is let to react in liquid phase and under high pressure with hydrogen cyanide in the presence of a base to produce lactonitrile. After its recovery and purification by distillation, hydrochloric acid or sulfuric acid is added to hydrolyze lactonitrile to lactic acid, which is then esterified with methanol to produce methyl lactate, and this is recovered and purified by distillation. The purified methyl lactate is finally hydrolyzed in acidic aqueous solution to lactic acid and methanol, the latter being recycled in the same process (Dey \& Pal, 2012; Narayanan, Roychoudhury, \& Srivastava, 2004a). Other chemical routes for lactic acid synthesis include base-catalyzed degradation of sugars, oxidation of propylene glycol, carbon monoxide and water at high temperature and pressure, hydrolysis of chloropropionic acid, and nitric acid oxidation of propylene, among others (John, Sukumaran, Nampoothiri, \& Pandey, 2007).

\section{Fermentation}

Lactic fermentation is relatively fast, has high yields and can lead, selectively, to one of the two stereoisomers of lactic acid or to their racemic mixture (Axelsson, 2004). After supplementation of nutrients, sugar solutions are inoculated with the selected microorganism, and the fermentation takes place. It is necessary to select the most favorable fermentation conditions, in terms of temperature, $\mathrm{pH}$, aeration, agitation, and so on, which vary depending on the microorganism.

The search for low-cost raw materials to be used in the production of lactic acid by fermentation has been promoting the development of competitive processes. The materials most frequently used to this purpose can be classified into two groups, namely the monosaccharides and disaccharides and the polymeric substrates.

\section{Monosaccharides and disaccharides}

In theory, any carbohydrate source containing pentoses or hexoses could be used for the production of lactic 
acid. This category of carbon sources includes food industry byproducts such as molasses and whey. Molasses have high sucrose content and are cheap and plentiful (Kotzamanidis, Roukas, \& Skaracis, 2002), while whey has high lactose content whose disposal constitutes a serious environmental challenge (Alvarez, Aguirre-Ezkauriatza, Ramírez-Medrano, \& Rodríguez-Sánchez, 2010; Büyükkileci \& Harsa, 2004). Another byproduct that was successfully used as substrate for lactic acid production is the date juice (Nancib et al., 2001; Nancib, Nancib, \& Boudrant, 2009).

\section{Polymeric substrates}

These substrates contain polysaccharides that, in most cases, cannot be directly assimilated by microorganisms, requiring an earlier stage of hydrolysis.

The so-called starchy materials contain starch, a biopolymer of glucose units linked via $\alpha(1-4)$ bonds forming chains of variable length, branched via $\alpha(1-6)$ bonds or not. Two different polysaccharide fractions are present in starch, namely the amylose that has a few branches and long linear chains and the amylopectin with opposite characteristics. Preparation of glucose solutions from starchy materials requires submitting the material to preliminary liquefaction by thermostable $\alpha$-amylase and subsequent saccharification by $\alpha$-amylase and amyloglucosidase, which prevents starch gelatinization (Massoud \& Elrazek, 2011; Palmarola-Adrados, Juhász, Galbe, \& Zacchi, 2004). The resulting glucose solutions can be used directly as carbon source to produce lactic acid. These materials can also be fermented by some microorganisms directly without any preliminary hydrolysis stage because of their ability to release extracellular amylases.

On the other hand, lignocellulosic biomass represents the most abundant global source of biomass, and for this reason it has been largely utilized in many applications. It is mainly composed of cellulose, hemicellulose and lignin which form approximately $90 \%$ of the dry matter (Taherzadeh \& Karimi, 2008). Lignocellulosic materials can be used to obtain sugar solutions that may be usefully exploited for the production of lactic acid through the following steps: a) pretreatment to break down the lignocellulosic structure, b) enzymatic hydrolysis to depolymerize lignocellulose to fermentative sugars, c) sugar fermentation to lactic acid by lactic acid bacteria and d) separation and purification of lactic acid (Abdel-Rahman et al., 2011; Bustos, Moldes, Cruz, \& Domínguez, 2005a; Chang, Lu, Yang, Zhao, \& Zhang, 2010; Moldes, Alonso, \& Parajó, 2001b; Parajó, Alonso, \& Moldes, 1997; Yáñez, Alonso, \& Parajó, 2004). In recent years, one of the most used processes to obtain lactic acid from lignocellulosic materials is the simultaneous saccharification and fermentation (Cui, Li, \& Wan, 2011; Nakano, Ugwu, \& Tokiwa, 2012; Ou, Ingram, \& Shanmugam, 2011), which is able to prevent enzyme inhibition by the product (Romaní, Yáñez, Garrote, \& Alonso, 2008).

\section{Direct fermentation by fungi}

Fungi and bacteria are the most widely employed microorganisms for lactic acid production. The main advantages of the use of fungi as fermenting agents are their ability to release extracellular amylases able to hydrolyze starchy materials, thus not requiring any prior stage of hydrolysis (Deng, Li, Xu, Gao, \& Huang, 2012; Jin, Yin, Ma, \& Zhao, 2005), and the easy separation of biomass because of mycelium formation. These fungi, which usually belong to the genus Rhizopus and produce especially the $\mathrm{L}(+)$ isomer (Wang, Sun, Wei, \& Wang, 2005), have been employed with starches from corn (Bai et al., 2004), rice (Fukushima, Sogo, Miura, \& Kimura, 2004), potato, wheat and pineapple (Jin, Huang, \& Lant, 2003; Jin et al., 2005), and hydrolyzed corn cobs (Miura et al., 2004), pine wood (Woiciechowski, Soccol, Ramos, \& Pandey, 1999) and waste paper (Marques, Santos, Gírio, \& Roseiro, 2008; Park, Anh, \& Okuda, 2004).

\section{Fermentation by bacteria}

Lactic acid bacteria are named according to their ability to produce lactic acid as the major (and sometimes the sole) product of sugar fermentation. Many lactic acid bacteria also encode the enzymes required for aerobic respiration, but none synthesize heme (some lactic acid bacteria also lack menaquinones). Thus, the respiration chain is non-functional unless heme (and for some bacteria heme and menaquinones) are added to the culture medium (Pedersen, Gaudu, Lechardeur, Petit, \& Gruss, 2012). Most lactic acid bacteria are catalase negative, immobile, do not form spores and have optimum growth temperature between 20 and $45{ }^{\circ} \mathrm{C}$. In addition, they have high tolerance to acidic conditions $(\mathrm{pH}<5)$, which confers them a competitive advantage over other bacteria. As shown in Table 1, the selection of a suitable microorganism enables one to ferment sugar solutions of different origin.

\section{Lactic acid purification}

Lactic acid purification is one of the most costly steps of the production process (Abdel-Rahman et al., 2011; Tong et al., 2004). Great attention should be paid to the addition of low-cost residues or other nutrients to the medium, because removal of impurities can significantly increase the costs of purification steps (Büyükkileci \& Harsa, 2004). Methods to reduce impurities in the final product include extraction (Järvinen, Myllykoski, Keiski, \& Sohlo, 2000), membrane separation (Persson, Jönsson, \& Zacchi, 2001), ion exchange (Moldes, Alonso, \& Parajó, 2001a), electrodialysis (Bailly, 2002) and distillation with chemical reaction (Choi \& Hong, 1999; Edreder, Mujtaba, \& Emtir, 2011).

According to Khunnonkwao, Boontawan, Haltrich, Maischberger, and Boontawan (2012), distillation is extremely difficult owing to the low volatility of lactic acid, and electrodialysis cannot separate charged components 
Table 1. Microorganisms and raw materials used in the production of lactic acid.

\begin{tabular}{|c|c|c|c|}
\hline Material & Microorganisms & Carbon source & References \\
\hline \multicolumn{4}{|c|}{ Monosaccharides and disaccharides } \\
\hline \multirow[t]{2}{*}{ Molasses } & L. casei & Saccharose & Hofvendahl and Hähn-Hägerdal, 2000; Kotzamanidis et al., 2002 \\
\hline & L. lactis & Saccharose & Milcent and Carrere, 2001 \\
\hline Pineapples syrup & L. lactis & Saccharose & Ueno, Ozawa, Ishikawa, Nakanishi, \& Kimura, 2003 \\
\hline Camel milk & L. delbrueckii & Lactose & Gassem \& Abu-Tarboush, 2000 \\
\hline Cow milk & L. delbrueckii & Lactose & Gassem \& Abu-Tarboush, 2000 \\
\hline \multirow[t]{7}{*}{ Whey } & L. acidophilus & Lactose & Gupta \& Gandhi, 1995; Kumar, Jha, \& Chauhan, 2001 \\
\hline & L. bulgaricus & Lactose & Chakraborty \& Dutta, 1999 \\
\hline & L. delbrueckii & Lactose & Chakraborty \& Dutta, 1999 \\
\hline & L. casei & Lactose & Göksungur, Gündüz, \& Harsa, 2005 \\
\hline & L. helveticus & Lactose & Amrane, 2001, 2003, 2005; Fitzpatrick and O'Keeffe, 2001; \\
\hline & Lactococcus lactis & Lactose & Roukas \& Kotzekidou, 1996, 1998 \\
\hline & S. thermophilus & Lactose & Liu, Liu, Liao, Wen, \& Chen, 2004 \\
\hline Date juice & L. rhamnosus & Saccharose & Nancib et al., 2001, 2005 \\
\hline \multicolumn{4}{|l|}{ Starchy materials } \\
\hline Corn & L. amylophilus & Starch & Vishnu, Seenayya, \& Reddy, 2002 \\
\hline \multirow[t]{2}{*}{ Potato } & L. amylophilus & Starch & Vishnu et al., 2002 \\
\hline & L. delbrueckii & Glucose $^{\mathrm{a}}$ & Ray, Mukherjee, \& Majumdar, 1991 \\
\hline \multirow[t]{4}{*}{ Wheat (bran) (flour) } & L. amylophilus & Starch & Naveena, Altaf, Bhadrayya, Madhavendra, \& Reddy, 2005 \\
\hline & L. bulgaricus & Glucose $^{\mathrm{a}}$ & Hofvendahl and Hahn-Hägerdal, 1997 \\
\hline & L. casei & Glucose $^{a}$ & Hofvendahl and Hahn-Hägerdal, 1997 \\
\hline & L. lactis & Glucose $^{a}$ & Hofvendahl and Hahn-Hägerdal, 1997 \\
\hline Rice & L. delbrueckii & Glucose $^{\mathrm{a}}$ & Fukushima et al., 2004 \\
\hline Barley & L. casei & Glucose $^{\mathrm{a}}$ & Linko and Javanainen, 1996 \\
\hline \multirow[t]{4}{*}{ Yucca } & L. lactis & Glucose $^{a}$ & Sirisansaneeyakul et al., 2000 \\
\hline & L. plantarum & Starch & Shamala \& Sreekantiah, 1988 \\
\hline & L. delbrueckii & Glucose $^{a}$ & John, Nampoothiri, et al., 2007; John, Sukumaran, et al., 2007 \\
\hline & L. casei & Glucose $^{\mathrm{a}}$ & John, Nampoothiri, et al., 2007; John, Sukumaran, et al., 2007 \\
\hline Tapioca & L. plantarum & Glucose $^{\mathrm{a}}$ & Shamala \& Sreekantiah, 1988 \\
\hline \multicolumn{4}{|c|}{ Lignocellulosic hydrolyzates } \\
\hline Bamboo & L. plantarum & Glucose & Asada, Nakamura, \& Kobayashi, 2005 \\
\hline Corrugated & L. Coryniformis & Glucose & Yáñez, Alonso, \& Parajó, 2005 \\
\hline \multirow[t]{4}{*}{ Alfalfa fifer } & L. delbrueckii & Glucose & Sreenath, Moldes, Koegel, \& Straub, 2001a, 2001b \\
\hline & L. pentoaceticus & Glucose & Sreenath et al., 2001b \\
\hline & L. plantarum & Glucose & Sreenath et al., 2001a,b \\
\hline & L. xylosus & Glucose & Sreenath et al., 2001b \\
\hline \multirow[t]{2}{*}{ Soy fiber } & L. delbrueckii & Glucose & Sreenath et al., 2001a \\
\hline & L. plantarum & Glucose & Sreenath et al., 2001a \\
\hline Wood of eucalyptus & L. delbrueckii & Glucose & Parajó, Alonso, \& Santos, 1996 \\
\hline Grape marc & L. pentosus & Xylose & Portilla, Moldes, Torrado, \& Domínguez, 2007 \\
\hline \multirow[t]{2}{*}{ Wheat straw } & L. pentosus & Xylose & Garde et al., 2002 \\
\hline & L. brevis & Xylose & Garde et al., 2002 \\
\hline Waste paper & L. rhamnosus & $\mathrm{G} / \mathrm{X} / \mathrm{C}^{\mathrm{C}}$ & Marques et al., 2008 \\
\hline Pulp & L. delbrueckii & Glucose & Roberto et al., 2007 \\
\hline Cellulosic residue & L. casei & Glucose & Thomas, 2000 \\
\hline \multirow[t]{3}{*}{$\mathrm{RSU}^{\mathrm{b}}$} & L. pentosus & $\mathrm{X} / \mathrm{G} / \mathrm{A}^{\mathrm{c}}$ & McCaskey, Zhou, Britt, \& Strickland, 1994 \\
\hline & L. plantarum & $\mathrm{X} / \mathrm{G} / \mathrm{A}^{\mathrm{c}}$ & McCaskey et al., 1994 \\
\hline & & Glucose & Bustos et al., 2005b \\
\hline Corn cobs & L. delbrium & Glucose & Luo, Xia, Lin, \& Cen, 1997 \\
\hline
\end{tabular}

especially contaminating amino acids and organic acids. On the other hand, nanofiltration combined with bipolar electrodialysis in downstream purification can replace multiple purification steps with only two steps, while yielding a monomer grade lactic acid from a mixture of unconverted sugars and lactic acid (Sikder, Chakraborty, Pala, Drioli, \& Bhattacharjee, 2012).
Chromatography has been developed for many years as a very useful tool for pharmaceutical industry, biotechnology as well as in the production of fine chemicals (Tong et al., 2004); in particular, the ion exchange technique is widely used in bioseparations, and several different ion exchangers have been successfully employed in the past few years to recover lactic acid (Thang \& Novalin, 2008). 


\section{Fundamentals of biochemistry and metabolism of lactic acid bacteria}

The largest and most diverse genus of lactic acid bacteria is Lactobacillus, which includes species with very different biochemical and physiological properties along with special resistance against acidic environment. Because of their high growth rate and productivity, microorganisms belonging to this genus are used in important industrial productions (Kylä-Nikkilä, Hujanen, Leisola, \& Palva, 2000) and make use of two main routes to ferment glucose (Gao et al., 2011; Mayo, Piekarczyk, Kowalczyk, Pablo, \& Bardowski, 2010).

Lactic acid production from glucose and related fermentation pathways

Homolactic fermentation

This process takes place in two steps. In the former step, called glycolysis or Embden-Meyerhof-Parnas pathway, glucose is transformed into pyruvic acid, while in the latter this is reduced to lactic acid by the reducing power previously produced in the form of NADH. Thus, lactic acid is obtained from glucose as the sole product (Fig. 2) according to the overall equation:

$$
\text { Glucose } \rightarrow 2 \text { Lactic Acid + } 2 \text { ATP }
$$

Microorganisms that use only this route for the consumption of carbohydrates are called Obligatory Homofermentative, and these include, among others, Lactobacillus acidophilus, Lactobacillus amylophilus, L. bulgaricus, Lactobacillus helveticus and L. salivarius (Mayo et al., 2010; Nigatu, 2000; Sanders \& Klaenhammer, 2001).

Homolactic fermentation should theoretically yield $2 \mathrm{~mol}$ of lactic acid per mole of consumed glucose with a theoretical yield of $1 \mathrm{~g}$ of product per $\mathrm{g}$ of substrate, but the experimental yields are usually lower $\left(0.74-0.99 \mathrm{~g} \mathrm{~g}^{-1}\right)$ because a portion of the carbon source is used for biomass production (0.07-0.22 $\mathrm{g} \mathrm{g}^{-1}$ ) (Bruno-Bárcena, Ragout, Córdoba, \& Siñeriz, 1999; Burgos-Rubio, Okos, \& Wankat, 2000; Hofvendahl \& Hahn-Hägerda, 1997; Srivastava, Roychoudhury, \& Sahai, 1992). Under stress conditions such as carbon source limitation, presence of different carbon sources other than glucose, high $\mathrm{pH}$ or low temperature, some homofermentative microorganisms can produce formic acid by mixed acid fermentation (Hofvendahl \& Hahn-Hägerda, 2000 ) by the action of pyruvate-formate lyase (Gao et al., 2011; Mayo et al., 2010).

\section{Heterolactic fermentation}

This process is characterized by the formation of coproducts such as $\mathrm{CO}_{2}$, ethanol and/or acetic acid in addition to lactic acid as the end product of fermentation (Fig. 3). The first step of glucose degradation, which is called pentose phosphate pathway, leads to glyceraldehyde 3phosphate, acetyl-phosphate and $\mathrm{CO}_{2}$. Glyceraldehyde 3 -phosphate enters the glycolysis through which it is transformed into lactic acid, while acetyl-phosphate is converted
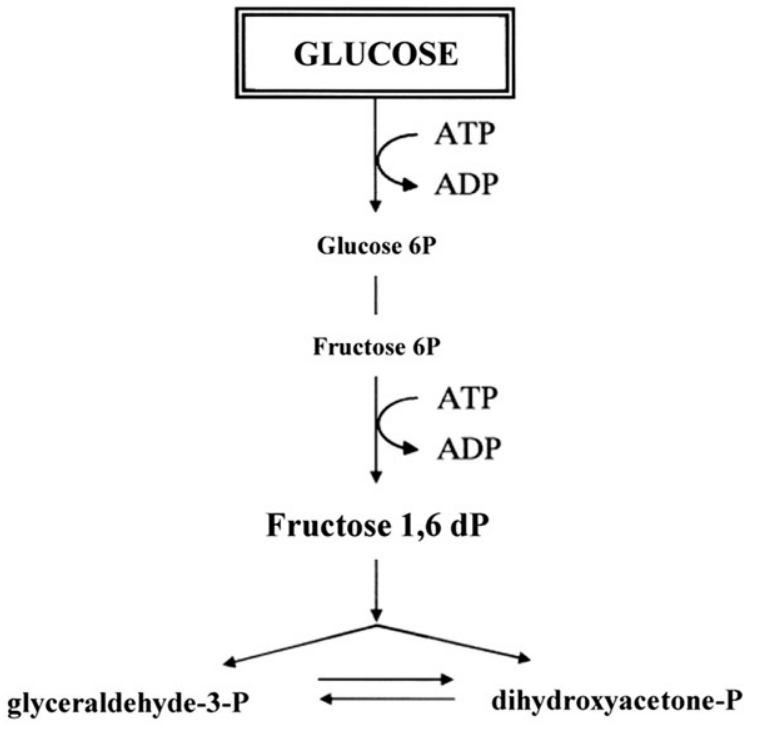

2

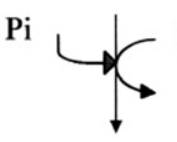

$2 \mathrm{NAD}^{+}$

$2 \mathrm{NADH}+2 \mathrm{H}^{+}$

1,3-diP-Glycerate

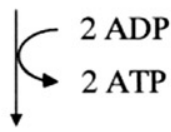

2

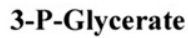

2

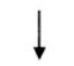

2-P-Glycerate

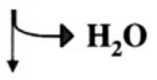

2

P-Enolpyruvate

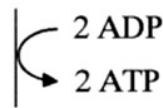

2 Pyruvate

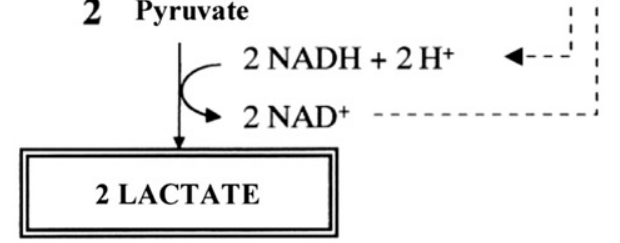

Fig. 2. Scheme of homofermentative pathway of glucose fermentation in lactic acid bacteria. Modified after Axelsson (2004) and Mayo et al. (2010).

into acetic acid and/or ethanol according to the overall equations:

Glucose $\rightarrow$ Lactic acid $+\mathrm{CO}_{2}+$ Ethanol + ATP

Glucose $\rightarrow$ Lactic acid $+\mathrm{CO}_{2}+$ Acetic acid +2 ATP

$+2 \mathrm{NADH}$ 


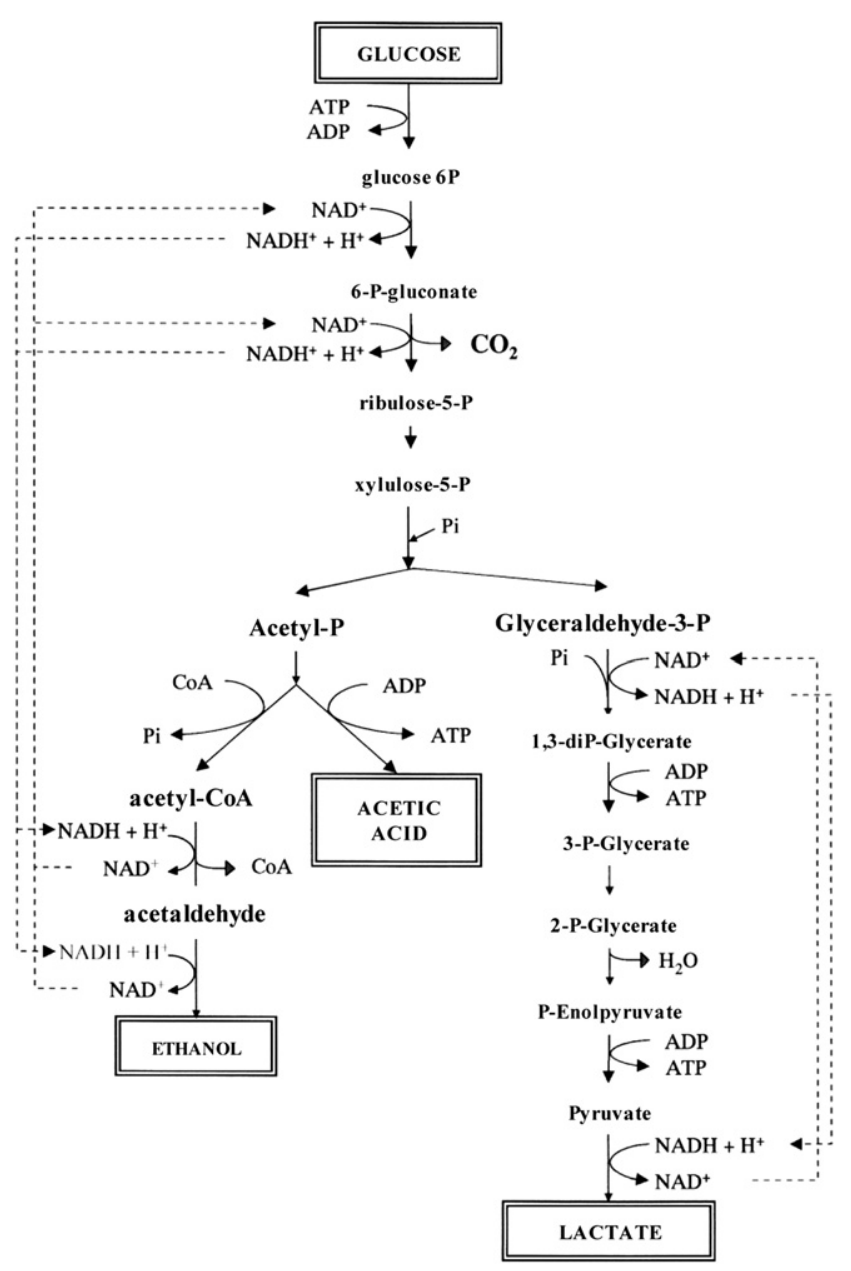

Fig. 3. Scheme of heterofermentative pathway of glucose fermentation in lactic acid bacteria. Modified after Axelsson (2004) and Mayo et al. (2010).

The relationship between the amounts of acetic acid and ethanol, which reduces the theoretical yield to $0.50 \mathrm{~g} \mathrm{~g}^{-1}$, depends on the ability of the microorganism to reoxidize the NADH generated in the early stages of the process along with its energy requirements. Microorganisms that use only this metabolic pathway for the consumption of carbohydrates are called Obligatory Heterofermentative, among which are Lactobacillus brevis, L. fermentum, L. parabuchneri and L. reuteri (Mayo et al., 2010; Nigatu, 2000; Sanders \& Klaenhammer, 2001).

\section{Lactic acid production from other carbon sources}

In addition to glucose, there are other hexoses such as fructose, mannose or galactose, which can be consumed by lactic acid bacteria (Table 2). On the other hand, hexosefermenting lactobacilli are unable to ferment pentoses. There are some species of this genus, classified as Facultative Heterofermentative, among which L. alimentarius, Lactobacillus plantarum (Gobbetti, Lavermicocca, Minervini, de Angelis, \& Corsetti, 2000), Lactobacillus casei, Lactobacillus rhamnosus (Nigatu, 2000; Rivas, Torrado, Rivas, Moldes, \& Domínguez, 2007; Romaní et al., 2008), Lactococcus lactis
(Ishizaki, Ueda, Tanaka, \& Stanbury, 1992, 1993; Joshi, Singhvi, Khire, \& Gokhale, 2010), Lactobacillus pentosus (Bustos et al., 2005a; Moldes et al., 2001a, 2001b) and Lactobacillus xylosus (Tyree, Clausen, \& Gaddy, 1990), that perform both fermentations, consuming hexoses by the homolactic pathway and pentoses by the heterolactic one. The catabolism of pentoses requires additional conversion steps through which they are transformed into metabolic intermediates of the pentose phosphate pathway. By this way, as an instance, xylose is transformed into xylulose and then phosphorylated to xylulose 5-phosphate, arabinose into ribulose, and this in turn is phosphorylated to ribulose 5-phosphate (Gao et al., 2011; Mayo et al., 2010).

In recent years, the utilization of lignocellulosics as raw material for lactic acid production has required the development of methods for efficient utilization of xylose (Yoshida, Okano, Tanaka, Ogino, \& Kondo, 2011). L. xylosus (Tyree et al., 1990) and L. rhamnosus (Iyer, Thomas, \& Lee, 2000) have been used in media containing a mixture of xylose and glucose and acidic hemicellulosic hydrolyzates of wood, respectively. L. pentosus allowed obtaining $33 \mathrm{~g} \mathrm{~L}^{-1}$ of lactic acid and $17 \mathrm{~g} \mathrm{~L}^{-1}$ of acetic acid from detoxified hemicellulosic liquor made from reeds (Perttunen, Myllykoski, \& Keiski, 2002) and $44.8 \mathrm{~g} \mathrm{~L}^{-1}$ of lactic acid and $6.5 \mathrm{~g} \mathrm{~L}^{-1}$ of acetic acid from concentrated hemicellulosic hydrolyzates of trimming vine shoots (Bustos, Moldes, Cruz, \& Domínguez, 2005b). In fermentations with Bacillus coagulans high levels of lactic acid were obtained from xylose and glucose $(\mathrm{Ou}$ et al., 2011). Wang et al. (2009) reached $83 \mathrm{~g} \mathrm{~L}^{-1}$ of lactic acid from the co-fermentation of glucose and xylose by $R h i$ zopus oryzae using low-energy ion beam irradiation. Mixed culture of lactic acid bacteria were also employed in the simultaneous fermentation of hexoses and pentoses, thereby allowing for efficient utilization of both cellulose- and hemicellulose-derived sugars (Cui et al., 2011).

From the metabolic viewpoint, contrary to hexoses, the heterolactic fermentation of pentoses does not imply any excess of $\mathrm{NADH}$; therefore, the only way to utilize acetyl-phosphate is its direct dephosphorylation to acetate with recovery of an additional mol of ATP:

Pentose $\rightarrow$ Lactic acid + Acetate +2 ATP

Lactic acid bacteria can also metabolize disaccharides such as lactose, maltose and sucrose, which are cleaved by the action of endocellular hydrolases. Additionally, certain species such as L. rhamnosus are able to consume cellobiose (Marques et al., 2008), a disaccharide made up of two glucose units linked through $\beta(1-4)$ bonds, which has special importance in processes employing cellulose hydrolyzates.

\section{Stereospecific lactic acid production}

Lactic acid bacteria may selectively produce one specific stereoisomer of lactic acid (D or L) or a mixture of them in various proportions. Such an ability is determined by the presence of the enzyme lactate dehydrogenase, which possesses 


\begin{tabular}{|c|c|c|}
\hline Microorganism & Carbon source & References \\
\hline L. amylophilus & $\begin{array}{l}\text { Glucose } \\
\text { Starch }\end{array}$ & $\begin{array}{l}\text { Mercier, Yerushalmi, Rouleau, \& Dochain, } 1992 \\
\text { Vishnu et al., } 2002\end{array}$ \\
\hline \multirow[t]{3}{*}{ L. bulgaricus } & Fructose & Amoroso, Manca de Nadra, \& Oliver, 1988 \\
\hline & Galactose & Burgos-Rubio et al., 2000 \\
\hline & Glucose & Burgos-Rubio et al., 2000; Chakraborty and Dutta, 1999 \\
\hline \multirow[t]{2}{*}{ L. casei } & Glucose & Ha, Kim, Lee, Kim, \& Kim, 2003; Kurbanoglu, 2004 \\
\hline & Lactose & Büyükkileci and Harsa, 2004; Göksungur et al., 2005 \\
\hline \multirow[t]{2}{*}{ L. coryniformis } & Glucose & Yáñez et al., 2005 \\
\hline & F/G/S & Zorba, Hancioglu, Genc, Karapinar, \& Ova, 2003 \\
\hline \multirow[t]{5}{*}{ L. delbrueckii } & Glucose & Hofvendahl and Hähn-Hägerdal, 2000 \\
\hline & Fructose & Robison, 1988; Suskovic, Beluhan, Beluhan, \& Kurtanjek, 1992 \\
\hline & Galactose & Kadam, Patil, Bastawde, Khire, \& Gokhale, 2006 \\
\hline & Lactose & Hofvendahl and Hähn-Hägerdal, 2000; Welman \& Maddox, 2003 \\
\hline & Saccharose & $\begin{array}{l}\text { Kotzamanidis et al., 2002; Srivastava et al., 1992; Suskovic et al., 1992; } \\
\text { Vinderola, Costa, Regenhardt, \& Reinheimer, 2002; Zlotkowska, } 2000\end{array}$ \\
\hline L. helveticus & Lactose & Amrane, 2001, 2005 \\
\hline \multirow[t]{2}{*}{ L. lactis } & $\mathrm{G} / \mathrm{X} / \mathrm{L}$ & Bai et al., 2003 \\
\hline & Saccharose & Milcent and Carrere, 2001; Ueno et al., 2003 \\
\hline L. manihotivorans & Starch & Guyot, Calderon, \& Morlon-Guyot, 2000 \\
\hline L. paracasei & Glucose & Xu et al., 2006 \\
\hline \multirow[t]{2}{*}{ L. pentosus } & Glucose & Bustos, Moldes, Cruz, \& Domínguez, 2004b \\
\hline & Xylose & Portilla et al., 2007 \\
\hline L. plantarum & Starch & Pintado, Guyot, \& Raimbault, 1999; Shamala \& Sreekantiah, 1988 \\
\hline L. rhamnosus & $\mathrm{Gal} / \mathrm{G} / \mathrm{M} / \mathrm{X}$ & lyer et al., 2000; Romaní et al., 2008 \\
\hline \multirow[t]{4}{*}{ Lactococcus lactis } & Glucose & Loubiere et al., 1997; Sakai, 2004 \\
\hline & Xylose & Kanagachandran, Stanbury, Hall, \& Ishizaki, 1997; Tanaka et al., 2002 \\
\hline & Lactose & Hofvendahl and Hähn-Hägerdal, 2000 \\
\hline & Maltose & Sato, Tokuda, \& Nakanishi, 2002 \\
\hline
\end{tabular}

stereospecific $\mathrm{NAD}^{+}$-dependent activity (Hofvendahl \& Hahn-Hägerda, 2000).

Among the bacteria that produce $\mathrm{L}(+)$ lactic acid are L. amilophylus (Yumoto \& Ikeda, 1995), L. brevis and L. buchneri (Wu-Tai, Driehuis, \& Van Wikselaar, 2003), L. casei (Büyükkileci \& Harsa, 2004; Hujanen, Linko, Linko, \& Leisola, 2001; John, Nampoothiri, et al., 2007; Korbekandi, Abedi, Jalali, Fazeli, \& Heidari, 2007), Lactobacillus delbrueckii (Hofvendahl \& Hahn-Hägerda, 1997; John, Sukumaran, et al., 2007; Thomas, 2000), L. rhamnosus (Lu, He, Shi, Lu, \& Yu, 2010; Marques et al., 2008; Narayanan, Roychoudhury, \& Srivastava, 2004b), L. lactis (Bai et al., 2003; Hofvendahl \& Hahn-Hägerda, 1997) and Streptococcus sp. (Ishizaki \& Ohta, 1989), whereas Lactobacillus coryniformis produces stereospecifically $\mathrm{D}(-)$-lactic acid (Bustos, Alonso, \& Vázquez, 2004; Yáñez, Moldes, Alonso, \& Parajó, 2003), and L. helveticus (Kylä-Nikkilä et al., 2000; Schepers, Thibault, \& Lacroix, 2002), L. plantarum (Hofvendahl \& Hahn-Hägerda, 2000; Yoshida et al., 2011) and L. pentosus (Hammes \& Vogel, 1995) mixtures of both isomers.

\section{Factors affecting lactic fermentation by bacteria}

Nutritional requirements of lactic acid bacteria

Several bottlenecks remain in lactic acid production processes, among which are meeting nutritional requirements of lactic acid bacteria, excess acidity, and substrate and product inhibition. To achieve good production, lactic acid bacteria need to be cultured under conditions that also ensure cell growth and viability, for which the necessary nutrients (carbon, nitrogen, minerals and vitamins) should be in directly available form (Roberto, Mussatto, Mancilha, \& Fernandes, 2007).

Carbon can be present in the culture medium in the form of sugars, amino acids and organic acids that have high energy content (Cui et al., 2011). Nitrogen, which is implied either in anabolic or catabolic processes, is available in the form of amino acids, peptides and inorganic compounds that can be added to the culture media as peptone, yeast extract, urea or ammonium sulfate (Nancib et al., 2001). Mineral elements $(\mathrm{Mg}, \mathrm{Mn}$ and $\mathrm{Fe})$, which are provided in the medium in the form of salts $\left(\mathrm{MgSO}_{4}, \mathrm{MnSO}_{4}\right.$ and $\left.\mathrm{FeSO}_{4}\right)$ (Büyükkileci \& Harsa, 2004; Fitzpatrick \& O'Keeffe, 2001), and vitamins (mainly belonging to the B group) present in yeast extract are essential elements that act as cofactors in many enzymatic reactions.

Studies have been addressed to the optimization of nutrients (Fitzpatrick \& O'Keeffe, 2001; Nancib et al., 2001; Pauli \& Fitzpatrick, 2002) as well as the utilization of corn steep liquor (Oh et al., 2005; Wee, Yun, Lee, Zeng, $\& \mathrm{Ryu}, 2005)$ and wastes from the winemaking process 
(Bustos, Alonso, \& Vázquez, 2004; Bustos, Moldes, Cruz, \& Domínguez, 2004a, 2005a, 2005b) as cheap sources of nitrogen, nutrients and minerals.

The cost of nutrients is one of the main drawbacks for the competitive biotechnological production of lactic acid. In an economic study carried out to produce lactic acid by fermentative means, it was found that yeast extract supplementation represented $38 \%$ of medium cost (Tejayadi \& Cheryan, 1995). Consequently, it is economically interesting to find low-cost media to replace the traditional nutrients employed in these processes (Salgado, Rodríguez, Cortés, \& Domínguez, 2009).

\section{Acidity}

Since lactic acid bacteria grow preferentially at $\mathrm{pH}$ between 5 and 7, the medium acidification associated with lactic acid production inhibits fermentation (Nomura, Iwahara, \& Hongo, 1987; Roberto et al., 2007). To minimize this occurrence, the $\mathrm{pH}$ can be maintained around 6 by addition of calcium carbonate at the beginning of batch fermentations, so that lactic acid can be neutralized at the same time it is formed. Hetényi, Németh, and Sevella (2011) tested five different compounds to control $\mathrm{pH}$, namely ammonium hydroxide, sodium hydroxide, dimethylamine, trimethylamine and calcium carbonate. Trimethylamine proved to be the best neutralizing agent, even though the use of ammonium hydroxide would also be advisable from the technological viewpoint. Peeva and Peev (1997) used a combined method for lactic acid production by L. casei, where, in line with fermentation, enzymatic urea hydrolysis released the ammonium hydroxide required to neutralize lactic acid.

The use of mutant strains able to grow under low $\mathrm{pH}$ may be an alternative strategy to overwhelm inhibition by the acidic product. Several authors reported that the increase in acid resistance of lactic acid bacteria may be due to the restoration of the optimum intracellular $\mathrm{pH}$ through arginine utilization by arginine deiminase and $\mathrm{NH}_{3}$ production (Araque, Bordons, \& Reguant, 2012; Bourdineaud, 2006; Sanders, Vemena, \& Kok, 1999). In addition, the use of strains able to tolerate acidic conditions would help to reduce the addition of buffering agents like calcium carbonate, thereby reducing the cost and pollution problems and making the recovery of free lactic acid from the fermentation broth easier (John \& Nampoothiri, 2008).

\section{Substrate inhibition}

Substrate inhibition seems to depend on both the microorganism and the carbon source. Whereas an increase in the initial glucose concentration was shown in fact to delay the growth of $L$. delbrueckii and L. bulgaricus reducing both the specific productivity (Gonçalves, Xavier, Almeida, \& Carrondo, 1991) and product yield (Burgos-Rubio et al., 2000), such an inhibition was not observed using L. casei on sucrose up to $100 \mathrm{~g} \mathrm{~L}^{-1}$ (Büyükkileci \& Harsa, 2004), L. brevis and L. pentosus on xylose up to $20 \mathrm{~g} \mathrm{~L}^{-1}$ (Garde, Jonsson, Schmidt, \& Ahring, 2002) and L. helveticus on lactose up to $110 \mathrm{~g} \mathrm{~L}^{-1}$ (Schepers et al., 2002). However, xylose inhibition of L. lactis fermentation was an order of magnitude stronger than that exerted by glucose (Ishizaki et al., 1992, 1993). To minimize this inhibition, substrate can be added to the fermentation medium according to the fedbatch process (Roukas \& Kotzekidou, 1998), but low initial substrate concentrations are required to obtain high lactic acid concentration $\left(210 \mathrm{~g} \mathrm{~L}^{-1}\right)$, yield $\left(0.97 \mathrm{~g} \mathrm{~g}^{-1}\right)$ and productivity $\left(2.2 \mathrm{~g} \mathrm{~L} \mathrm{~h}^{-1}\right.$ ) (Bai et al., 2003).

\section{Product inhibition}

Lactic acid was shown to exert an inhibitory effect on cell growth, which is stronger than that on fermentation activity (Madzingaidzo, Danner, \& Braun, 2002; Milcent \& Carrere, 2001). Loubiere, Cocaign-Bousquet, Matos, Goma, and Lindley (1997) suggested that lactic acid inhibition on cell proliferation and metabolism is possibly due to the increase in medium osmotic pressure, and that also some fermentation byproducts such as formic acid, acetic acid or sodium formate may exert individual inhibitory effects (Lin, Du, Koutinas, Wang, \& Webb, 2008; Loubiere et al., 1997). For example, Loubiere et al. (1997) observed a decrease of $50 \%$ on the growth of Lc. lactis in the presence of 76 and $187 \mathrm{mmol} \mathrm{L}^{-1}$ of formic acid and acetic acid, respectively. The concentration of the undissociated form of lactic acid plays a role in the inhibition (Bajpai \& Ianotti, 1988) more important than that of lactate (Monteagudo, Rodríguez, Rinco, \& Fuertes, 1997). To mitigate the effect of inhibition, various strategies have been proposed, among which are the use of fermentation technologies able to remove the product from the medium at the same time it is released (Kaufman, Cooper, Budner, \& Richardson, 1996; Moldes et al., 2001a); the neutralization of lactic acid to give its dissociated form that has a less inhibitory effect (Madzingaidzo et al., 2002; Milcent \& Carrere, 2001); and the microorganism adaptation and/or the use of mixed cultures (Cui et al., 2011; Robison, 1988; Tsai, Coleman, Moon, Schneider, \& Millard, 1993).

\section{Fermentation technologies}

Lactic acid production from sugar solutions

Even though only one type of microorganism is usually employed in the production of lactic acid, mixed cultures of various lactobacilli (Cui et al., 2011; John, Sukumaran, et al., 2007; Tsai et al., 1993) or lactobacilli and Kluyveromyces marxianus (Plessas et al., 2008) were shown to ensure better results compared to pure cultures. Other authors have used mixed cultures of two microorganisms, one of them to carry out the fermentation and the other to carry out the hydrolysis of a polymeric substrate $(\mathrm{Ge}$, Qian, \& Zhang, 2009; Kurosawa, Ishikawa, \& Tanaka, 1988; Romaní et al., 2008).

\section{Suspended-cell systems}

Most of the published work on fermentative production of lactic acid by free cells was carried out operating in 
batch mode (Amrane, 2001; Büyükkileci \& Harsa, 2004; Chen et al., 2012; Korbekandi et al., 2007), although there are examples of continuous (Dey \& Pal, 2012; Lunelli et al., 2011; Nishiwaki \& Dunn, 2005; Salgado, Rodríguez, Cortés, \& Domínguez, 2012; Xu et al., 2006) and fed-batch (Bai et al., 2003; Ge et al., 2009; Zhang, Cong, \& Shi, 2011) productions.

Ultrafiltration of effluents from continuous suspendedcell systems allows retaining and separating cells from the fermented medium and recirculating them to the bioreactor (Lu, Wei, \& Yu, 2012; Richter \& Nottelmann, 2004; $\mathrm{Xu}$ et al., 2006), ensuring higher cell concentrations and productivities $\left(33-57 \mathrm{~g} \mathrm{~L}^{-1} \mathrm{~h}\right)$ than batch systems with comparable yields (Dey \& Pal, 2012; Ishizaki \& Vonktaveesuk, 1996; Kwon, Yoo, Lee, Chang, \& Chang, 2001). Dey and Pal (2012) obtained efficient production of lactic acid from sugarcane juice in a novel two stage membrane-integrated fermenter.

\section{Immobilized-cell systems}

Immobilization of lactic acid bacteria is able to remarkably increase yields and productivities compared with suspended-cell systems, because it allows preventing the limits related to washout. Support materials are usually alginate gel (Cortón, Piuri, Battaglini, \& Ruzal, 2000; Voo, Ravindra, Tey, \& Chan, 2011), $k$-carrageenan (Norton et al., 1994) or agar (Zayed \& Zahran, 1991). However, the entrapment within gel has some drawbacks such as the formation of $\mathrm{pH}$ gradients inside the particles, occlusions and preferential flow, loss of gel mechanical stability, reduction of cell activity along the time and occurrence of diffusion limitations (Elezi et al., 2003).

Owing to these drawbacks, more stable immobilization supports have been proposed; among them are ceramic and porous glass particles (Bruno-Bárcena et al., 1999) or gluten beads (Chronopoulos et al., 2002), which, however, are relatively expensive. In other works, it was proposed the immobilization of L. brevis on delignified lignocellulosic materials (Elezi et al., 2003), L. plantarum on polypropylene matrices treated with chitosan (Krishnan, Gowthaman, Misra, \& Karanth, 2001) and $R$. oryzae on a fibrous matrix composed of stainless-steel mesh and cotton cloth (Chen et al., 2012), which ensured high yields and productivities.

\section{Lactic acid production by simultaneous}

saccharification and fermentation of polysaccharides

The aim of the "simultaneous saccharification and fermentation" (SSF) process is the one-step production of lactic acid from a polysaccharide material, consisting in the preliminary enzymatic hydrolysis of substrate to monosaccharides (saccharification) and their subsequent fermentation to lactic acid. This process has been studied using either starchy (Ge et al., 2009; Linko \& Javanainen, 1996) or lignocellulosic (Bustos et al., 2005a; John, Nampoothiri, et al., 2007; Marques et al., 2008; Moldes et al., 2001b; Romaní et al., 2008; Yáñez et al., 2003) waste materials.

There are some interesting advantages that make the SSF of great interest from an industrial point of view such as the cost reduction associated with the use of only one reactor for hydrolysis and fermentation (Bustos et al., 2004a; Lee, Koo, \& Lin, 2004). From the technological point of view, since the limiting step of SSF is the biopolymer enzymatic hydrolysis, the microorganism consumes glucose at the same rate it is formed, which allows reducing the substrate inhibition and, consequently, the enzyme loading and the risk of external contamination.

Using Eucalyptus globulus wood as raw material and $L$. delbrueckii NRRL-B445 as a fermenting agent, Moldes et al. (2001b) obtained interestingly $108 \mathrm{~g} \mathrm{~L}^{-1}$ of lactic acid after $115 \mathrm{~h}$ of SSF, corresponding to a yield of $0.94 \mathrm{~g} \mathrm{~g}^{-1}$, by intermittent addition of substrate (after $8-75 \mathrm{~h})$, cellulases and nutrients (48 h) and simultaneous elimination of produced lactic acid by ion exchange. Even higher lactic acid concentration $\left(162 \mathrm{~g} \mathrm{~L}^{-1}\right)$ and excellent productivity $\left(1.4 \mathrm{~g} \mathrm{~L}^{-1} \mathrm{~h}^{-1}\right)$ were reported by Lee et al. (2004) for similar exploitation of paper industry wastes. Lactic acid was also produced by SSF of broken rice, reaching a volumetric productivity of $3.59 \mathrm{~g} \mathrm{~L}^{-1} \mathrm{~h}^{-1}$ (Nakano et al., 2012).

\section{Conclusions}

This review paper reports on the fermentative and biotechnology processes to produce lactic acid. Polymeric substrates cannot be directly assimilated by lactic acid bacteria; therefore, they require an earlier stage of hydrolysis prior to lactic acid fermentation. On the other hand, fungi as fermenting agents are able to release extracellular amylases and, consequently, to directly hydrolyze starchy materials, thus not requiring any prior stage of hydrolysis. In fact, the high cost of hydrolytic enzymes for the saccharification of hemicellulosic materials is a serious drawback lactic acid industry, but it is noteworthy that lignocellulosic biomass represents the most abundant global source of biomass, and for this reason it can be largely utilized to give bioproducts. Therefore, different technologies and microorganisms have to be developed with the aim to increase the fermentation yield and the volumetric productivity of lactic acid.

\section{Acknowledgments}

We are grateful for the financial support of this work to the Xunta de Galicia (project 09TAL13383PR), FEDER funds, CAPES and FAPESP (processes numbers 2011/ 50195-7, 2011/14048-0).

\section{References}

Abdel-Rahman, M. A., Tashiro, Y., \& Sonomoto, K. (2011). Lactic acid production from lignocellulose-derived sugars using lactic acid bacteria: overview and limits. Journal of Biotechnology, 156(4), $286-301$. 
Alvarez, M., Aguirre-Ezkauriatza, E. J., Ramírez-Medrano, A., \& Rodríguez-Sánchez, A. (2010). Kinetic analysis and mathematical modeling of growth and lactic acid production of Lactobacillus casei var. rhamnosus in milk whey. Journal of Dairy Science, 93(12), 5552-5560.

Amoroso, M. J., Manca de Nadra, M. C., \& Oliver, G. (1988). Glucose, galactose, fructose, lactose and sucrose utilization by Lactobacillus bulgaricus and Streptococcus thermophilus isolated from commercial yogurt. Milchwissenschaft, 43(10), 626-631.

Amrane, A. (2001). Batch cultures of supplemented whey permeate using Lactobacillus helveticus: unstructured model for biomass formation, substrate consumption and lactic acid production. Enzyme and Microbial Technology, 28(9-10), 827-834.

Amrane, A. (2003). Seed culture and its effect on the growth and lactic acid production of Lactobacillus helveticus. The Journal of General and Applied Microbiology, 49(1), 21-27.

Amrane, A. (2005). Analysis of the kinetics of growth and lactic acid production for Lactobacillus helveticus growing on supplemented whey permeate. Journal of Chemical Technology and Biotechnology, 80(3), 345-352.

Araque, I., Bordons, A., \& Reguant, C. (2012). Effect of ethanol and low $\mathrm{pH}$ on citrulline and ornithine excretion and arc gene expression by strains of Lactobacillus brevis and Pediococcus pentosaceus. Food Microbiology. http://dx.doi.org/10.1016/j.fm. 2012.09.005

Asada, C., Nakamura, Y., \& Kobayashi, F. (2005). Waste reduction system for production of useful materials from un-utilized bamboo using steam explosion followed by various conversion methods. Biochemical Engineering Journal, 23(2), 131-137.

Axelsson, L. (2004). Lactic acid bacteria: classification and physiology. In S. Salminen, A. Von Wright, \& A. Ouwehand (Eds.), Microbiological and functional aspects. New York: Marcel Dekker, Inc.

Bai, D., Wei, Q., Yan, Z., Zhao, X., Li, X., \& Xu, S. (2003). Fed-batch fermentation of Lactobacillus lactis for hyper-production of L-lactic acid. Biotechnology Letters, 25(21), 1833-1835.

Bai, D., Zhao, X., Li, X., \& Xu, S. (2004). Strain improvement of Rhizopus oryzae for over-production of $\mathrm{L}(+)$-lactic acid and metabolic flux analysis of mutants. Biochemical Engineering Journal, 18(1), 41-48.

Bailly, M. (2002). Production of organic acids by bipolar electrodialysis: realizations and perspectives. Desalination, 144, 157-162.

Bajpai, R. K., \& lanotti, E. L. (1988). Product inhibition. In L. E. Erickson, \& D. Y.-C. Fung (Eds.), Handbook of anaerobic fermentation. New York: Marcel Dekker Inc.

Boswell, C. (2001). Bioplastics aren't the stretch they once seemed. Chemical Market Reporter, 260(8), 15-18.

Bourdineaud, J. P. (2006). Both arginine and fructose stimulate $\mathrm{pH}$ independent resistance in the wine bacteria Oenococcus oeni. International Journal of Food Microbiology, 107(3), 274-280.

Bruno-Bárcena, J. M., Ragout, A. L., Córdoba, P. R., \& Siñeriz, F. (1999). Continuous production of $\mathrm{L}(+)$-lactic acid by Lactobacillus casei in two-stage systems. Applied Microbiology and Biotechnology, 51(3), 316-324.

Burgos-Rubio, C. N., Okos, M. R., \& Wankat, P. C. (2000). Kinetic study of the conversion of different substrates to lactic acid using Lactobacillus bulgaricus. Biotechnology Progress, 16(3), 305-314.

Bustos, G., Alonso, J. L., \& Vázquez, M. (2004). Optimization of dlactic acid production by Lactobacillus coryniformis using response surface methodology. Food Microbiology, 21(2), $143-148$

Bustos, G., Moldes, A. B., Cruz, J. M., \& Domínguez, J. M. (2004). Evaluation of vinification lees as a general medium for Lactobacillus strains. Journal of Agricultural and Food Chemistry, 52(16), 5233-5239.
Bustos, G., Moldes, A. B., Cruz, J. M., \& Domínguez, J. M. (2004b). Production of fermentable media from vine-trimming wastes and bioconversion into lactic acid by Lactobacillus pentosus. Journal of Agricultural and Food Chemistry, 84(15), 2105-2112.

Bustos, G., Moldes, A. B., Cruz, J. M., \& Domínguez, J. M. (2005a). Production of lactic acid from vine-trimming wastes and viticulture lees using a simultaneous saccharification fermentation. Journal of the Science of Food and Agriculture, 472, 466-472.

Bustos, G., Moldes, A. B., Cruz, J. M., \& Domínguez, J. M. (2005b). Influence of the metabolism pathway on lactic acid production from hemicellulosic trimming vine shoots hydrolyzates using Lactobacillus pentosus. Biotechnology Progress, 21(3), 793-798.

Büyükkileci, A. O., \& Harsa, S. (2004). Batch production of L(+) lactic acid from whey by Lactobacillus casei (NRRL B-441). Chemical Technology, 79(9), 1036-1040.

Chahal, S. P. (2000). Lactic acid. Ullmann's Encyclopedia of Industrial Chemistry. Widnes: Croda Colloids Ltd.

Chakraborty, P., \& Dutta, S. K. (1999). Kinetics of lactic acid production by Lactobacillus delbrueckii and L. bulgaricus in glucose and whey media. Journal of Food Science and Technology, 36, 210-216.

Chang, L., Lu, J., Yang, R., Zhao, C., \& Zhang, F. (2010). Effect of degree of polymerization of lignocellulosic biomass on characteristics of enzymatic hydrolysis products for L-lactic acid production. Journal of Biotechnology, 150, 535.

Chen, X., Zhang, B. B., Wang, Y. L., Luo, Y. F., Wang, R. G., Ren, H. Q., et al. (2012). Production of L-lactic acid from corn starch hydrolysate by immobilized Rhizopus oryzae on a new asterisk-shaped matrix. Advanced Materials Research, 347-353, 1193-1197.

Choi, J., \& Hong, W. H. (1999). Recovery of lactic acid by batch distillation with chemical reactions using ion exchange resin. Journal of Chemical Engineering of Japan, 32, 184-189.

Chronopoulos, G., Bekatorou, A., Bezirtzoglou, E., Kaliafas, A. Koutinas, A., Marchant, R., et al. (2002). Lactic acid fermentation by Lactobacillus casei in free cell form and immobilised on gluten pellets. Biotechnology Letters, 24(15), 1233-1236.

Cortón, E., Piuri, M., Battaglini, F., \& Ruzal, S. M. (2000). Characterization of Lactobacillus carbohydrate fermentation activity using immobilized cell technique. Biotechnology Progress, 16(1), 59-63.

Cui, F., Li, Y., \& Wan, C. (2011). Lactic acid production from corn stover using mixed cultures of Lactobacillus rhamnosus and Lactobacillus brevis. Bioresource Technology, 102(2), 1831-1836.

Datta, R., \& Henry, M. (2006). Lactic acid: recent advances in products, processes and technologies - a review. Journal of Chemical Technology and Biotechnology, 81(7), 1119-1129.

Datta, R., Tsai, S. P., Bonsignore, P., Moon, S. H., \& Frank, J. R. (1995). Technological and economic potential of poly(lactic acid) and lactic acid derivatives. FEMS Microbiology Reviews, 16, 221-231.

Deng, Y., Li, S., Xu, Q., Gao, M., \& Huang, H. (2012). Production of fumaric acid by simultaneous saccharification and fermentation of starchy materials with 2-deoxyglucose-resistant mutant strains of Rhizopus oryzae. Bioresource Technology, 107, 363-367.

Dey, P., \& Pal, P. (2012). Direct production of $\mathrm{L}(+)$ lactic acid in a continuous and fully membrane-integrated hybrid reactor system under non-neutralizing conditions. Journal of Membrane Science, 389, 355-362.

Edreder, E. A., Mujtaba, I. M., \& Emtir, M. (2011). Optimal operation of different types of batch reactive distillation columns used for hydrolysis of methyl lactate to lactic acid. Chemical Engineering Journal, 172(1), 467-475.

Elezi, O., Kourkoutas, Y., Koutinas, A. A., Kanellaki, M., Bezirtzoglou, E., Barnett, Y. A., et al. (2003). Food additive lactic acid production by immobilized cells of Lactobacillus brevis on 
delignified cellulosic material. Journal of Agricultural and Food Chemistry, 51(18), 5285-5289.

Fitzpatrick, J. J., \& O'Keeffe, U. (2001). Influence of whey protein hydrolysate addition to whey permeate batch fermentations for producing lactic acid. Process Biochemistry, 37(2), 183-186.

Fukushima, K., Sogo, K., Miura, S., \& Kimura, Y. (2004). Production of D-lactic acid by bacterial fermentation of rice starch. Macromolecular Bioscience, 4(11), 1021-1027.

Gao, C., Ma, C., \& Xu, P. (2011). Biotechnological routes based on lactic acid production from biomass. Biotechnology Advances, 29(6), 930-939.

Garde, A., Jonsson, G., Schmidt, A., \& Ahring, B. (2002). Lactic acid production from wheat straw hemicellulose hydrolysate by Lactobacillus pentosus and Lactobacillus brevis. Bioresource Technology, 81(3), 217-223.

Gassem, M. A., \& Abu-Tarboush, H. M. (2000). Lactic acid production by Lactobacillus delbrueckii ssp. bulgaricus in camel's and cow's wheys. Milchwissenschaft, 55, 374-378.

Ge, X.-Y., Qian, H., \& Zhang, W.-G. (2009). Improvement of L-lactic acid production from Jerusalem artichoke tubers by mixed culture of Aspergillus niger and Lactobacillus sp. Bioresource Technology, 100(5), 1872-1874.

Gobbetti, M., Lavermicocca, P., Minervini, F., de Angelis, M., \& Corsetti, A. (2000). Arabinose fermentation by Lactobacillus plantarum in sourdough with added pentosans and alphaalpha-Larabinofuranosidase: a tool to increase the production of acetic acid. Journal of Applied Microbiology, 88(2), 317-324.

Göksungur, Y., Gündüz, M., \& Harsa, S. (2005). Optimization of lactic acid production from whey by $L$. casei NRRL B-441 immobilized in chitosan stabilized Ca-alginate beads. Journal of Chemical Technology and Biotechnology, 80, 1282-1290.

Gonçalves, L. M. D., Xavier, A. M. R. B., Almeida, J. S., \& Carrondo, M. J. T. (1991). Concomitant substrate and product inhibition kinetics in lactic acid production. Enzyme, 13(4), 314-319.

Gupta, R., \& Gandhi, D. N. (1995). Effect of supplementation of some nutrients in whey on the production of lactic acid. Indian Journal of Dairy Science, 48, 636-641.

Guyot, J. P., Calderon, M., \& Morlon-Guyot, J. (2000). Effect of pH control on lactic acid fermentation of starch by Lactobacillus manihotivorans LMG 18010T. Journal of Applied Microbiology, 88, 176-182.

Ha, M.-Y., Kim, S.-W., Lee, Y.-W., Kim, M.-J., \& Kim, S.-J. (2003). Kinetics analysis of growth and lactic acid production in $\mathrm{pH}$ controlled batch cultures of Lactobacillus casei $\mathrm{KH}-1$ using yeast extract/corn steep liquor/glucose medium. Journal of Bioscience and Bioengineering, 96, 134-140.

Hammes, W. P., \& Vogel, R. F. (1995). The genus Lactobacillus. In B. J. B. Wood, \& W. H. Holzapfel (Eds.), The genera of lactic acid bacteria. London: Blackie Academic \& Professional.

Hetényi, K., Németh, Á., \& Sevella, B. (2011). Role of pH-regulation in lactic acid fermentation: second steps in a process improvement. Chemical Engineering and Processing: Process Intensification, 50(3), 293-299.

Hofvendahl, K., \& Hahn-Hägerda, B. (1997). L-lactic acid production from whole wheat flour hydrolysate using strains of Lactobacilli and Lactococci. Enzyme, 20(4), 301-307.

Hofvendahl, K., \& Hahn-Hägerda, B. (2000). Factors affecting the fermentative lactic acid production from renewable resources(1). Enzyme and Microbial Technology, 26(2-4), 87-107.

Hujanen, M., Linko, S., Linko, Y.-Y., \& Leisola, M. (2001). Optimisation of media and cultivation conditions for $\mathrm{L}(+)(\mathrm{S})$-lactic acid production by Lactobacillus casei NRRL B-441. Applied Microbiology and Biotechnology, 56, 126-130.

Ishizaki, A., \& Ohta, T. (1989). Batch culture kinetics of L-lactate fermentation employing. Journal of Fermentation and Bioengineering, 67(1), 46-51.
Ishizaki, A., Ueda, T., Tanaka, K., \& Stanbury, P. F. (1992). L-lactate production from xylose employing Lactococcus lactis IO-1. Biotechnology Letters, 14(7), 599-604.

Ishizaki, A., Ueda, T., Tanaka, K., \& Stanbury, P. F. (1993). The kinetics of end-product inhibition of L-lactate production from xylose and glucose by Lactococcus lactis IO-1. Biotechnology Letters, 15(5), 489-494.

Ishizaki, A., \& Vonktaveesuk, P. (1996). Optimization of substrate feed for continuous production of lactic acid by Lactococcus lactis IO1. Biotechnology Letters, 18(10), 1113-1118.

Iyer, P. V., Thomas, S., \& Lee, Y. Y. (2000). High-yield fermentation of pentoses into lactic acid. Applied Biochemistry and Biotechnology, 84-86(4), 665-677.

Järvinen, M., Myllykoski, L., Keiski, R., \& Sohlo, J. (2000). Separation of lactic acid from fermented broth by reactive extraction. Bioseparation, 9(3), 163-166.

Jin, B., Huang, L. P., \& Lant, P. (2003). Rhizopus arrhizus - a producer for simultaneous saccharification and fermentation of starch waste materials to L(+)-lactic acid. Biotechnology Letters, 25(23), 1983-1987.

Jin, B., Yin, P., Ma, Y., \& Zhao, L. (2005). Production of lactic acid and fungal biomass by Rhizopus fungi from food processing waste streams. Journal of Industrial Microbiology \& Biotechnology, 32(11-12), 678-686.

John, R. P., \& Nampoothiri, K. M. (2008). Strain improvement of Lactobacillus delbrueckii using nitrous acid mutation for L-lactic acid production. Survival, 24(12), 3105-3109.

John, R. P., Nampoothiri, K. M., \& Pandey, A. (2007). Fermentative production of lactic acid from biomass: an overview on process developments and future perspectives. Applied Microbiology and Biotechnology, 74(3), 524-534.

John, R. P., Sukumaran, R., Nampoothiri, K. M., \& Pandey, A. (2007). Statistical optimization of simultaneous saccharification and $\mathrm{L}(+)$ lactic acid fermentation from cassava bagasse using mixed culture of lactobacilli by response surface methodology. Biochemical Engineering Journal, 36(3), 262-267.

Joshi, D., Singhvi, M., Khire, J., \& Gokhale, D. (2010). Strain improvement of Lactobacillus lactis for D-lactic acid production. Biotechnology Letters, 32(4), 517-520.

Kadam, S. R., Patil, S. S., Bastawde, K. B., Khire, J. M., \& Gokhale, D. V. (2006). Strain improvement of Lactobacillus delbrueckii NCIM 2365 for lactic acid production. Process Biochemistry, 41, 120-126.

Kanagachandran, K., Stanbury, P. F., Hall, S. J., \& Ishizaki, A. (1997). Glucose repression of xylose utilization by Lactococcus lactis IO1. Biotechnology Letters, 19, 923-925.

Kaufman, E. N., Cooper, S. P., Budner, M. K., \& Richardson, G. R. (1996). Continuous and simultaneous fermentation and recovery of lactic acid in a biparticle fluidized-bed bioreactor. Applied Biochemistry and Biotechnology, 57-58(1), 503-515.

Khunnonkwao, P., Boontawan, P., Haltrich, D., Maischberger, T., \& Boontawan, A. (2012). Purification of L-(+)-lactic acid from pretreated fermentation broth using vapor permeation-assisted esterification. Process Biochemistry, . http://dx.doi.org/10.1016/j. procbio.2012.07.011.

Korbekandi, H., Abedi, D., Jalali, M., Fazeli, M., \& Heidari, M. (2007). Optimization of Lactobacillus casei growth and lactic acid production in batch culture. Journal of Biotechnology, 131(2), S182-S183.

Kotzamanidis, C., Roukas, T., \& Skaracis, G. (2002). Optimization of lactic acid production from beet molasses by Lactobacillus delbrueckii NCIMB 8130. World Journal of Microbiology \& Biotechnology, 18, 441-448.

Krishnan, S., Gowthaman, M. K., Misra, M. C., \& Karanth, N. G. (2001). Chitosan-treated polypropylene matrix as immobilization support for lactic acid production using Lactobacillus plantarum NCIM 2084. Journal of Chemical Technology and Biotechnology, 76(5), 461-468. 
Kumar, S., Jha, Y. K., \& Chauhan, G. S. (2001). Process optimisation for lactic acid production from whey using Lactobacillus strains. Journal of Food Science and Technology, 38, 59-61.

Kurbanoglu, E. B. (2004). Enhancement of lactic acid production with ram horn peptone by Lactobacillus casei. World Journal of Microbiology \& Biotechnology, 20, 37-42.

Kurosawa, H., Ishikawa, H., \& Tanaka, H. (1988). r-Lactic acid production from starch by coimmobilized mixed culture system of Aspergillus awamori and Streptococcus lactis. Biotechnology and Bioengineering, 31(2), 183-187.

Kwon, S., Yoo, I.-K., Lee, W. G., Chang, H. N., \& Chang, Y. K. (2001). High-rate continuous production of lactic acid by Lactobacillus rhamnosus in a two-stage membrane cell-recycle bioreactor. Biotechnology and Bioengineering, 73(1), 25-34.

Kylä-Nikkilä, K., Hujanen, M., Leisola, M., \& Palva, A. (2000). Metabolic engineering of Lactobacillus helveticus CNRZ32 for production of pure L-(+)-lactic acid. Applied and Environmental Microbiology, 66(9), 3835-3841.

Lee, K., \& Lee, D.-S. (1993). A kinetic model for lactic acid production in Kimchi, a Korean fermented vegetable dish. Journal of Fermentation and Bioengineering, 75(5), 392-394.

Lee, S., Koo, Y., \& Lin, J. (2004). Production of lactic acid from paper sludge by simultaneous saccharification and fermentation. Advances in Biochemical Engineering/Biotechnology, 87, 173-194.

Lin, S. K. C., Du, C., Koutinas, A., Wang, R., \& Webb, C. (2008). Substrate and product inhibition kinetics in succinic acid production by Actinobacillus succinogenes. Biochemical Engineering Journal, 41(2), 128-135.

Linko, Y., \& Javanainen, P. (1996). Simultaneous liquefaction, saccharification, and lactic acid fermentation on barley starch. Enzyme, 19(2), 118-123.

Liu, C., Liu, Y., Liao, W., Wen, Z., \& Chen, S. (2004). Simultaneous production of nisin and lactic acid from cheese whey: optimization of fermentation conditions through statistically based experimental designs. Applied Biochemistry and Biotechnology, 113-116, 627-638.

Loubiere, P., Cocaign-Bousquet, M., Matos, J., Goma, G., \& Lindley, N. D. (1997). Influence of end-products inhibition and nutrient limitations on the growth of Lactococcus lactis subsp. lactis. Journal of Applied Microbiology, 82(1), 95-100.

Lu, Z., He, F., Shi, Y., Lu, M., \& Yu, L. (2010). Fermentative production of $\mathrm{L}(+)$-lactic acid using hydrolyzed acorn starch, persimmon juice and wheat bran hydrolysate as nutrients. Bioresource Technology, 101(10), 3642-3648.

Lu, Z., Wei, M., \& Yu, L. (2012). Enhancement of pilot scale production of $\mathrm{L}(+)$-lactic acid by fermentation coupled with separation using membrane bioreactor. Process Biochemistry, 47(3), 410-415.

Lunelli, B. H., Melo, D. N., de Morais, E. R., Victorino, I., de Toledo, V., Regina Wolf Maciel, M., et al. (2011). Real-time optimization for lactic acid production from sucrose fermentation by Lactobacillus plantarum. Computers \& Chemical Engineering, 29, 1396-1400.

Luo, J., Xia, L., Lin, J., \& Cen, P. (1997). Kinetics of simultaneous saccharification and lactic acid fermentation processes. Biotechnology Progress, 13, 762-767.

Madzingaidzo, L., Danner, H., \& Braun, R. (2002). Process development and optimisation of lactic acid purification using electrodialysis. Journal of Biotechnology, 96(3), 223-239.

Marques, S., Santos, J. A. L., Gírio, F. M., \& Roseiro, J. C. (2008). Lactic acid production from recycled paper sludge by simultaneous saccharification and fermentation. Biochemical Engineering Journal, 41, 210-216.

Massoud, M. I., \& El-Razek, A. M. A. (2011). Suitability of Sorghum bicolor L. stalks and grains for bioproduction of ethanol. Annals of Agricultural Sciences, 56(2), 83-87, Faculty of Agriculture, Ain Shams University.
Mayo, B., Piekarczyk, T. A., Kowalczyk, M., Pablo, A., \& Bardowski, J. (2010). Updates in the metabolism of lactic acid bacteria. In F. Mozzi, R. R. Raya, \& G. M. Vignolo (Eds.), Biotechnology of lactic acid bacteria novel applications. Massachusetts: WileyBlackwell.

McCaskey, T. A., Zhou, S. D., Britt, S. N., \& Strickland, R. (1994). Bioconversion of municipal solid waste to lactic acid by Lactobacillus species. Applied Biochemistry and Biotechnology, 45-46(1), 555-568.

Mercier, P., Yerushalmi, L., Rouleau, D., \& Dochain, D. (1992). Kinetics of lactic acid fermentation on glucose and corn by Lactobacillus amylophilus. Journal of Chemical Technology and Biotechnology, 55, 111-121.

Milcent, S., \& Carrere, H. (2001). Clarification of lactic acid fermentation broths. Separation and Purification Technology, 2223(3), 393-401.

Miura, S., Arimura, T., Itoda, N., Dwiarti, L., Feng, J. I. N., Bin, C. U. I. H., et al. (2004). Production of L-lactic acid from Corncob. Journal of Bioscience and Bioengineering, 97(3), 153-157.

Moldes, A. B., Alonso, J. L., \& Parajó, J. C. (2001a). Resin selection and single-step production and recovery of lactic acid from pretreated wood. Applied Biochemistry and Biotechnology, 95(2), 69-81.

Moldes, A. B., Alonso, J. L., \& Parajó, J. C. (2001b). Strategies to improve the bioconversion of processed wood into lactic acid by simultaneous saccharification and fermentation. Journal of Chemical Technology and Biotechnology, 284(3), 279-284.

Monteagudo, J. M., Rodríguez, L., Rinco, J., \& Fuertes, J. (1997). Kinetics of lactic acid fermentation by Lactobacillus delbrueckii grown on beet molasses. Journal of Chemical Technology and Biotechnology, 68(3), 271-276.

Mujtaba, Iqbal, M., Edreder, E. A., \& Emtir, M. (2012). Significant thermal energy reduction in lactic acid production process. Applied Energy, 89(1), 74-80.

Nakano, S., Ugwu, C. U., \& Tokiwa, Y. (2012). Efficient production of D-(-)-lactic acid from broken rice by Lactobacillus delbrueckii using $\mathrm{Ca}(\mathrm{OH}) 2$ as a neutralizing agent. Bioresource Technology, 14, 791-794.

Nancib, N., Nancib, A., Boudjelal, A., Benslimane, C., Blanchard, F., \& Boudrant, J. (2001). The effect of supplementation by different nitrogen sources on the production of lactic acid from date juice by Lactobacillus casei subsp. rhamnosus. Bioresource Technology, 78(2), 149-153.

Nancib, A., Nancib, N., \& Boudrant, J. (2009). Production of lactic acid from date juice extract with free cells of single and mixed cultures of Lactobacillus casei and Lactococcus lactis. World Journal of Microbiology \& Biotechnology, 25, 1423-1429.

Nancib, A., Nancib, N., Meziane-Cherif, D., Boubendir, A., Fick, M., \& Boudrant, J. (2005). Joint effect of nitrogen sources and $B$ vitamin supplementation of date juice on lactic acid production by Lactobacillus casei subsp. rhamnosus. Bioresource Technology, 96(1), 63-67.

Narayanan, N., Roychoudhury, P. K., \& Srivastava, A. (2004a). L(+) lactic acid fermentation and its product polymerization. Electronic Journal of Biotechnology, 7(2), 167-179.

Narayanan, N., Roychoudhury, P. K., \& Srivastava, A. (2004b). Isolation of adh mutant of Lactobacillus rhamnosus for production of $\mathrm{L}(+)$ lactic acid. Biotechnology Industry and Microbial Biotechnology, 7(1), 72-84.

Naveena, B. J., Altaf, M., Bhadrayya, K., Madhavendra, S. S., \& Reddy, G. (2005). Direct fermentation of starch to L(+)-lactic acid in SSF by Lactobacillus amylophilus GV6 using wheat bran as support and substrate: medium optimization using RSM. Process Biochemistry, 40, 681-690.

Nigatu, A. (2000). Evaluation of numerical analyses of RAPD and API $50 \mathrm{CH}$ patterns to differentiate Lactobacillus plantarum, Lact. 
isolated from kocho and tef. Journal of Applied Microbiology, 89, 969-978.

Nishiwaki, A., \& Dunn, I. (2005). Comparison of lactic acid productivities at high substrate conversions in a continuous twostage fermenter with cell recycle using different kinetic models. Chemical Engineering Communications, 192(2), 219-236.

Nomura, Y., Iwahara, M., \& Hongo, M. (1987). Lactic acid production by electrodialysis fermentation using immobilized growing cells. Biotechnology and Bioengineering, 30(6), 788-793.

Norton, S., Lacroix, C., \& Vuillemard, J.-C. (1994). Kinetic study of continuous whey permeate fermentation by immobilized Lactobacillus helveticus for lactic acid production. Enzyme and Microbial Technology, 16(6), 457-466.

Oh, H., Wee, Y.-J., Yun, J.-S., Ho Han, S., Jung, S., \& Ryu, H.-W. (2005). Lactic acid production from agricultural resources as cheap raw materials. Bioresource Technology, 96(13), 1492-1498.

Ou, M. S., Ingram, L. O., \& Shanmugam, K. T. (2011). L: (+)-lactic acid production from non-food carbohydrates by thermotolerant Bacillus coagulans. Journal of Industrial Microbiology \& Biotechnology, 38(5), 599-605.

Palmarola-Adrados, B., Juhász, T., Galbe, M., \& Zacchi, G. (2004). Hydrolysis of nonstarch carbohydrates of wheat-starch effluent for ethanol production. Biotechnology Progress, 20(2), 474-479.

Parajó, J. C., Alonso, J. L., \& Moldes, A. B. (1997). Production of lactic acid from lignocellulose in a single stage of hydrolysis and fermentation. Food Biotechnology, 11(1), 45-58.

Parajó,, J. C., Alonso, J. L., \& Santos, V. (1996). Lactic acid from wood. Process Biochemistry, 31, 271-280.

Park, E. Y., Anh, P. N., \& Okuda, N. (2004). Bioconversion of waste office paper to $\mathrm{L}(+)$-lactic acid by the filamentous fungus Rhizopus oryzae. Bioresource Technology, 93(1), 77-83.

Pauli, T., \& Fitzpatrick, J. J. (2002). Malt combing nuts as a nutrient supplement to whey permeate for producing lactic by fermentation with Lactobacillus casei. Process Biochemistry, $38(1), 1-6$.

Pedersen, M. B., Gaudu, P., Lechardeur, D., Petit, M. A., \& Gruss, A. (2012). Aerobic respiration metabolism in lactic acid bacteria and uses in biotechnology. Annual Reviews in Food Science and Technology, 3(1), 37-58.

Peeva, L., \& Peev, G. (1997). A new method for $\mathrm{pH}$ stabilization of the lactoacidic fermentation. Enzyme and Microbial Technology, 21(3), 176-181.

Persson, A., Jönsson, A. S., \& Zacchi, G. (2001). Separation of lactic acid-producing bacteria from fermentation broth using a ceramic microfiltration membrane with constant permeate flow. Biotechnology and Bioengineering, 72(3), 269-277.

Perttunen, J., Myllykoski, L., \& Keiski, R. (2002). Lactic acid fermentation of hemicellulose liquors and their activated carbon pretreatments. Engineering and Manufacturing for Biotechnology, $4(1), 29-38$.

Pintado, J., Guyot, J. P., \& Raimbault, M. (1999). Lactic acid production from mussel processing wastes with an amylolytic bacterial strain. Enzyme and Microbial Technology, 24(8-9), 590-598.

Plessas, S., Bosnea, L., Psarianos, C., Koutinas, A., Marchant, R., \& Banat, I. (2008). Lactic acid production by mixed cultures of Kluyveromyces marxianus, Lactobacillus delbrueckii ssp. bulgaricus and Lactobacillus helveticus. Bioresource Technology, 99(13), 5951-5955.

Portilla, O. M., Moldes, A. B., Torrado, A. M., \& Domínguez, J. M. (2007). Undetoxified hemicellulosic hydrolysates from grape marc enhances lactic acid fermentation compared with commercial hemicellulosic sugars. Journal of Biotechnology, 131(2), 137.

Ray, L., Mukherjee, G., \& Majumdar, S. K. (1991). Production of lactic acid from potato fermentation. Indian Journal of Dairy Science, 29, 681-682
Richter, K., \& Nottelmann, S. (2004). An empiric steady state model of lactate production in continuous fermentation with total cell retention. Engineering in Life Sciences, 4(5), 426-432.

Rivas, B., Torrado, A., Rivas, S., Moldes, A. B., \& Domínguez, J. M. (2007). Simultaneous lactic acid and xylitol production from vine trimming wastes. Journal of the Science of Food and Agriculture, 87(8), 1603-1612.

Roberto, I., Mussatto, S., Mancilha, I., \& Fernandes, M. (2007). The effects of $\mathrm{pH}$ and nutrient supplementation of brewer's spent grain cellulosic hydrolysate for lactic acid production by Lactobacillus delbrueckii. Journal of Biotechnology, 131, 181-182.

Robison, P. D. (1988). Lactic acid process - US Patent 4749652

Romaní, A., Yáñez, R., Garrote, G., \& Alonso, J. L. (2008). SSF production of lactic acid from cellulosic biosludges. Bioresource Technology, 99(10), 4247-4254.

Roukas, T., \& Kotzekidou, P. (1996). Continuous production of lactic acid from deproteinized whey by coimmobilized Lactobacillus casei and Lactococcus lactis cells in a packed-bed reactor. Food Biotechnology, 10, 231-242.

Roukas, T., \& Kotzekidou, P. (1998). Lactic acid production from deproteinized whey by mixed cultures of free and coimmobilized Lactobacillus casei and Lactococcus lactis cells using fedbatch culture. Enzyme and Microbial Technology, 22(3), 199-204.

Sakai, S. (2004). Bioreactors in relation to food industry. Gekkan Fudo Kemikaru, 20, 78-81.

Salgado, J. M., Rodríguez, N., Cortés, S., \& Domínguez, J. M. (2009). Development of cost-effective media to increase the economic potential for larger-scale bioproduction of natural food additives by Lactobacillus rhamnosus, Debaryomyces hansenii, and Aspergillus niger. Journal of Agricultural and Food Chemistry, 57(21), 10414-10428.

Salgado, J. M., Rodríguez, N., Cortés, S., \& Domínguez, J. M. (2012). Coupling two sizes of CSTR-type bioreactors for sequential lactic acid and xylitol production from hemicellulosic hydrolysates of vineshoot trimmings. New Biotechnology, 29(3), 421-427.

Salminen, S., Ouwehand, A., Wright, A. V., \& Daly, C. (1993). Future aspects of research and product development of lactic acid bacteria. In S. Salminen, A. von Wright, \& A. Ouwehand (Eds.), Lactic acid bacteria microbiological and functional aspects (pp. 429-432). New York: Marcel Dekker, Inc.

San-Martín, M., Pazos, C., \& Coca, J. (1992). Reactive extraction of lactic acid with alamine 336 in the presence of salts and lactose. Journal of Chemical Technology and Biotechnology, 54, 1-6.

Sanders, M. E., \& Klaenhammer, T. R. (2001). Invited review: the scientific basis of Lactobacillus acidophilus NCFM functionality as a probiotic. Journal of Dairy Science, 84(2), 319-331.

Sanders, J. W., Vemena, G., \& Kok, J. (1999). Environmental stress responses in Lactococcus lactis. FEMS Microbiology Reviews, 23(4), 483-501.

Sato, S., Tokuda, H., \& Nakanishi, K. (2002). L-Lactic acid production from starch in a mixed culture of Bacillus amyloliquefaciens and Lactococcus lactis. Nippon Jozo Kyokaishi, 97, 515-521.

Schepers, A., Thibault, J., \& Lacroix, C. (2002). Lactobacillus helveticus growth and lactic acid production during $\mathrm{pH}$-controlled batch cultures in whey permeate/yeast extract medium. Part I. Multiple factor kinetic analysis. Enzyme and Microbial Technology, 30(2), 176-186.

Shamala, T. R., \& Sreekantiah, K. R. (1988). Fermentation of starch hydrolysates by Lactobacillus plantarum. Journal of Industrial Microbiology and Biotechnology, 3(3), 175-178.

Sikder, J., Chakraborty, S., Pala, P., Drioli, E., \& Bhattacharjee, C. (2012). Purification of lactic acid from microfiltrate fermentation broth by cross-flow nanofiltration. Biochemical Engineering Journal, 69(1), 130-137.

Singhvi, M., Joshi, D., Adsul, M., Varma, A., \& Gokhale, D. (2010). D-(-)-Lactic acid production from cellobiose and cellulose by 
Lactobacillus lactis mutant RM2-24. Green Chemistry, 12(6), 1106-1109.

Sirisansaneeyakul, S., Mekvichitsaeng, P., Kittikusolthum, K., Pattaragulwanit, S., Laddee, M., Bhuwapathanapun, S., et al. (2000). Lactic acid production from starch hydrolysates using Lactococcus lactis IO-1. Thai Journal of Agricultural Science, $33(1-2), 53-64$

Sreenath, H. K., Moldes, A. B., Koegel, R. G., \& Straub, R. J. (2001a). Lactic acid production by simultaneous saccharification and fermentation of alfalfa fiber. Journal of Bioscience and Bioengineering, 92(6), 518-523.

Sreenath, H. K., Moldes, A. B., Koegel, R. G., \& Straub, R. J. (2001b). Lactic acid production from agriculture residues. Biotechnology Letters, 23(3), 179-184.

Srivastava, A., Roychoudhury, P. K., \& Sahai, V. (1992). Extractive lactic acid fermentation using ion-exchange resin. Biotechnology and Bioengineering, 39(6), 607-613.

Suskovic, J., Beluhan, S., Beluhan, D., \& Kurtanjek, Z. (1992). Mathematical model and estimation of kinetic parameters for production of lactic acid by Lactobacillus delbrueckii. Chemical and Biochemical Engineering, 6(3), 127-132.

Taherzadeh, M. J., \& Karimi, K. (2008). Pretreatment of lignocellulosic wastes to improve ethanol and biogas production: a review. International Journal of Molecular Sciences, 9, 1621-1651.

Tanaka, K., Komiyama, A., Sonomoto, K., Ishizaki, A., Hall, S. J., \& Stanbury, P. F. (2002). Two different pathways for D-xylose metabolism and the effect of xylose concentration on the yield coefficient of L-lactate in mixed-acid fermentation by the lactic acid bacterium Lactococcus lactis IO-1. Applied Microbiology and Biotechnology, 60(1-2), 160-167.

Tejayadi, S., \& Cheryan, M. (1995). Lactic acid production from cheese whey permeate, production and economics of continuous membrane bioreactor. Applied Microbiology and Biotechnology, 43(2), 242-248.

Thang, V. H., \& Novalin, S. (2008). Green Biorefinery: separation of lactic acid from grass silage juice by chromatography using neutral polymeric resin. Bioresource Technology, 99(10), 4368-4379.

Thomas, S. (2000). Production of lactic acid from pulp mill solid waste and xylose using Lactobacillus delbrueckii (NRRL B445). Applied Biochemistry and Biotechnology, 84-86, 455-468.

Tong, W.-Y., Fu, X.-Y., Lee, S.-M., Yu, J., Liu, J.-W., Wei, D.-Z., et al. (2004). Purification of $\mathrm{L}(+)$-lactic acid from fermentation broth with paper sludge as a cellulosic feedstock using weak anion exchanger Amberlite IRA-92. Biochemical Engineering Journal, 18(2), 89-96.

Tsai, S. P., Coleman, R. D., Moon, S. H., Schneider, K. A., \& Millard, C. S. (1993). Strain screening and development for industrial lactic acid fermentation. Applied Biochemistry and Biotechnology, 39-40(1), 323-335.

Tsuji, H., Saeki, T., Tsukegi, T., Daimon, H., \& Fujie, K. (2008). Comparative study on hydrolytic degradation and monomer recovery of poly(L-lactic acid) in the solid and in the melt. Polymer Degradation and Stability, 93(10), 1956-1963.

Tyree, R. W., Clausen, E. C., \& Gaddy, J. L. (1990). The fermentative characteristics of Lactobacillus xylosus on glucose and xylose. Biotechnology Letters, 12(1), 51-56.

Ueno, T., Ozawa, Y., Ishikawa, M., Nakanishi, K., \& Kimura, T. (2003). Lactic acid production using two food processing wastes, canned pineapple syrup and grape invertase, as substrate and enzyme. Biotechnology Letters, 25(7), 573-577.

Vinderola, C., Costa, G., Regenhardt, S., \& Reinheimer, J. A. (2002). Influence of compounds associated with fermented dairy products on the growth of lactic acid starter and probiotic bacteria. International Dairy Journal, 12(7), 579-589.

Vishnu, C., Seenayya, G., \& Reddy, G. (2002). Direct fermentation of various pure and crude starchy substrates to $\mathrm{L}(+)$-lactic acid using Lactobacillus amylophilus GV6. World Journal of Microbiology \& Biotechnology, 18(5), 429-433.
Voo, W., Ravindra, P., Tey, B., \& Chan, E. (2011). Comparison of alginate and pectin based beads for production of poultry probiotic cells. Journal of Bioscience and Bioengineering, 111(3), 294-299.

Wang, P., Li, J., Wang, L., Tang, M.-L., Yu, Z.-L., \& Zheng, Z.-M. (2009). L(+)-lactic acid production by co-fermentation of glucose and xylose with Rhizopus oryzae obtained by low-energy ion beam irradiation. Journal of Industrial Microbiology \& Biotechnology, 36(11), 1363-1368.

Wang, X., Sun, L., Wei, D., \& Wang, R. (2005). Reducing byproduct formation in L-lactic acid fermentation by Rhizopus oryzae. Journal of Industrial Microbiology \& Biotechnology, 32(1), 38-40.

Wee, Y.-J., Yun, J.-S., Lee, Y. Y., Zeng, A.-P., \& Ryu, H.-W. (2005). Recovery of lactic acid by repeated batch electrodialysis and lactic acid production using electrodialysis wastewater. Journal of Bioscience and Bioengineering, 99(2), 104-108.

Welman, A. D., \& Maddox, I. S. (2003). Fermentation performance of an exopolysaccharide producing strain of Lactobacillus delbrueckii subsp. bulgaricus. Journal of Industrial Microbiology and Biotechnology, 30(11), 661-668.

Woiciechowski, A. L., Soccol, C. R., Ramos, L. P., \& Pandey, A. (1999). Experimental design to enhance the production of $\mathrm{L}-$ $(+)$-lactic acid from steam-exploded wood hydrolysate using Rhizopus oryzae in a mixed-acid fermentation. Process Biochemistry, 34, 949-955.

Wu-Tai, G., Driehuis, F., \& Van Wikselaar, P. (2003). The influences of addition of sugar with or without $L$. buchneri on fermentation and aerobic stability of whole crop maize silage ensiled in air-stress silos. Asian-Australasian Journal of Animal Sciences, 16(12), 1738-1742.

Xu, G., Chu, J., Wang, Y.-H., Zhuang, Y.-P., Zhang, S.-L., \& Peng, H.Q. (2006). Development of a continuous cell-recycle fermentation system for production of lactic acid by Lactobacillus paracasei. Process Biochemistry, 41(12), 2458-2463.

Yáñez, R., Alonso, J. L., \& Parajó, J. C. (2004). Production of hemicellulosic sugars and glucose from residual corrugated cardboard. Process Biochemistry, 39, 1543-1551.

Yáñez, R., Alonso, J. L., \& Parajó, J. C. (2005). D-Lactic acid production from waste cardboard. Journal of Chemical Technology and Biotechnology, 80, 76-84.

Yáñez, R., Moldes, A. B., Alonso, J. L., \& Parajó, J. C. (2003). Production of $\mathrm{D}(-)$-lactic acid from cellulose by simultaneous saccharification and fermentation using Lactobacillus coryniformis subsp. torquens. Biotechnology Letters, 25, 1161-1164.

Yoshida, S., Okano, K., Tanaka, T., Ogino, C., \& Kondo, A. (2011). Homo-D-lactic acid production from mixed sugars using xyloseassimilating operon-integrated Lactobacillus plantarum. Applied Microbiology and Biotechnology, 92(1), 67-76.

Yumoto, I., \& Ikeda, K. (1995). Direct fermentation of starch to L(+)-lactic acid using Lactobacillus amylophilus. Biotechnology Letters, 17(5), 543-546.

Zayed, G., \& Zahran, A. S. (1991). Lactic acid production from salt whey using free and agar immobilized cells. Letters in Applied Microbiology, 12, 241-243.

Zhang, Y., Cong, W., \& Shi, S. Y. (2011). Repeated fed-batch lactic acid production in a packed bed-stirred fermentor system using a $\mathrm{pH}$ feedback feeding method. Bioprocess and Biosystems Engineering, 34, 67-73.

Zlotkowska, H. (2000). Selection of the substrates of inoculum and production cultures for lactic acid biosynthesis with use of the bacterial Lactobacillus delbrueckii strains producing $\mathrm{L}(+)$-lactic acid. Prace Instytutow i Laboratoriow Badawczych Przemyslu Spozywczego, 38, 60-66.

Zorba, M., Hancioglu, O., Genc, M., Karapinar, M., \& Ova, G. (2003). The use of starter cultures in the fermentation of boza, a traditional Turkish beverage. Process Biochemistry, 38, 1405-1411. 